University of Louisville

ThinkIR: The University of Louisville's Institutional Repository

Electronic Theses and Dissertations

$5-2015$

\title{
The effects of cumulative victimization on psychological distress.
}

Amanda Dishon Brown

University of Louisville

Follow this and additional works at: https://ir.library.louisville.edu/etd

Part of the Social Work Commons

\section{Recommended Citation}

Brown, Amanda Dishon, "The effects of cumulative victimization on psychological distress." (2015). Electronic Theses and Dissertations. Paper 2023.

https://doi.org/10.18297/etd/2023

This Doctoral Dissertation is brought to you for free and open access by ThinkIR: The University of Louisville's Institutional Repository. It has been accepted for inclusion in Electronic Theses and Dissertations by an authorized administrator of ThinkIR: The University of Louisville's Institutional Repository. This title appears here courtesy of the author, who has retained all other copyrights. For more information, please contact thinkir@louisville.edu. 
THE EFFECTS OF CUMULATIVE VICTIMIZATION ON PSYCHOLOGICAL DISTRESS

By:

Amanda Dishon Brown

B.A. University of Louisville, 2008

M.S.S.W., University of Louisville, 2011

A Dissertation submitted to the Faculty of the Raymond A. Kent School of Social Work in Partial Fulfillment of the Requirements for the Degree of

Doctor of Philosophy in Social Work

Kent School of Social Work

University of Louisville

Louisville, KY

May 2015 
Copyright 2015 by Amanda D. Brown

All rights reserved 

THE EFFECTS OF CUMULATIVE VICTIMIZATION ON PSYCHOLOGICAL DISTRESS

By:

\section{Amanda Dishon Brown}

B.A. University of Louisville, 2008

M.S.S.W., University of Louisville, 2011

A Dissertation Approved on April 13, 2015

By the following Dissertation Committee:

Dr. Seana Golder

Dr. Martin Hall

Dr. Eli Karam

Dr. George Higgins

Dr. Chris Flaherty 


\section{DEDICATION}

This dissertation is dedicated to my parents, Ronald and Deborah Dishon, for their relentless support, encouragement, prayer, and guidance. Without your leadership, I would not have completed this process and I am eternally grateful for your sacrifice to make me a better person. I forever love you mom and dad. I also dedicate this dissertation to my husband, Nicholas Brown, who walked beside me through my moments of doubt and discouragement. Your love, encouragement, prayer, sacrifice, and dedication to our family carried me through times when I thought I did not have the strength to continue writing this dissertation. I love you more and more each day! Finally, I dedicate this dissertation to my grandmother, Myrl Simmons. You are missed and loved more than words can say; forever you are in my heart. 


\section{ACKNOLWEDGEMENTS}

I would like to thank my dissertation chair, Dr. Seana Golder for your mentorship and guidance through this process. You challenged me throughout my doctoral work to be a better scholar and I am grateful for the opportunity to be a better version of myself. I would also like to thank Dr. Eli Karam for your mentorship, encouragement and support through my professional development, I am beyond grateful. Additionally, I would like to thank my committee members, Dr. George Higgins, Dr. Martin Hall, and Dr. Chris Flaherty for your dedication to my scholarship and support in my doctoral career.

I would also like to thank all of my family, particularly my parents and husband for their countless prayers, words of encouragement, and love through this process. I don't know what I would have done without you pushing me to not give up on my dream. Mom and Dad, I have watched you both sacrifice so much so that I could access higher education; I am forever grateful. Nick, you were always a strong tower, ready to catch me if I started to fall- thank you for never letting me fall. I also thank my Aunt Sue, for being my second mom, and literally cheering me on when I needed an extra prayer or push onward. 
I would like to thank my colleague and dear friend, Tanya Rae Renn for being a constant source of encouragement and strength. I am blessed by your friendship and I thank God for allowing us to walk this journey together. I also want to thank my friends, especially Pam, Emily, and Julie for years of friendship, love, and support throughout my student career. You never gave up on me, even in times I had given up on myself. Finally, I thank my Heavenly Father for the opportunity to exercise faith in times of doubt, hope in times of discouragement, and peace in times of worry. I could not have accomplished this without Your presence in my life, all praise be unto You. 


\section{ABSTRACT \\ THE EFFECTS OF CUMULATIVE VICTIMIZATION ON PSYCHOLOGICAL DISTRESS}

\section{Amanda D. Brown}

April 13, 2015

Justice-involved women experience significantly higher rates of victimization and psychological distress when compared to the general population. While both childhood victimization and adult Intimate Partner Violence (IPV) both directly contribute to psychological distress, scant research examines the effects of cumulative victimization (both child and adult IPV) across a woman's lifetime on psychological distress. Additionally, a gap in the literature is the investigation of behavior specific mechanisms (self-esteem, social support, coping, and substance use) that may mediate the relationship between victimization and psychological distress. As such, the primary aim of this dissertation was to explore the relationship between cumulative victimization (childhood and adult IPV), the hypothesized mediators (self-esteem, social support, coping, and substance use), and psychological distress among a sample of 406 victimized women on

probation and parole. Results of the Structural Equation Model (SEM) indicated a partial mediation model with both direct and indirect effects from the victimization to psychological distress when mediated by self-esteem and coping. Based upon the results of this research, implications for practice are explored specifically regarding targeted 
treatment models for justice-involved women who are highly victimized and experience significant levels of psychological distress, as both have been found to contribute to women's involvement in the CJ system. 


\section{TABLE OF CONTENTS}

DEDICATION

ACKNOWLEDGMENTS

ABSTRACT

LIST OF TABLES

LIST OF FIGURES

CHAPTER I: PROBLEM STATEMENT

Intimate Partner Violence

Childhood Victimization

Cumulative Victimization

Cumulative Victimization and Psychological Distress

Related Factors

Justice Involved Women

Primary Aim of the Study

Plan for the Chapters p. iii

p. iv

p. vi

p. xii

p. xiv p. 1

p. 1

p. 2

p. 3

p. 4

p. 5

p. 6

p. 8

p.8

p. 11

p. 11

p. 12

p. 12

Childhood Victimization

p. 14

Adult Victimization 
$\begin{array}{ll}\text { Cumulative Victimization } & \text { p. } 17\end{array}$

$\begin{array}{ll}\text { Victimization and Psychological Distress } & \text { p. } 18\end{array}$

$\begin{array}{lr}\text { Child Victimization and Psychological Distress } & \text { p.18 }\end{array}$

$\begin{array}{ll}\text { Adult Victimization and Psychological Distress } & \text { p. } 19\end{array}$

$\begin{array}{ll}\text { Cumulative Victimization and Psychological Distress } & \text { p. } 20\end{array}$

$\begin{array}{ll}\text { Related Factors } & \text { p.21 }\end{array}$

$\begin{array}{ll}\text { Coping and Psychological Distress } & \text { p. } 21\end{array}$

$\begin{array}{ll}\text { Substance Use and Psychological Distress } & \text { p. } 22\end{array}$

$\begin{array}{ll}\text { Self-Esteem and Psychological Distress p. } 23 & \text { p }\end{array}$

$\begin{array}{ll}\text { Social Support and Psychological Distress } & \text { p. } 24\end{array}$

$\begin{array}{ll}\text { CHAPTER III: METHODOLOGY p. } 34 & \text { p. }\end{array}$

$\begin{array}{ll}\text { Sampling and Recruitment } & \text { p. } 34\end{array}$

$\begin{array}{ll}\text { Data Collection } & \text { p. } 36\end{array}$

$\begin{array}{ll}\text { Measures } & \text { p. } 36\end{array}$

$\begin{array}{ll}\text { Demographics } & \text { p. } 36\end{array}$

$\begin{array}{ll}\text { Victimization } & \text { p. } 37\end{array}$

$\begin{array}{ll}\text { Psychological Distress } & \text { p. } 38\end{array}$

$\begin{array}{ll}\text { Mediators } & \text { p. } 39\end{array}$

$\begin{array}{ll}\text { Self-Esteem } & \text { p. } 39\end{array}$

$\begin{array}{ll}\text { Coping } & \text { p. } 39\end{array}$

$\begin{array}{ll}\text { Social Support } & \text { p. } 40\end{array}$

$\begin{array}{ll}\text { Substance Use p. } 40 & \text { p. }\end{array}$

$\begin{array}{ll}\text { Analysis Strategy } & \text { p. } 41\end{array}$ 
Introduction

Descriptive Findings

Demographics

Victimization

Child Victimization

Adult Victimization

Cumulative Victimization

Psychological Distress

Mediators

Structural Equation Modeling

Model Identification

p. 58

Operationalization of the Data

p. 59

Descriptive Statistics

p. 60

Bivariate Correlations

p. 60

Measurement Model

p. 63

Structural Model

p. 69

CHAPTER V: DISCUSSION

Introduction

Interpretation of Results

p. 80

Descriptive Results

p. 80

Victimization

p. 80

Related Factors

p. 81

Psychological Distress

p. 82 
$\begin{array}{ll}\text { Justice-Involved Women } & \text { p. } 82\end{array}$

$\begin{array}{ll}\text { Structural Equation Model Results } & \text { p. } 83\end{array}$

$\begin{array}{lr}\text { Implications for Practice } & \text { p. } 86\end{array}$

$\begin{array}{ll}\text { Limitations } & \text { p. } 94\end{array}$

$\begin{array}{ll}\text { Areas for Future Research } & \text { p. } 96\end{array}$

$\begin{array}{lr}\text { REFERENCES } & \text { p. } 98\end{array}$

$\begin{array}{lr}\text { APPENDIX 1. Screening Form. } & \text { p. } 112\end{array}$

APPENDIX 2. Victimization and Age Data Report of Women Screened Eligible. p. 120

APPENDIX 3. Final Recruitment Data Report. $\quad$ p. 124

$\begin{array}{lr}\text { APPENDIX 4. Informed Consent. } & \text { p. } 127\end{array}$

$\begin{array}{ll}\text { CURRICULUM VITAE } & \text { p. } 133\end{array}$ 


\section{LIST OF TABLES}

TABLE 1. Types of Child Victimization and Psychological Distress Outcomes.

TABLE 2. Types of IPV and Psychological Distress Outcomes.

TABLE 3. Cumulative Victimization and Psychological Distress Outcomes.

TABLE 4. Power Analysis.

TABLE 5. Operationalization of the Data.

TABLE 6. Descriptive Statistics.

TABLE 7. Demographic Characteristics.

TABLE 8. Victimization Demographics, reported in percentages, raw numbers, and means with standard deviations and range.

TABLE 9. Psychological Distress Demographics reported in percentages, raw numbers, and means with standard deviations and range.

TABLE 10. Psychological Distress Demographics reported in percentages, raw numbers, and means with standard deviations and range.

TABLE 11. Coping Demographics reported in means with standard deviations and range. 
TABLE 12. Social Support Demographics reported in means with standard deviations and range.

TABLE 13. Missing Data.

TABLE 14. Correlation Matrix

TABLE 15. Reliability testing of the measures.

TABLE 16. Factor Loadings.

TABLE 17. Correlations of Trimmed CFA.

TABLE 18. Maximum Likelihood Estimates.

TABLE 19. Direct, Indirect, and Total Effects.

TABLE 20. Chi-square Difference Test. 


\section{LIST OF FIGURES}

FIGURE 1. Conceptual Model.

FIGURE 2. Original CFA.

FIGURE 3. Trimmed CFA.

FIGURE 4. Final Trimmed Structural Model.

FIGURE 5. CFA with Psychological Distress Operationalized by Depression.

FIGURE 6. Structural Model with Psychological Distress Operationalized by Depression.

FIGURE 7. CFA with Psychological Distress Operationalized by PTSD.

FIGURE 8. Structural Model with Psychological Distress Operationalized by PTSD. 


\section{CHAPTER 1: PROBLEM STATEMENT}

\section{Intimate Partner Violence}

Instances of intimate partner violence (IPV) are an endemic social and public health concern (Ansara \& Hindin, 2010; Kelly, 2011; Westbrook \& Finn, 2012). There are a number of negative outcomes associated with experiences of IPV specifically for women, including injury, psychological trauma, negative health outcomes, and even death; the National Center for Injury Prevention and Control (NCIPC; 2003) states that often times, "the consequences of IPV can last a lifetime" (p.3). IPV is defined as any aggressive act including controlling behavior that consists of threats, forced completion and completion of sexual intercourse/rape (Krug, Dahlber, Mercy, Zwi, \& Lozano, 2002). Perpetrators of IPV include spouses, ex-spouses, and/or current or former boyfriends/girlfriends/intimate partners (National Center for Injury Prevention and Control (NCIPC, 2003).

Different types of IPV exist including psychological, physical, and sexual victimization (Krebs, Breiding, Browne, \& Warner, 2011). Typically these types of violence (i.e., psychological, physical, and sexual) overlap and are experienced simultaneously; this phenomenon is defined in violence literature as polyvictimization (Barnett, Miller-Perrin, \& Perrin, 2011, p. 254; Krebs et al., 2011). The most often reported occurrence of polyvictimization is the co-occurrence of psychological victimization with physical and/or sexual types of violence (Briere \& Jordan, 2009; 
Krebs, et al., 2011). Research also demonstrates that various types of IPV are also often experienced recurrently (Classen et al., 2002; Fargo, 2009; Follette, Polusay, Bechtle, \& Nangie, 1996; Kelly, 2011; Kennedy et al., 2012; Krebs, et al., 2011; Nurius \& Macy, 2008, 2010; Tjaden \& Thoennes, 2000). As such, evidence suggests that many women are subject to polyvictimization by several partners over their lifetime (Krebs et al., 2011).

Currently, the United States (U.S.) spends approximately $\$ 5.8$ billion a year on IPV and associated sequelae; yet incidents of IPV continue to increase (Breiding, Black, \& Ryan, 2008; NCIPC, 2003). In the United States, 26.4\% of women report at least one experience of IPV in their lifetime (Center for Disease Control and Prevention (CDC, 2005). In Kentucky, this number is even higher, $36.6 \%$ of women living in KY report experiencing IPV in their lifetime (Cook, Morris Mandel, \& Kelly, 2006).

\section{Childhood Victimization}

The experience of childhood victimization significantly increases the likelihood of future victimization in a woman's lifetime (Briere \& Jordan, 2004; Classen et al., 2001; Dong, et al., 2003; Engstrom, El-Bassel, \& Gilbert, 2012; Renner \& Slack, 2006; Sitaker, 2008). Tjaden and Thoennes (2000) found a significant relationship between victimization as a minor and subsequent victimization as an adult; if victimization occurs under the age of 18 , women are two times more likely to be raped or physically assaulted, and are seven times more likely to be stalked (p.iv). Further, results from the Adverse Childhood Experiences (ACE) Study found that childhood physical and sexual abuse, as 
well as witnessing maternal abuse, substantially increases risk for adult IPV (Whitfield, Anda, Dube, \& Felitti, 2003).

\section{Cumulative Victimization ${ }^{1}$}

While violence literature demonstrates both a direct and indirect relationship between child victimization and adult IPV, literature examining cumulative accounts of victimization is minimal (Briere \& Jordan, 2004, 2009; Whitfield et al., 2003). Cumulative victimization is defined as various types of victimization experiences (i.e. psychological, physical, and sexual) that occur both as isolated and recurrent instances ${ }^{2}$ (particularly IPV). Further, cumulative victimization takes into account violent childhood and adult IPV experiences (Golder, Connell, \& Sullivan, 2012). Although the function of childhood victimization as it relates to later IPV is understudied, it is hypothesized to significantly impacts ones normalization and acceptance process of future violence (Engstrom, El-Bassel, \& Gilbert, 2012; Sitaker, 2007). Additionally, childhood victimization has been shown to negatively impact biological, psychological, and social functioning which further disables self-esteem development, seeking positive social support, and healthy coping skills that directly contribute to risk for revictimization (Briere \& Jordan, 2009; Classen, et al., 2001; Ehrensaft, 2008; Engstrom, El-Bassel, \& Gilbert, 2012). Thus, women who experience victimization over the course of their lives are also consequentially at greater risk for exacerbated levels of PTSD and other psychological distress symptoms in adulthood (Dutton, 2009). While research on this

\footnotetext{
${ }^{1}$ For purposes of this research, the terms IPV and adult victimization are used interchangeably.

${ }^{2}$ In the case of IPV, this concept refers to subsequent victimization experiences of women. Research shows that women are highly likely to experience violence subsequently after the first violent act occurs (Tjaden \& Thoennes, 2000).
} 
topic is growing, few studies have fully examined a comprehensive model of cumulative victimization in general or specifically related to its relationship with psychological distress.

Cumulative victimization and psychological distress. There are a number of negative psychosocial outcomes associated with childhood and adult victimization. In particular, extensive research has linked child and adult victimization with psychological distress (Classen, et al., 2001; Logan, Walker, Jordan, Leukefeld, 2006; Fargo, 2009; Follette et al., 1996; Renner \& Slack, 2006; Tjaden \& Thoennes, 2000). Types of psychological distress associated with childhood victimization include depression, anxiety (including panic and phobias), bodily distress ${ }^{3}$ (intensified by psychological trauma associated with child sexual victimization (CSV), identity disturbance/selfawareness $^{4}$, chronic interpersonal difficulties (sensitivity to rejection, problems with trusting others, unstable and/or chaotic relationships, ambivalence regarding intimacy, and abandonment issues), difficulties with emotional regulation (particularly maladaptive or self-harming behaviors), chronic stress, and avoidance responses ${ }^{5}$ (Briere \& Jordan, 2004, 2009; Classen, et al., 2001; Fargo, 2009, Logan et al., 2006). For adult IPV, chronic stress and posttraumatic stress have been significantly correlated as types of

3 This includes types of somatization responses such as chronic pelvic pain and gastrointestinal distress (Briere \& Jordan, 2009, p. 377).

${ }^{4}$ Defined as "typically involving problems in self-monitoring that would otherwise inform abuse survivors about their feelings, thoughts, needs, goals, and behaviors, and may result in confusion about the boundaries between self and others, as well as greater susceptibility to the influence of others" (Briere \& Jordan, 2009, p.377).

${ }^{5}$ Also known as coping responses to abuse-related distress and may include factors such as dissociation, substance abuse, self-medication, and tension reduction behaviors (TRB's) "defined as external activities used to reduce negative internal stress such as compulsive sexual behavior, impulsive aggression, and suicidality" (Briere \& Jordan, 2009, p. 378). 
psychological distress (Briere \& Jordan, 2004, 2009; Follette, et al., 1996; Kennedy, et al., 2012; Logan et al., 2006). Chronic stress experiences are traumatic, persistent, recurrent, threatening and long-term in nature; the result is often posttraumatic stress, which affects social, economic, and psychological functioning (Aneshensel, 1992; Bonanno, 2004; Logan, et al., 2006).

Related factors. Individually, childhood and adult victimization have been directly associated with psychological distress; however, significant gaps remain in understanding the cumulative effects of both child and adult victimization over time on psychological functioning (Briere \& Jordan, 2004, 2009; Classen, et al., 2002; Kennedy, et al., 2012). Further research is needed to understand the mechanisms through which cumulative victimization (i.e., both childhood and adult) affects psychological distress. Research has identified a number of potential factors that mediate the relationship between cumulative victimization and psychological distress (Bonanno, 2004, 2009; Kennedy, et al., 2012). Among the most salient factors for understanding the relationship between victimization and psychological distress are self-esteem, social support, coping, and substance use (Bonanno, 2004; Briere \& Jordan, 2009; Charney, 2004; Classen, et al., 2001). Substantial research has examined the relationships between these factors, victimization, and psychological distress; however, major gaps exist:

1. Victimization has been examined in childhood or adulthood rather than concurrently (Classen, et al., 2001; Hill, Kaplan, French, \& Johnson, 2010; Soler, Kirchner, Paretilla, \& Forns, 2013).

2. Current studies that examine the relationship between victimization and psychological distress fail to account for a significant number of potentially 
related factors (self-esteem, social support, coping, and substance use) that might influence this relationship.

3. Research examining the relationships among self-esteem, social support, coping, and substance use, within the context of victimization and psychological distress has tended to examine these indicators independently rather than simultaneously.

\section{Justice Involved Women}

Women represent one of the fastest growing segments of the criminal justice system, and have significantly high rates of victimization and psychological distress that contribute to their involvement in the justice system (Bloom, Owen, \& Covington, 2003; Borelli, Goshin, Joestl, Clark, \& Byrne, 2010; Golder \& Logan, 2011; McDaniels-Wilson \& Belknap, 2008; Salisbury \& Voorhis, 2009; Sitaker, 2007). Research of women in the criminal justice system demonstrates rates of lifetime victimization between $60 \%$ and 99\% (Bloom, Owen, Covington, 2003; Browne, Miller, \& Maguin, 1999; Kubiak, Nnawulezi, Karim, Sullivan, \& Beeble, 2012; Richie, 2000; Reichert, Adams, \& Bostwick, 2010; Salisbury \& Voorhis, 2009). In a sample of 163 incarcerated women in Illinois state prisons, $99 \%$ of the women reported experiencing at least one type of victimization in their lifetime. In this same sample, $98 \%$ of women reported physical violence, $85 \%$ reported psychological/stalking abuse, and $75 \%$ reported sexual victimization (Reichert, Adams, \& Bostwick, 2010). Further, extant literature shows that women in this segment of the population also experience significant childhood victimization (Bloom, Owen, Covington, 2003; Reichert, Adams, \& Bostwick, 2010; Richie, 2000; Tripodi \& Pettus-Davis, 2013). In a study of 125 women in North Carolina 
state prisons, more than one-third of participants reported experiencing childhood physical and/or sexual violence (Tripodi \& Pettus-Davis, 2013). McDaniels-Wilson and Belknap (2008) found over 50\% of incarcerated women in their study reported childhood sexual victimization.

Justice involved women report rates of psychological distress, particularly Post Traumatic Stress Disorder (PTSD) symptoms, as high as 60\% (Reichert, Adams, \& Bostwick, 2010). Research also demonstrates high rates of depression, anxiety, and deficits in overall mental health functioning for this population (McDaniels-Wilson \& Belknap, 2008; Messina Grella, 2006; Peltan \& Cellucci, 2011; Reichert, Adams, \& Bostwick, 2010; Tripodi \& Pettus-Davis, 2013). Moreover, women on probation/parole are twice as likely to experience mental illness when compared to the general population (Bloom, Owen, Covington, 2003; Center for Behavioral Health Statistics and Quality, 2012). Further, research demonstrates self-esteem, social support, coping, and substance use are factors found to be associated with successful reentry into their community, however very little research has been done which examines these factors in this population as related to victimization and psychological distress (Bloom, Owen, Covington, 2003; Center for Behavioral Health Statistics and Quality, 2012; Salisbury \& Voorhis, 2009, p.545).

A more comprehensive understanding of these factors would significantly address this current gap in general victimization literature. Particularly, this knowledge could influence the design of programs and interventions developed for women with cooccurring and presenting problems. An understanding of the relationship between the different types of victimization and psychological distress would significantly benefit 
targeted and specific intervention strategies for this high-risk population. This information is necessary, as victimization and psychological distress has been demonstrated to directly influence women's involvement and recidivism within the justice system (McDaniels-Wilson \& Belknap, 2008; Salisbury \& Voorhis, 2009; Tripodi \& Pettus-Davis, 2013).

\section{Primary Aim of the Study}

Therefore, the primary aim of this study is to address the identified gaps in substantive knowledge surrounding victimization and psychological distress, as well as general knowledge regarding women in the criminal justice system. Specifically, this study will explore the relationship between cumulative victimization (childhood and adult IPV), the hypothesized mediators (self-esteem, social support, coping, and substance use), and psychological distress among a sample of 406 victimized women on probation and parole. The conceptual model guiding this research can be seen in Figure 1.

\section{Plan for the Chapters}

Chapter 1 has highlighted an overview of the problem, particularly examining the complexity of victimization and associated negative sequelae that lead to psychological distress. Chapter 2 presents a review of the literature pertinent to this discussion as well as a theoretical model to further explain the relationship(s) and mechanisms by which victimization and psychological distress are associated. Chapter 3 provides the research design and methodology, with the results presented in Chapter 4. Lastly, Chapter 5 
provides a discussion of the study finding, including implications for policy and practice, particularly interventions developed to target specific needs of victimized women. 
Figure 1. Conceptual Model

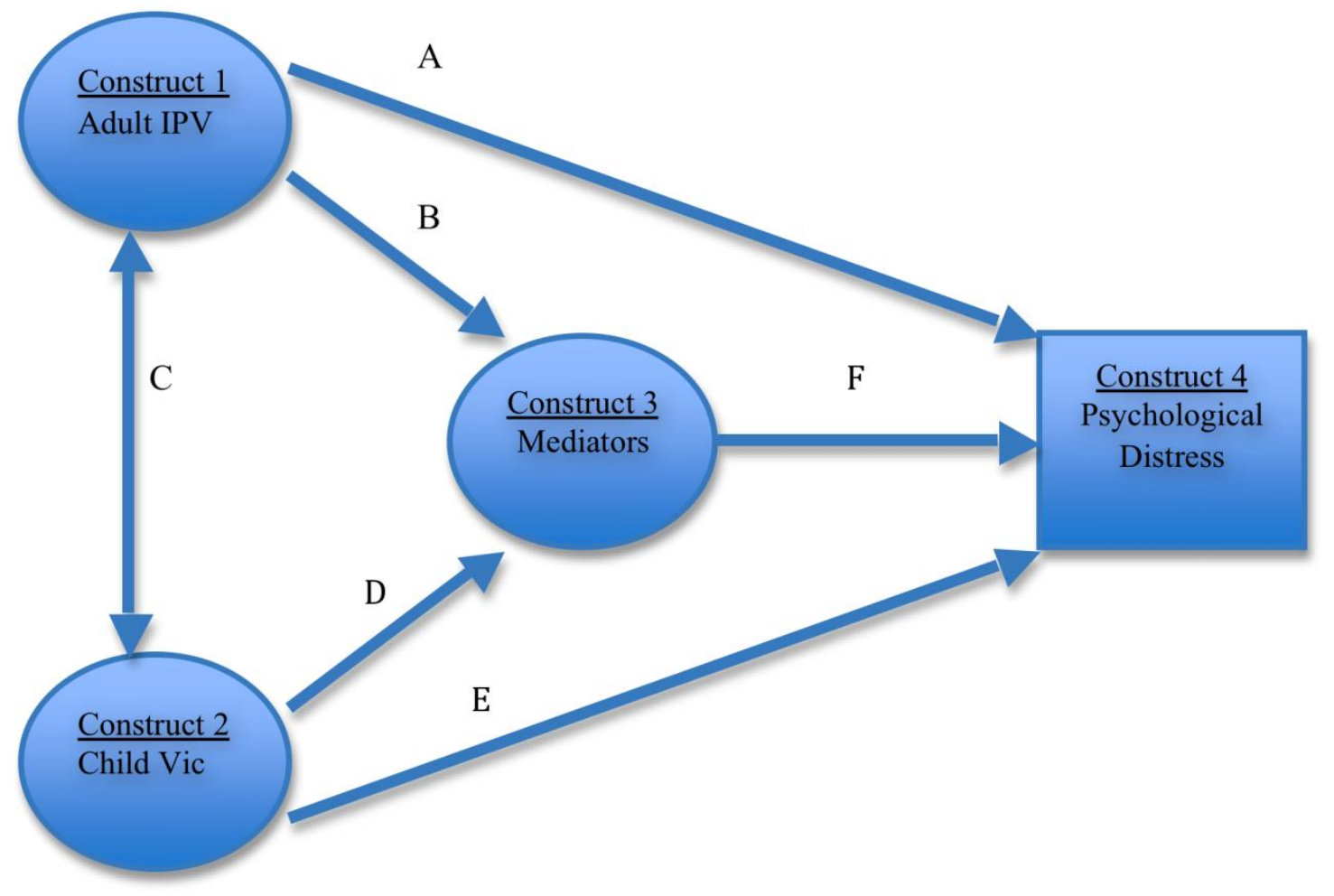




\section{CHAPTER 2: LITERATURE REVIEW}

\section{Conceptual Model}

Researchers have documented a need for more effective models to address a number of current gaps in knowledge related to victimization and psychological distress (Barnett, Miller-Perrin, and Perrin, 2011; Briere and Jordan, 2004, 2009; Salisbury and Voorhis, 2009; Sitaker, 2007; Tjaden and Thoennes, 2000). As such, the conceptual model presented in Chapter 1 is a response to this call due to its unique, theory-building nature that expands upon prior evidence in the literature. Specifically, the conceptual model builds upon current knowledge of the independent direct effects from childhood victimization and adult IPV on psychological distress by examining violence cumulatively rather than independently. Additionally, this model addresses the gap of understanding regarding the function of other factors that potentially impact this relationship. Guided by the model, this chapter will explore evidence in the literature concerning both direct relationships (Paths A and E) between victimization (adult IPV [Construct 1] and child victimization [Construct 2] correlated by Path C), and psychological distress (Construct 4) while concurrently examining the indirect

relationship(s) (Paths B, D, and F) through the related factors (self-esteem, social support, coping, and substance use) that potentially mediate this relationship (Construct 3). 
This chapter will begin by examining the scope and breadth of general childhood victimization (Construct 2) and adult IPV (Construct 1). This is followed by the presentation of evidence to study victimization cumulatively (Path C), rather than independently. Next, prevalent psychological distress literature is presented (Construct 4), particularly as it relates to victimization (Paths A and E). Lastly, research of the factors (Construct 3) that potentially impact the relationship between victimization and psychological distress outcomes is presented (Paths B, D, and F).

\section{Victimization}

Childhood victimization ${ }^{6}$ (Construct 2). In 2012, approximately 3.8 million children were involved in Child Protective Services (CPS) reports (U.S. Department of Health and Human Services, Administration for Children and Families, Administration on Children, Youth and Families, Children's Bureau, 2013). Of the victimization reported, more than 650,000 children had experienced at least one type of substantiated ${ }^{7}$ abuse and/or neglect; this equates to 9.2 out of every 1000 children in the United States (Child Welfare Information Gateway, 2014). Types of childhood victimization include physical, sexual, and psychological abuse, as well as neglect (Barnett, Miller-Perrin, \& Perrin, 2011;Briere \& Jordan, 2009; Child Welfare Information Gateway, 2014; Tjaden \& Thoennes, 2000; U.S. Department of Health and Human Services, Administration for Children and Families, Administration on Children, Youth and Families, Children's

${ }^{6}$ The terms "childhood victimization" and "child abuse" are used interchangeably for purposes of this research.

${ }^{7}$ According to the US Department of Health and Human Services, Administration for Children and Families, Administration on Children, Youth and Families, Children's Bureau (2013), substantiated abuse/neglect is defined as "an investigation disposition that concludes that the allegation of maltreatment or risk of maltreatment was supported or founded by state law or policy" (p.16). 
Bureau, 2013). Statistics from the U.S. Department of Health and Human Services report lifetime child neglect at $78.3 \%$, child physical abuse at $18.3 \%$, and sexual abuse at $9.3 \%$, respectively regardless of gender (2013). Both familial and social risks have been identified for all types of childhood victimization (Briere \& Jordan, 2009). Familial risk factors include poor parental psychological functioning, parental substance use, witnessing/exposure to maternal abuse, poor quality of parent/caregiver-child relationship, and overall negative family functioning (Briere \& Jordan, 2009). Social risk factors include poverty/economic deprivation, community violence, inadequate social support, and belonging to an ethnic minority group (Briere \& Jordan, 2009; Daro, Edleson, \& Pinderhughes, 2004).

Childhood victimization is one of the most significant contributing risk factors for adult victimization (Briere \& Jordan, 2004, 2009; Classen et al., 2001; Dong, et al., 2003; Messman-Moore \& Long, 2000; Sitaker, 2008; Tjaden \& Thoennes, 2000; Whitfield, et al., 2003). Dong and colleagues' (2003) Adverse Childhood Experiences (ACE) Study found that child sexual victimization (CSV) most often occurs with physical and/or psychological abuse. However, isolated CSV has been the most extensively examined pathway of childhood to adult victimization against women in existing literature (Briere \& Jordan, 2009; Classen, et al., 2001; Elliot, Mok, \& Briere, 2004; Logan, et al., 2006; Messman-Moore \& Long, 2000; Renner \& Slack, 2006; Roodman \& Clum, 2001; Tjaden \& Thoennes, 2000). In a study of 633 college women, Messman-Moore and Long (2000) found childhood sexual abuse directly contributed to women's experiences of physical, sexual, and psychological violence as an adult. Further, a study conducted in 2004 examined sexual assault histories of 941 participants comprised of $50.2 \%$ female 
respondents (Elliot, Mok, \& Briere, 2004). Results indicated over half of the women who were sexually assaulted in adulthood had histories of CSV that significantly contributed to the subsequent violence. The previously mentioned ACE Study also examined adult IPV experiences specifically; results indicated that women's risk of IPV is 3.5 times more likely to occur if they experienced all three forms of child victimization (Whitfield, et al., 2003). The Franklin and Kercher (2012) study that randomly sampled 502 participants (189 males, 360 females) indicated experiences of child victimization directly influenced future risk of psychological victimization by an intimate partner. As the evidence suggests, childhood victimization is endemic and directly related to later experiences of adult IPV.

Adult victimization (Construct 1). As stated previously, IPV includes physical, sexual, and psychological acts of aggression ranging from threats to completion (Krug, Dahlber, Mercy, Zwi, \& Lozano, 2002). Physical aggression consists of slapping, hitting, kicking, beating (Krug et al., 2002) as well as pushing, shoving, grabbing, pulling hair, biting, choking, and threatening or using a knife, gun, or other weapon (Tjaden \& Thoennes, 2000). Sexual aggression includes coercion or forced sexual acts of intercourse (Krug et al., 2002; Lacey, McPherson, Samuel, Sears, \& Head, 2013; Tjaden $\&$ Thoennes, 2000) in addition to attempted or completed rape (meaning sexual acts without victims consent) that involve penetration of the vagina, mouth, or anus. Psychological aggression includes intimidation, constant belittling, and humiliation (Krug et al., 2002).

In addition to childhood victimization, there are a number of social and environmental risk factors that increase risk of adult IPV, including personal 
demographics such as race, gender, socioeconomic status, and high-risk neighborhoods (Barnett, et al., 2011; Bogat, Levondosky, \& von Eye, 2005; Logan et al., 2006; Tjaden \& Thoennes, 2000). Research that examines race as a specific risk factor for IPV is consistent in finding racial differences but differs with regard to which races are at greater risk. Tjaden and Thoennes (2000) found that non-Hispanic ${ }^{8}$ women are significantly more likely to be raped than their Hispanic counterparts, although there were no differences between races for physical victimization or stalking. Further, these authors found no significant differences in victimization experiences for AfricanAmerican women and White women, however women of mixed race/ethnicity were significantly more likely to be raped than White women (Tjaden \& Thoennes, 2000). However, other research suggests that race is a significant contributing factor for adult IPV, particularly for women of color and non-white ethnic minorities (Carbone-Lopez, 2013; Houry, Kaslow, \& Thompson, 2005; Kennedy et al., 2012; Lacey et al., 2013). Research has shown that women with lower incomes and limited access to education and/or employment are at greater risk for adult IPV (Breiding, et al., 2008; Sitaker, 2008). Necessary to note, a growing body of research suggests socioeconomic status more accurately predicts victimization risk than race as mentioned previously (Logan et al., 2006; Mitchell, et al., 2006). Thus, poor women who also experience any of the previously mentioned risk factors are at an even higher risk for experiencing victimization than women with higher socioeconomic status (Breiding, et al., 2008; Logan et al., 2006).

${ }^{8}$ This indicates any race with an absence of Hispanic background. 
Further, substance-using women are also more likely to experience IPV compared to non-substance using women (Briere \& Jordan, 2004; Engstrom, El-Bassel, \& Gilbert, 2012; Golder, Connell, \& Sullivan, 2012; Golder \& Logan 2011; Logan et al., 2006; Peters, Khondkaryan, \& Sullivan, 2012). It is hypothesized that women who are involved in risky or illicit activities are less likely to seek assistance from institutions such as the criminal justice system due to perceived stigmatization and fear of connecting themselves with criminal activity (Logan et al., 2006). Further, substance and alcohol use particularly place women at risk for adult IPV.

Finally, women who have restricted access to resources are at greater risk for experiencing violence. Kennedy and colleagues (2012) identify a number of limitations that interfere with women's access to institutional resources. Perceived stigmatization, discrimination, and criminalization are among the most significant barriers of helpseeking (Barnett et al., 2011; Kennedy et al., 2012; Logan et al., 2006). Additionally, women who have been victimized previously are less likely to seek formal support systems (such as healthcare or clinical settings) and are more likely to find informal support systems for assistance (family and friends; Kennedy et al., 2012). Research suggests that the combination of the aforementioned barriers as well as social location ${ }^{9}$ and needs appraisa $1^{10}$ influences a woman's ability to access resources to prevent current or future victimization (Kennedy et al., 2012; Logan et al., 2006). Burgess-Proctor (2011) further identified factors that heavily obstruct women's ability to pursue help, including economic dependence on one's partner, fear, abuse severity, presence of children, and

\footnotetext{
${ }^{9}$ Such as one's neighborhood, geographical location, and ability to access help. 10 This is a complex, problem-defining process to assess the cost and benefit of accessing help.
} 
marital status (p. 310). Thus, women's decisions related to seeking help must be accounted for by multiple "individual, cultural, and structural influences" (BurgessProctor, 2011, p. 314). This finding echoes numerous studies that demonstrate the heterogeneous ${ }^{11}$ experiences of IPV and related barriers to "getting-out" (Briere \& Jordan, 2004, 2009; Burgess-Proctor, 2011; Kelly, 2011; Logan et al., 2006).

In the United States, 1 out of every 5 women has experienced physical IPV (Tjaden \& Thoennes, 2000). Additionally, 1 out of every 6 women experience sexual assault by an intimate partner (both rape and attempted rape) in the United States (Tjaden \& Thoennes, 2000). Further, "[in the United States] women are far more likely to be injured during assaults by intimate partners than are men, and women suffer more severe forms of violence than men (Krug et al., 2002, p.94). Over 1000 women die and over two million injuries are reported annually in the United States as a result of IPV (Breiding, et al., 2008).

Cumulative victimization (Correlation C). Further compounding women's experiences of adult IPV are the cumulative histories of violence across their lifespan, which contribute to recurrent and sequential violence (Briere \& Jordan, 2004, 2009; Classen et al., 2001; Dong, et al., 2003; Messman-Moore \& Long, 2000; Sitaker, 2008; Tjaden \& Thoennes, 2000; Whitfield, et al., 2003). The majority of current research focuses on childhood or adulthood violence; this gap hinders understanding of women's lifetime experiences of victimization. This limitation in knowledge is particularly true for researchers seeking to understand the relationship between lifetime victimization and psychological distress. It is therefore necessary to understand women's victimization

${ }^{11}$ Defined as different, unalike, diversified. 
experiences cumulatively, rather than isolated and discreet events. This knowledge is particularly crucial for practice interventions aimed to treat victimized women with associated negative sequelae (such as psychological distress). While current literature demonstrates both direct (and indirect) relationships between childhood violence and adult IPV with psychological distress (Paths A and E), studies of cumulative victimization (Correlation C) are scantly represented and the mechanisms that function within an indirect relationship (Paths B, D, and F) are minimally examined (Hedtke et al., 2008; Pico-Alfonso et al., 2006).

\section{Victimization and Psychological Distress (Paths A and E)}

Women's victimization experiences, both childhood violence and adult IPV have been directly associated with psychological distress (Paths A and E). This includes, but is not limited to Post-Traumatic Stress Disorder (PTSD), depression, and anxiety (Briere \& Jordan, 2004; Dutton, 2009). The following sections examine childhood victimization, adult IPV, and cumulative victimization in relationship to psychological distress. The supporting literature is synthesized in Tables 1-3.

\section{Child victimization and psychological distress (Path E). Extant research} indicates psychological distress is a direct outcome of childhood victimization (Briere \& Jordan, 2009; Chapman et. al, 2004; Classen et. al, 2002; Dube et. al, 2003; Filipas \& Ullman, 2006; Finkelhor \& Dzuiba-Leatherman, 1994; Kendall-Tackett, 2002; Lang, Stein, Kennedy \& Foy, 2004; Thomas, DiLillo, Walsh, \& Polusny, 2011). Specifically, the types of violence experienced in childhood (physical, sexual, psychological) are interrelated and significantly increase the likelihood of women to develop depressive 
symptoms, PTSD, anxiety, borderline personality disorder, dissociative disorder, cognitive disturbance, mood disturbance, somatization, and emotional regulation deficits in adulthood (Briere \& Jordan, 2009; Chapman et. al, 2004; Classen, et al., 2001, 2002; Kendall-Tackett, 2002). The most extensively examined forms of psychological distress in this literature are depression, anxiety, and PTSD (Barnett, Miller-Perrin, \& Perrin, 2011; Briere \& Jordan, 2009; Chapman et. al, 2004; Classen et al., 2002; Dube et. al, 2003; Kendall-Tackett, 2002; Lang, Stein, Kennedy \& Foy, 2004; Thomas, DiLillo, Walsh, \& Polusny, 2011). Briere and Jordan (2009) found that anxiety and depression are the most common symptoms of psychological distress associated with child victimization, regardless of type. Additionally, a number of studies indicate a strong association between CSV and PTSD (Barnett, Miller-Perrin, \& Perrin, 2011; Briere \& Jordan, 2009; Classen et al., 2002; Filipas \& Ullman, 2006; Kendall-Tackett, 2002).

Adult victimization and psychological distress (Path A). Additionally, based on seminal research by Houskamp and Foy (1991), and Golding (1999) there is clear evidence of a relationship between adult IPV and psychological distress (Basile, Arias, Desai, \& Thompson, 2004; Becker, Stuewig, \& McCloskey, 2010; Bonomi et al., 2006; Briere \& Jordan, 2004; Carbone-Lopez, Kruttschnitt, \& Macmillan, 2006; Clements \& Sawhney, 2000; Coker et al., 2002a; Coker et al., 2000b; Coker, Watkins, Smith, \& Brandt, 2003; Dienemann et al., 2000; Dutton, 2009; Golder, Connell, Sullivan, 2012; Hedtke, et al., 2008; Houry, Kaslow, \& Thompson, 2005; Kennedy et.al, 2012; Krebs, Breiding, Browne, \& Warner, 2011; Lacey, et al., 2013; Mburia-Mwalili, ClementsNolle, Lee, Shadley, \& Yang, 2010; Mitchell et al., 2006; Najdowski \& Ullman, 2009; Nurius \& Macy, 2008; Peters, Khondkarayn, \& Sullivan, 2012; Pico-Alfonso et al., 2006; 
Salisbury \& Voorhis, 2009; Woods, 2005; Young-Wolff et al., 2013). Various types of psychological distress result from adult IPV experiences including depression, suicidality, anxiety, PTSD, dissociation, somatization, and chronic stress (Briere \& Jordan, 2004; Clements \& Sawhney, 2000; Dutton, 2009; Nurius \& Macy, 2008). As with childhood victimization, the most extensively studied psychological distress in relationship to adult IPV is depression, anxiety, and PTSD (Briere \& Jordan, 2004; Dutton, 2009; Kennedy et. al, 2012). Research demonstrates $25 \%-33 \%$ of women who experience adult sexual IPV develop PTSD in their lifetime (Kennedy et. al, 2012). Further, PTSD and depression typically co-occur, and women that experience physical adult IPV are two times more likely to experience depression (Dutton, 2009). Moreover, meta-analyses have demonstrated that on average, more than $48 \%$ of women who experience adult IPV also exhibit signs and symptoms of depression (Dutton, 2009). Further, a longitudinal study investigated types of IPV and subsequent PTSD and depression; results indicated that women with sexual abuse histories were three times more likely to develop PTSD (Hedtke, et al., 2008). In addition, this study found that women who experienced physical and sexual, or all three types of IPV experienced greater PTSD and depression symptoms. This finding is similar to the results of Basile and colleague's (2004) research regarding adult IPV and PTSD. Their investigation revealed women who had increased victimization experiences also had increased symptoms of PTSD.

\section{Cumulative victimization and psychological distress (Correlation $\mathrm{C}$ through}

Paths A and E). Although a number of studies suggest that both childhood victimization and adult IPV are directly related to psychological distress, scant research exists which 
examines cumulative victimization and psychological distress (Carlson, McNutt, \& Choi, 2003; Engstrom, El-Bassel, \& Gilbert, 2012; Golder \& Logan, 2011; Salisbury \& Voorhis, 2009). Whitaker and colleagues' (2005) examination of victimization in childhood, adolescence, and adulthood found that psychological distress resulted from violence experienced at any point in a woman's lifetime. This finding, along with other research that only takes into account either childhood victimization or adult IPV and psychological distress indicate there is evidence to suggest a cumulative effect of victimization (Becker, Stuewig, \& McCloskey, 2009).

\section{Related factors in the relationships between victimization and psychological}

distress (Path B, D, and F). Not only is victimization significantly related to psychological distress, a number of other related factors have also been found in literature to influence this relationship (Path B, D, and F). The factors most examined in the literature (although not simultaneously) include coping, substance use, self-esteem, and social support. Understanding the function of these factors, as they relate to victimization and psychological distress is crucial to the development of targeted intervention strategies.

Coping and psychological distress. Coping is defined as "cognitive and behavioral efforts made to master, tolerate, or reduce external and internal demands and conflicts" (Aneshensel, 1992, p. 18); put more simply, coping includes actions taken by an individual that result in a decreased rate of reported stress (Mitchell et al., 2006). Coping is understood to encompass both positive and negative behaviors. Examples of positive coping include developing problem solving strategies or receiving social support. Examples of negative coping include internalizing blame for the presenting problem or 
withdrawing/isolating oneself. The ability to cope significantly influences the development and experience of various types of psychological distress (Lazarus, 2006). When an individual possesses a variety of positive coping skills, the likelihood of psychological distress decreases; in contrast if one utilizes negative coping skills, the likelihood of distress increases (Charney, 2004; Dutton, 2009; Lazarus, 2006; Mitchell et al., 2006). Importantly, positive coping mediates the effects of adverse events, like victimization, on the subsequent development of psychological distress including PTSD and depression (Clements \& Sawhney, 2000; Filipas \& Ullman, 2006; Najdowski \& Ullman, 2009). Specifically, Filipas and Ullman (2006) examined the effects of coping within the relationship of sexual abuse and PTSD. Respondents with maladaptive coping skills (such as high-risk sexual activity, self-blame, using substances, and acting out aggressively) and a history of sexual abuse had more frequent and severe symptoms of PTSD.

Substance use and psychological distress. A number of empirical studies examine the relationship between substance use and psychological distress (Briere \& Jordan, 2004; Engstrom, El-Bassel, \& Gilbert, 2012; Kendall-Tackett, 2002; Kendler, Gardner, \& Prescott, 2002; Testa, Livingston, \& Leonard, 2003). In particular, there is a clear association between substance use, depression and PTSD (Kendler, Gardner, \& Prescott, 2002). Substance use, psychological distress, and victimization have been found to co-occur and simultaneously influence continued use, distress, and violence (Briere \& Jordan, 2004; Engstrom, El-Bassel, \& Gilbert, 2012; Golder, Connell, \& Sullivan, 2012; Golder \& Logan 2011; Logan et al., 2006; Peters, Khondkaryan, \& Sullivan, 2012). In a study by Hedtke and colleagues (2008), women with IPV experienced greater rates of 
substance use and subsequent PTSD. It is also hypothesized that substance use may occur in this relationship as a mediating factor between victimization and psychological distress when used as an avoidance technique (Carbone-Lopez, Kruttschnitt, \& Macmillan, 2006; Filipas \& Ullman, 2006; Golder \& Logan, 2011; Peters, Khondkaryan, \& Sullivan, 2012). In a literature review conducted by Briere and Jordan (2004) effects of substance use were examined in relation to psychological distress's influence on victimization experiences. Findings were consistent across the studies; increased substance use resulted in greater symptoms of PTSD and subsequent victimization/revictimization. However, minimal research has examined whether substance use mediates the relationship between victimization and psychological distress (Logan et al., 2006; Peters, Khondkaryan, \& Sullivan, 2012).

Self-esteem and psychological distress. A growing body of literature has examined self-esteem's impact on psychological distress that results from victimization (Dutton, 2009; Hill, Kaplan, French, \& Johnson, 2010; Soler, Kirchner, Paretilla, \& Forns, 2013). Self-esteem is defined as the "evaluative component of self-concept" (Gray-Little, Williams, \& Hancock, 1997, p. 443) that encompasses both positive and negative feelings of self (Rosenberg, 1965). Higher levels of self-esteem equate to more positive feelings, and lower levels of self-esteem equate to negative feelings. Empirical evidence suggests low self-esteem is directly influenced by victimization experiences, and then continues to affect the occurrence of psychological distress (Classen et. al, 2001; Hill, Kaplan, French, \& Johnson, 2010). Results from a study conducted by Hill and colleagues (2010) indicate that self-esteem was a significant mediator for childhood sexual abuse and adult psychological distress among 2,402 women of color living at or 
below the poverty line. Further, Dutton (2009) examined self-esteem as a mediator between adult IPV and PTSD; the findings from this study indicate that self-esteem directly and indirectly impacts this relationship. Missing from this investigation however, was an account of childhood victimization, cumulative victimization, and other related factors that potentially influence psychological distress outcomes. Kendall-Tackett's (2002) research examined childhood victimization's effect on poor self-esteem, which significantly impacts risk of experiencing depression in adulthood. As with prior studies, this research is informative, yet lacking the account of adult IPV and cumulative victimization.

Social support and psychological distress. Lack of social support ${ }^{12}$, vastly researched in the literature, is a clear predictor of psychological distress (Borelli, Goshin, Joestl, Clark, \& Byrne, 2010; Cohen \& Wills, 1985; Coker et al., 2002b; Coker, Watkins, Smith, \& Brandt, 2003; Collins, \& Feeney, 2004; Crouch, Milner, \& Caliso, 1995; Kendler, Gardner, \& Prescott, 2002; Mitchell et al., 2006; Mburia-Mwalili et al., 2010; Nurius et al., 2003). Brewin and colleagues' meta-analysis (2000) found that a lack of social support is a significant risk factor for post-traumatic stress. In particular, insufficient social support has significantly impacted psychological distress, in the context of PTSD (Dutton, 2009). Further, victimization literature indicates low levels of social support are a direct outcome of violence (Briere \& Jordan, 2004; Ulla-Diez, 2009). This relationship is also seen in studies that examine the relationship of IPV to PTSD, while looking at the mediating effect of social support on outcomes (Dutton, 2009). Additionally, research has demonstrated that higher levels of social support reduce future

12 This encompasses interpersonal relationships with others (spouses, friends, family) who provide "psychological and material resources" (Cohen \& Wills, 1985). 
distress and revictimization (Ansara \& Hindin, 2010; Kennedy, et al., 2012). Powers and colleagues (2009) found that perceived social support significantly buffered depression among minority and poor women who were participants in the Grady Trauma Project ${ }^{13}$. Therefore understanding the particular impact of this factor as it relates to cumulative victimization and psychological distress is a current gap in the existing research.

Table 1. Types of Child Victimization and Psychological Distress Outcomes

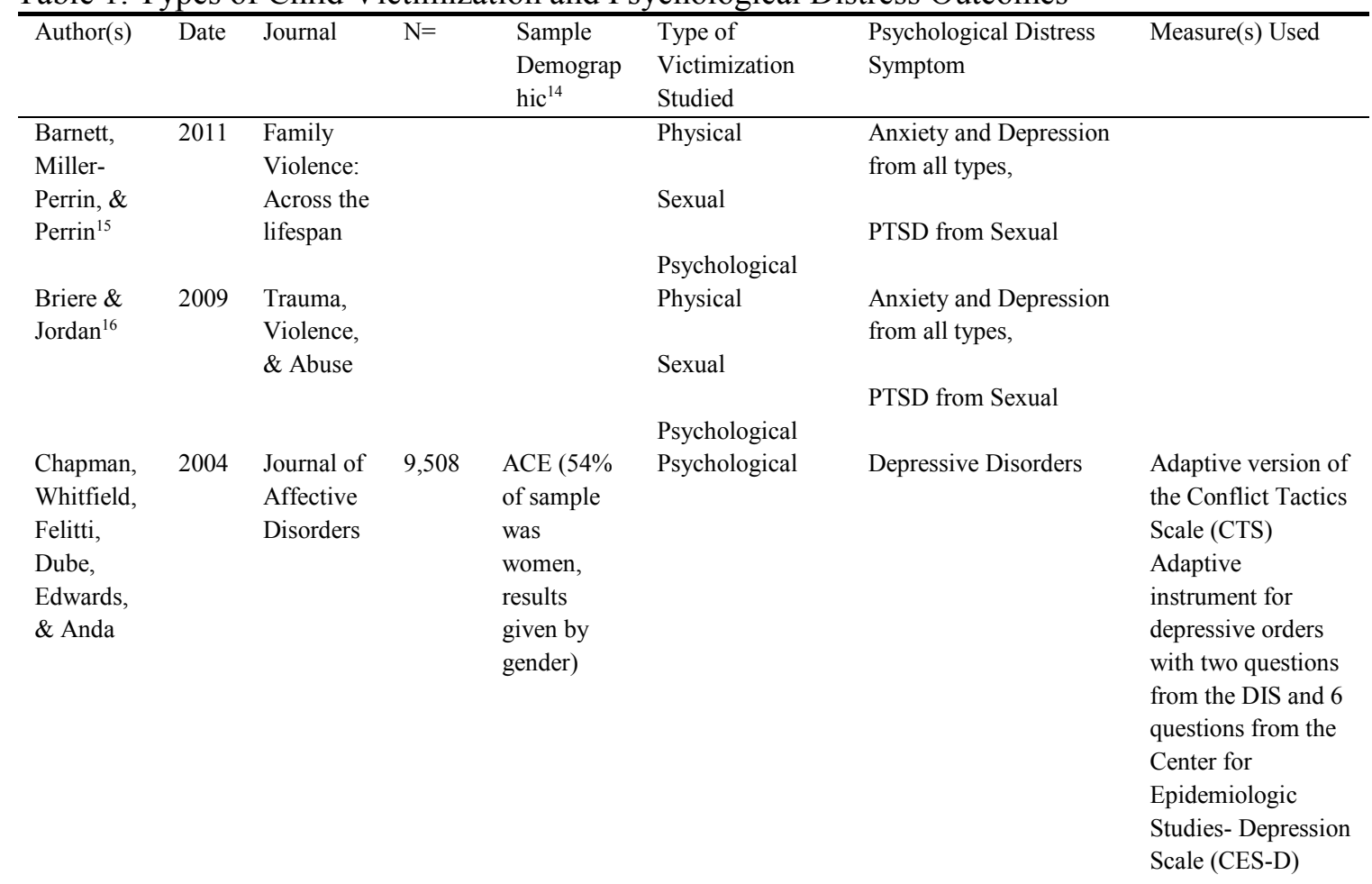

13 This study was a 5-year NIH-funded study of risk and resilience of PTSD at Grady Hospital in Atlanta, Georgia (Bradley et al., 2008 as cited in Powers et al., 2009). This sample was comprised of both men and women $(\mathrm{N}=378)$, and $54 \%$ of the sample was female. Ninety-three percent of the women in this study were African-American, and over 50\% were living on less than $\$ 1,000$ a month.

${ }^{14}$ Samples are female gendered, unless otherwise specified.

15 This is a textbook reference, which synthesizes family violence.

${ }^{16}$ This is a literature review. 


\begin{tabular}{|c|c|c|c|c|c|c|c|}
\hline $\begin{array}{l}\text { Classen, } \\
\text { Field, } \\
\text { Koopman, } \\
\text { Nevill- } \\
\text { Manning, } \\
\text { Spiegel }\end{array}$ & 2001 & $\begin{array}{l}\text { Journal of } \\
\text { Interperso } \\
\text { nal } \\
\text { Violence }\end{array}$ & 52 & $\begin{array}{l}\text { Community } \\
\text { Sample }\end{array}$ & Sexual & PTSD & $\begin{array}{l}\text { The Sexual } \\
\text { Experiences Survey } \\
\text { (SES) } \\
\text { Inventory of } \\
\text { Interpersonal } \\
\text { Problems (IIP) }\end{array}$ \\
\hline $\begin{array}{l}\text { Classen, } \\
\text { Nevo, } \\
\text { Koopman, } \\
\text { Gore- } \\
\text { Felton, } \\
\text { Rose, \& } \\
\text { Spiegel }\end{array}$ & 2002 & $\begin{array}{l}\text { Journal of } \\
\text { Interperso } \\
\text { nal } \\
\text { Violence }\end{array}$ & 58 & $\begin{array}{l}\text { Community } \\
\text { Sample }\end{array}$ & Sexual & PTSD & $\begin{array}{l}\text { SES } \\
\text { CAPS } \\
\text { Trauma Symptom } \\
\text { Checklist-40 (TSC- } \\
40 \text { ) } \\
\text { Stanford Acute } \\
\text { Stress Reaction } \\
\text { Questionnaire } \\
\text { (SASRQ) } \\
\text { Psychiatric } \\
\text { Epidemiology } \\
\text { Research Interview } \\
\text { Life Events Scale } \\
\text { (PERI) }\end{array}$ \\
\hline $\begin{array}{l}\text { Dube, } \\
\text { Felitti, } \\
\text { Dong, } \\
\text { Giles, \& } \\
\text { Anda }\end{array}$ & 2003 & $\begin{array}{l}\text { Preventiv } \\
\mathrm{e} \\
\text { Medicine }\end{array}$ & $\begin{array}{l}17,33 \\
7\end{array}$ & $\begin{array}{l}\text { ACE }(54 \% \\
\text { women, } \\
\text { results by } \\
\text { gender) }\end{array}$ & $\begin{array}{l}\text { Physical, Sexual, } \\
\text { Psychological } \\
\text { (other ACE's } \\
\text { included } \\
\text { substance use, } \\
\text { mental illness, } \\
\text { maternal } \\
\text { violence) }\end{array}$ & $\begin{array}{l}\text { Depressive affect, } \\
\text { suicidality }\end{array}$ & \\
\hline $\begin{array}{l}\text { Filipas \& } \\
\text { Ullman }\end{array}$ & 2006 & $\begin{array}{l}\text { Journal of } \\
\text { Interperso } \\
\text { nal } \\
\text { Violence }\end{array}$ & 577 & $\begin{array}{l}\text { College } \\
\text { Students }\end{array}$ & Sexual & PTSD & $\begin{array}{l}\text { ASA (Shortened } \\
\text { version of the } \\
\text { Sexual Experiences } \\
\text { Survey) } \\
\text { Child Sexual Abuse } \\
\text { (CSA) } \\
\text { questionnaire } \\
\text { adopted from } \\
\text { Finkelhor } \\
\text { Foa's Posttraumatic } \\
\text { Stress Diagnostic } \\
\text { Scale (PDS) }\end{array}$ \\
\hline $\begin{array}{l}\text { Kendall- } \\
\text { Tackett }^{18}\end{array}$ & 2002 & $\begin{array}{l}\text { Child } \\
\text { Abuse \& } \\
\text { Neglect }\end{array}$ & & & Sexual & Depression and PTSD & \\
\hline
\end{tabular}

${ }^{17}$ This study measured ACE's cumulatively, rather than examining each ACE individually.

${ }^{18}$ Measure not specified, as this article is a literature review. 


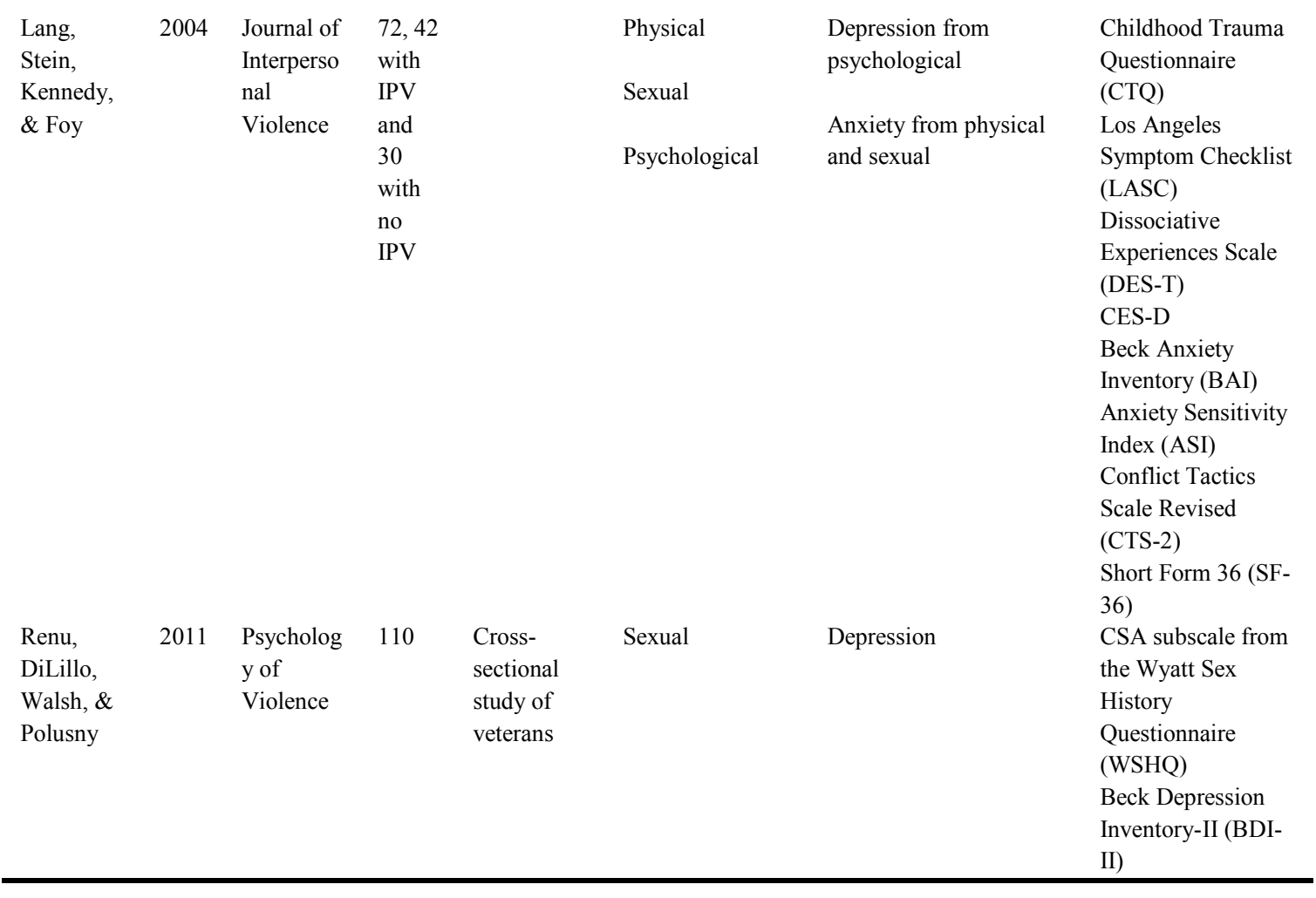

Table 2. Types of IPV and Psychological Distress Outcomes.

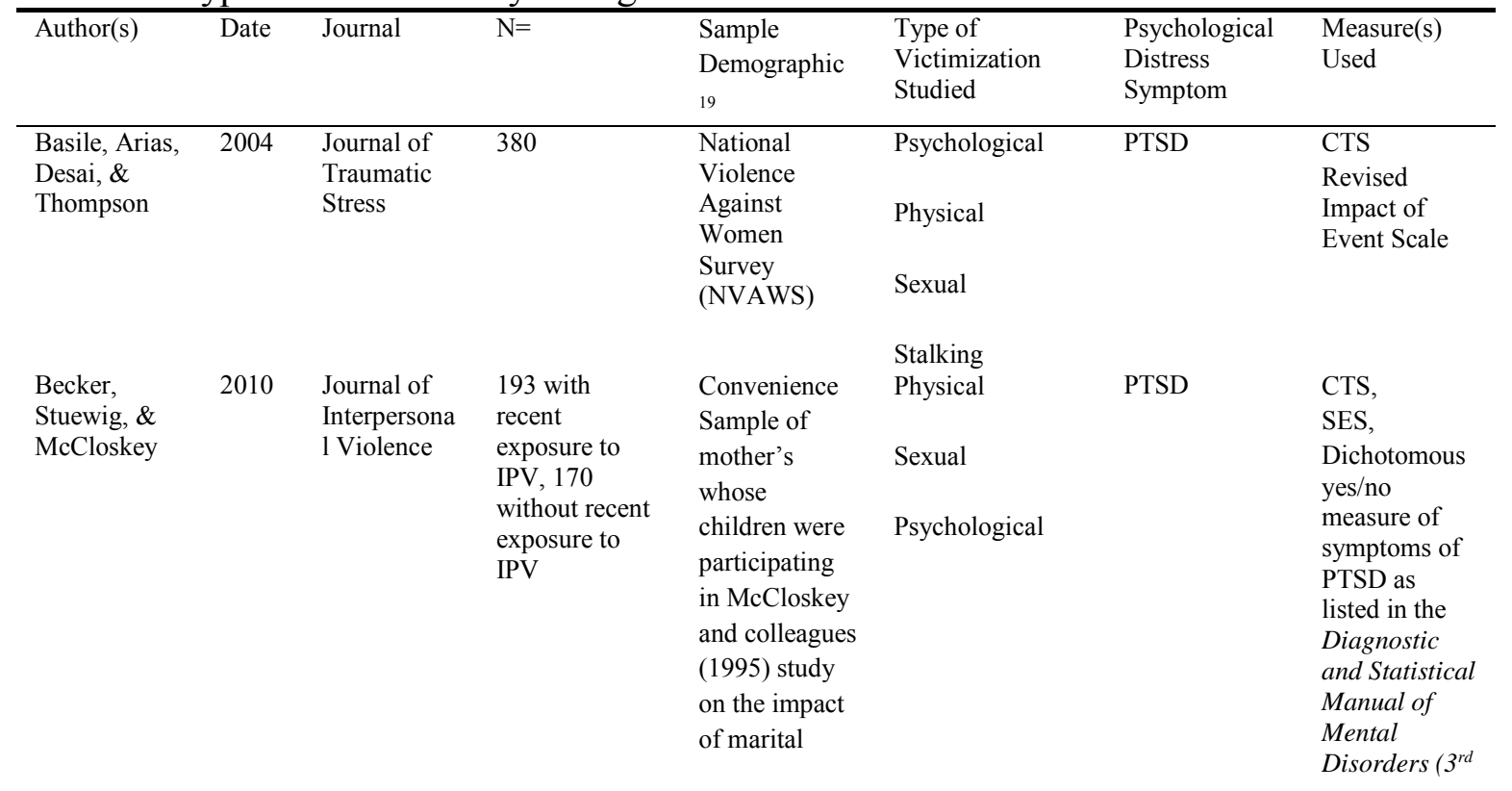

${ }^{19}$ Samples are female gendered, unless otherwise specified. 


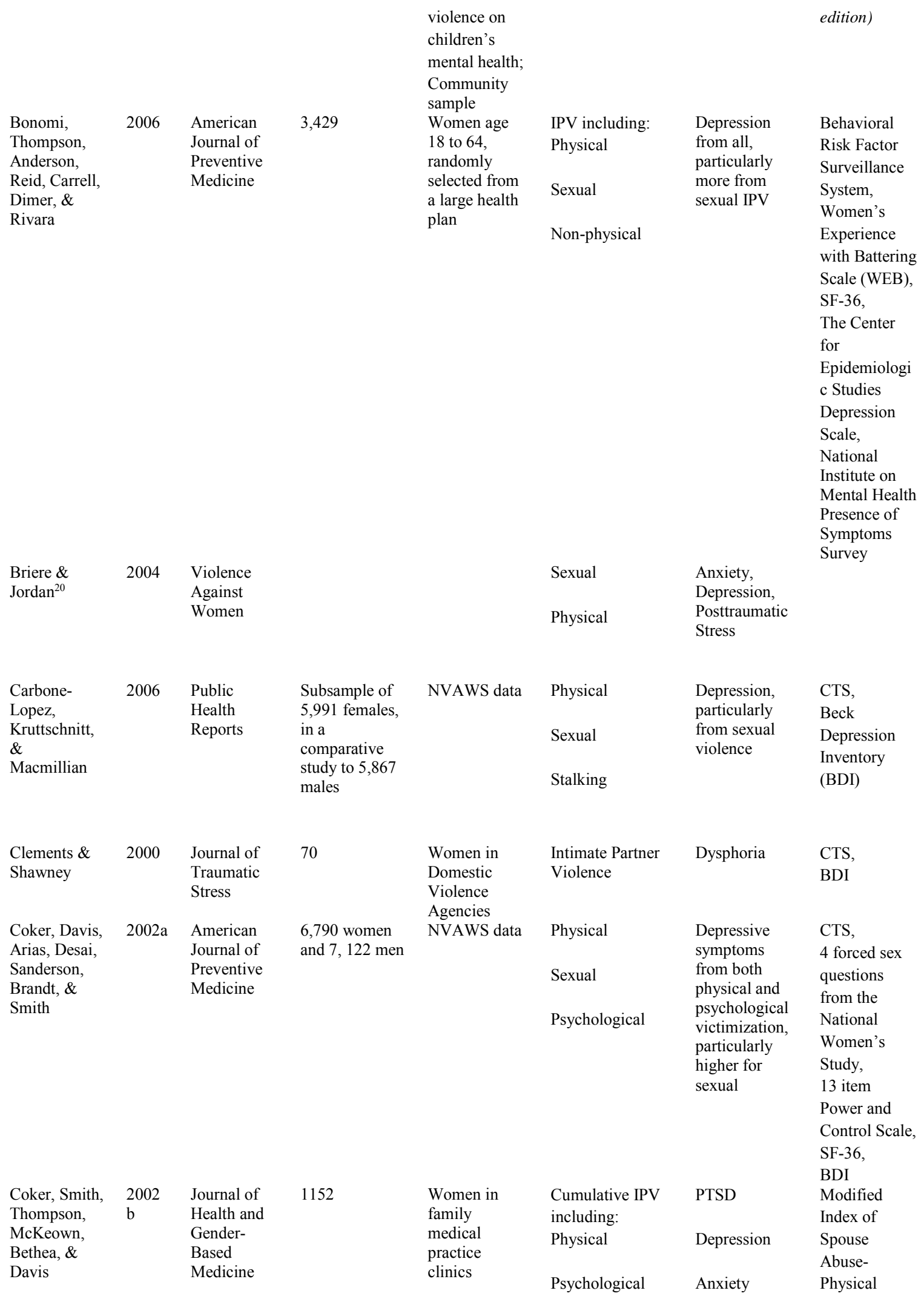

20 This article is a literature review. 


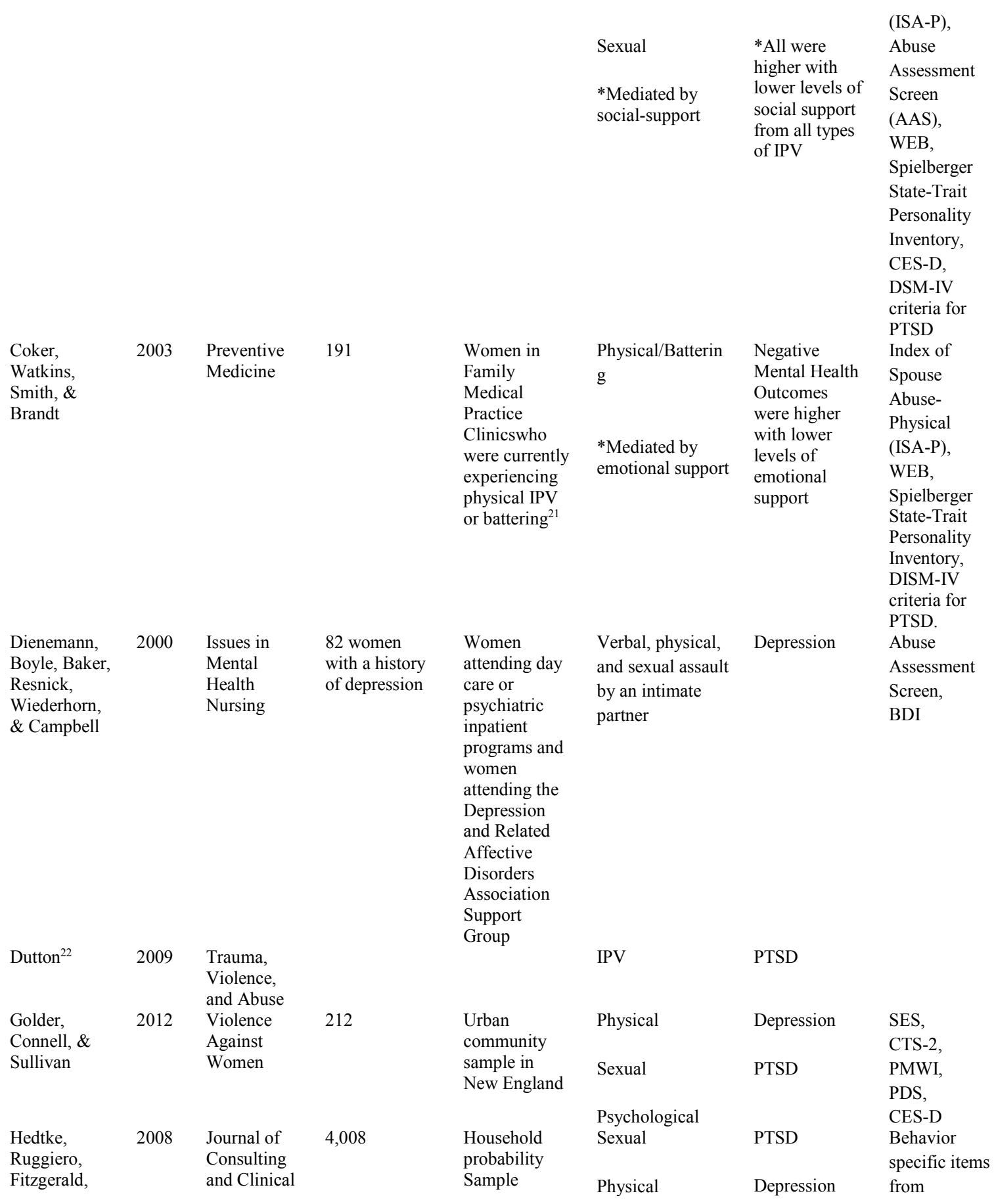

${ }^{21}$ Battering was defined as: "women's persistent feelings of susceptibility to future harm; use of multiple forms of intrapsychic and overt action in an effort to minimize harm or loss; yearning, often futilely for intimacy; development of an increasingly negative selfconcept based on the batterer's reflected negative images; increasing entrapment in the relationship; and finally women's growing disempowerment as the sustained exposure leads to a modification of thoughts, feelings, and behaviors" (p.260).

22 This article is not a scientific study, rather it is a theory building conceptualization of violence. 


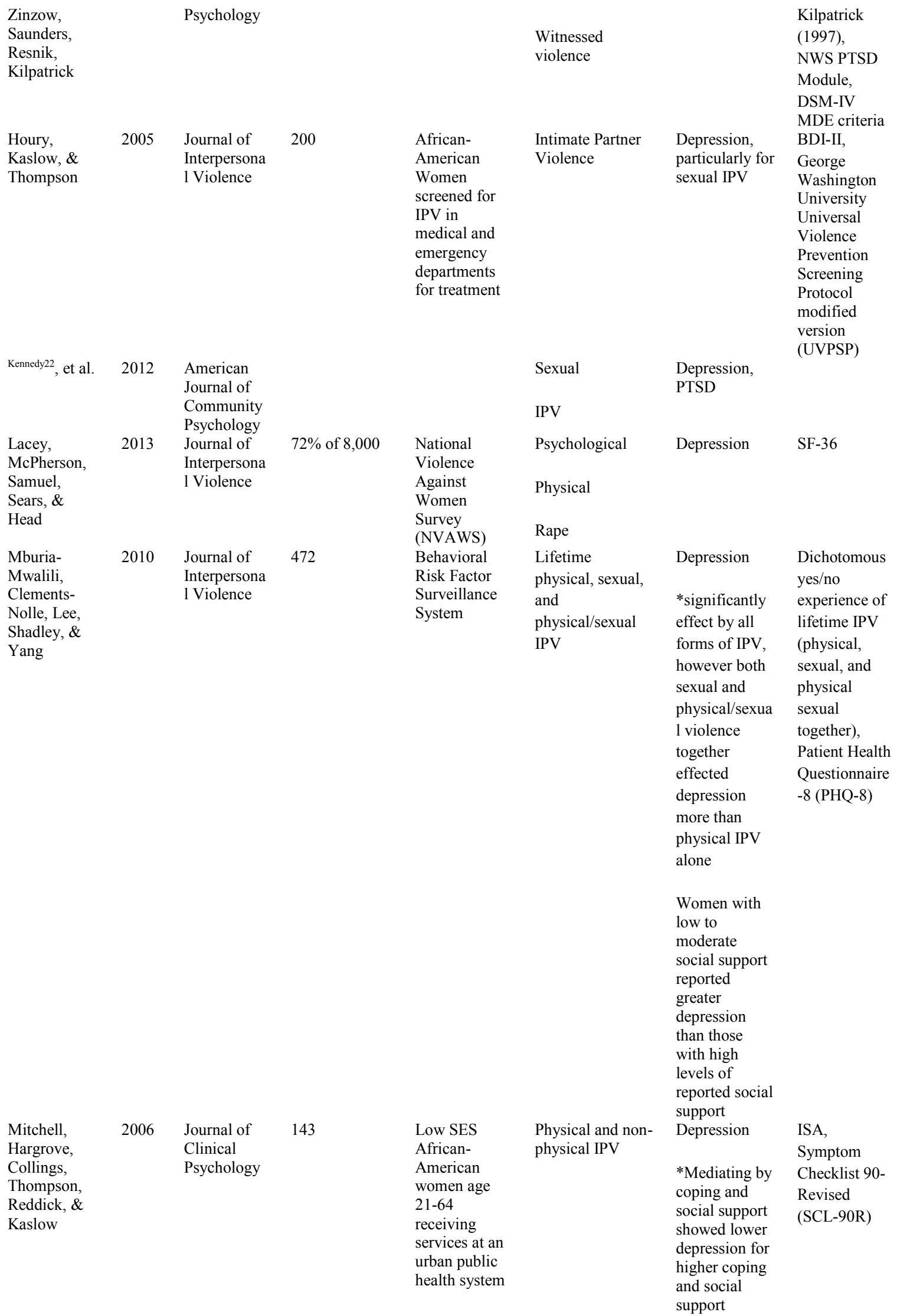




\begin{tabular}{|c|c|c|c|c|c|c|c|}
\hline $\begin{array}{l}\text { Najdowski \& } \\
\text { Ullman }\end{array}$ & 2009 & $\begin{array}{l}\text { Psychology } \\
\text { of Women } \\
\text { Quarterly }\end{array}$ & 969 & $\begin{array}{l}\text { Adult Sexual } \\
\text { Abuse } \\
\text { survivors } \\
\text { recruited } \\
\text { through } \\
\text { community } \\
\text { sample in } \\
\text { Chicago } \\
\text { metropolitan } \\
\text { area }\end{array}$ & Sexual & PTSD & $\begin{array}{l}\text { SES, } \\
\text { PDS }\end{array}$ \\
\hline $\begin{array}{l}\text { Nurius, } \\
\text { Macy, } \\
\text { Bhuyan, } \\
\text { Holt, Kernic, } \\
\text { \& Rivara }\end{array}$ & 2003 & $\begin{array}{l}\text { Journal of } \\
\text { Interpersona } \\
1 \text { Violence }\end{array}$ & 448 & $\begin{array}{l}\text { Women who } \\
\text { filed police } \\
\text { report of IPV } \\
\text { in Seattle, } \\
\text { Washington }\end{array}$ & $\begin{array}{l}\text { Physical } \\
\text { Sexual } \\
\text { Psychological }\end{array}$ & Depression & $\begin{array}{l}\text { CTS-2, } \\
\text { WEB, } \\
\text { CES-D }\end{array}$ \\
\hline $\begin{array}{l}\text { Peters, } \\
\text { Khondkaryan } \\
\text {, \& Sullivan }\end{array}$ & 2012 & $\begin{array}{l}\text { Journal of } \\
\text { Interpersona } \\
\text { 1 Violence }\end{array}$ & 212 & $\begin{array}{l}\text { Community } \\
\text { Sample }\end{array}$ & $\begin{array}{l}\text { Physical } \\
\text { Sexual } \\
\text { Psychological }\end{array}$ & $\begin{array}{l}\text { PTSD and } \\
\text { Depression } \\
\text { from severity } \\
\text { of all three } \\
\text { types }\end{array}$ & $\begin{array}{l}\text { CTS-2, } \\
\text { SES, } \\
\text { Psychological } \\
\text { Maltreatment } \\
\text { of Women } \\
\text { Inventory } \\
\text { (PMWI), } \\
\text { PDS, } \\
\text { CTQ }\end{array}$ \\
\hline $\begin{array}{l}\text { Pico-Alfonso, } \\
\text { Garcia- } \\
\text { Linares, } \\
\text { Celda- } \\
\text { Navarro, } \\
\text { Blasco-Ros, } \\
\text { Echeburua, \& } \\
\text { Martinez }\end{array}$ & 2006 & $\begin{array}{l}\text { Journal of } \\
\text { Women's } \\
\text { Health }\end{array}$ & $\begin{array}{l}\text { Comparative } \\
\text { Study of } 75 \\
\text { physical and } \\
\text { psychologicall } \\
\text { y abused } \\
\text { women; } \\
55 \\
\text { psychologicall } \\
\text { y abused } \\
\text { women; } \\
52 \text { control } \\
\text { group women }\end{array}$ & $\begin{array}{l}\text { Subsample of } \\
\text { women from } \\
\text { the Valencian } \\
\text { Community in } \\
\text { Spain } \\
\text { examining } \\
\text { endocrine and } \\
\text { immune } \\
\text { system } \\
\text { functioning in } \\
\text { women who } \\
\text { experience } \\
\text { IPV }\end{array}$ & IPV & $\begin{array}{l}\text { Depression } \\
\text { Axiety } \\
\text { PTSD } \\
\text { *Both abused } \\
\text { groups had } \\
\text { equally } \\
\text { elevated rates } \\
\text { of PTSD, } \\
\text { depressive and } \\
\text { anxiety } \\
\text { symptoms } \\
\text { when } \\
\text { compared to } \\
\text { the control } \\
\text { group, } \\
\text { particularly for } \\
\text { sexual IPV }\end{array}$ & $\begin{array}{l}\text { Dichotomous } \\
\text { yes/no } \\
\text { measure of } \\
\text { physical, } \\
\text { sexual, and } \\
\text { psychological } \\
\text { IPV; } \\
\text { Spanish } \\
\text { version of the } \\
\text { BDI; } \\
\text { Spanish } \\
\text { version of the } \\
\text { State-Trait } \\
\text { Anxiety } \\
\text { Inventory } \\
\text { adapted by } \\
\text { TEA edition; } \\
\text { Echeburua's } \\
\text { Severity of } \\
\text { Symptom } \\
\text { Scale of } \\
\text { Posttraumatic } \\
\text { Stress } \\
\text { Disorder, } \\
\text { structured } \\
\text { from the } \\
\text { DSM-IV } \\
\text { criteria of } \\
\text { PTSD } \\
\text { diagnosis }\end{array}$ \\
\hline Woods $^{23}$ & 2005 & $\begin{array}{l}\text { Journal of } \\
\text { Interpersona } \\
1 \text { Violence }\end{array}$ & & & $\begin{array}{l}\text { Intimate Partner } \\
\text { Violence }\end{array}$ & PTSD & \\
\hline $\begin{array}{l}\text { Young- } \\
\text { Wolff, } \\
\text { Hellmuth, } \\
\text { Jaquier, }\end{array}$ & 2013 & $\begin{array}{l}\text { Journal of } \\
\text { Interpersona } \\
1 \text { Violence }\end{array}$ & 412 & $\begin{array}{l}\text { Community } \\
\text { Sample }\end{array}$ & Psychological & Depression & $\begin{array}{l}\text { PMWI-S } \\
\text { (short } \\
\text { version), } \\
\text { SES, }\end{array}$ \\
\hline
\end{tabular}

${ }^{23}$ This article is a literature review. 
Swan,

Connell, \&

Sullivan
Physical

CTS-2,

Past Abusive

Behavior

Inventory,

CTQ,

CED-S,

PDS 
Table 3. Cumulative Victimization and Psychological Distress Outcomes.

\begin{tabular}{|c|c|c|c|c|c|c|c|}
\hline Author(s) & Date & Journal & $\mathrm{N}=$ & $\begin{array}{l}\text { Sample } \\
\text { Demographic }{ }^{24}\end{array}$ & $\begin{array}{l}\text { Type of } \\
\text { Victimization } \\
\text { Studied }\end{array}$ & $\begin{array}{l}\text { Psychological } \\
\text { Distress } \\
\text { Symptom }\end{array}$ & $\begin{array}{l}\text { Measure(s) } \\
\text { Used }\end{array}$ \\
\hline $\begin{array}{l}\text { Carlson, } \\
\text { McNutt, \& } \\
\text { Choi }\end{array}$ & 2003 & $\begin{array}{l}\text { Journal of } \\
\text { Interpersonal } \\
\text { Violence }\end{array}$ & 557 & $\begin{array}{l}\text { Women } \\
\text { screened for } \\
\text { domestic } \\
\text { violence at } \\
\text { primary care } \\
\text { setting }\end{array}$ & $\begin{array}{l}\text { Cumulative } \\
\text { physical and } \\
\text { sexual } \\
\text { victimization }\end{array}$ & $\begin{array}{l}\text { Depression } \\
\text { from physical } \\
\text { and sexual } \\
\text { child abuse, } \\
\text { cumulative } \\
\text { abuse; } \\
\text { Anxiety from } \\
\text { recent IPV, } \\
\text { child abuse, } \\
\text { cumulative } \\
\text { abuse }\end{array}$ & $\begin{array}{l}\text { CMIS, } \\
\text { Physical } \\
\text { aggression } \\
\text { subscale of } \\
\text { the CTS, } \\
\text { Primary Care } \\
\text { Evaluation of } \\
\text { Mental } \\
\text { Disorders } \\
\text { (PRIME-MD) }\end{array}$ \\
\hline $\begin{array}{l}\text { Engstrom, } \\
\text { El-Bassell \& } \\
\text { Gilbert }\end{array}$ & 2012 & $\begin{array}{l}\text { Journal of } \\
\text { Substance } \\
\text { Abuse } \\
\text { Treatment }\end{array}$ & 416 & $\begin{array}{l}\text { Women in } \\
\text { methadone } \\
\text { treatment }\end{array}$ & $\begin{array}{l}\text { Child Sexual } \\
\text { Abuse } \\
\text { IPV } \\
\text { cumulatively } \\
\text { (physical, } \\
\text { sexual, } \\
\text { psychological) }\end{array}$ & PTSD & $\begin{array}{l}\text { Child Sexual } \\
\text { Abuse } \\
\text { Interview } \\
\text { (CSAI), } \\
\text { Revised CTS, } \\
\text { PDS }\end{array}$ \\
\hline $\begin{array}{l}\text { Golder \& } \\
\text { Logan }\end{array}$ & 2011 & $\begin{array}{l}\text { Violence and } \\
\text { Victims }\end{array}$ & 386 & $\begin{array}{l}\text { Subsample of } \\
\text { women in the } \\
\text { Kentucky } \\
\text { National } \\
\text { Institute on } \\
\text { Drug Abuse } \\
\text { AIDS } \\
\text { Cooperative } \\
\text { Agreement }\end{array}$ & $\begin{array}{l}\text { Child } \\
\text { psychological, } \\
\text { physical, and } \\
\text { sexual } \\
\text { victimization } \\
\text { Adult IPV } \\
\text { (psychological, } \\
\text { physical, } \\
\text { sexual, } \\
\text { stalking) }\end{array}$ & $\begin{array}{l}\text { General } \\
\text { psychological } \\
\text { distress } \\
\text { PTSD } \\
\text { symptoms }\end{array}$ & $\begin{array}{l}\text { Global } \\
\text { Severity Index } \\
\text { (GSI) from } \\
\text { the Brief } \\
\text { Symptom } \\
\text { Index (BSI), } \\
\text { Dichotomous } \\
\text { yes/no sum } \\
\text { variable of } 16 \\
\text { questions } \\
\text { related to } \\
\text { PTSD } \\
\text { symptoms for } \\
\text { one month or } \\
\text { longer }\end{array}$ \\
\hline $\begin{array}{l}\text { Salisbury \& } \\
\text { Voorhis }\end{array}$ & 2009 & $\begin{array}{l}\text { Criminal } \\
\text { Justice and } \\
\text { Behavior }\end{array}$ & 313 & $\begin{array}{l}\text { Women } \\
\text { Probationers }\end{array}$ & $\begin{array}{l}\text { Child physical } \\
\text { and sexual } \\
\text { abuse } \\
\text { Adult physical } \\
\text { or sexual IPV }\end{array}$ & $\begin{array}{l}\text { Depression } \\
\text { Anxiety }\end{array}$ & $\begin{array}{l}\text { Dichotomous } \\
\text { yes/no } \\
\text { measure of } \\
\text { child and } \\
\text { adult abuse, } \\
\text { Dichotomous } \\
\text { yes/no } \\
\text { measure of } \\
\text { symptoms of } \\
\text { depression } \\
\text { and anxiety }\end{array}$ \\
\hline
\end{tabular}

${ }^{24}$ Samples are female gendered, unless otherwise specified. 


\section{CHAPTER 3: METHODOLOGY}

The proposed study utilized secondary data from the Women's Health Research Study (R01DA027981, Golder PI). The WHRS is a longitudinal study that collected data at three time points, baseline, 12 months post baseline, and 24 months post baseline ${ }^{25}$. The primary study aims of the WHRS included: 1) identify and characterize latent class trajectories based on victimization, substance use, and psychological distress among 400 victimized women on probation and parole; 2) determine the extent to which women in the identified trajectory classes vary, over a two year time period, in levels of risk and protection in the health seeking process; and 3) examine the theory based components of the health seeking process among 400 victimized women on probation and parole. The sampling, recruitment, and data collection methods described below reflect the procedures of the WHRS. For purposes of the current research, only de-identified baseline data collected from July 2010 to January 2013 were utilized. Variables were selected from the original WHRS based upon their relevance to this study's research aim.

\section{Sampling and Recruitment}

Four hundred and six female participants from the Women's Health Research Study comprised both the primary and secondary data sample. The sampling strategy utilized a non-probabilistic availability and recruitment method (Rubin \& Babbie, 2011).

2524 months post baseline data collection is in progress and will be completed by February 2015. 
Individuals were recruited through a number of methods including: direct mailings (33\%), word of mouth (33\%), flyers posted in public locations such as local transit stops, neighborhood convenient stores, grocery stores, libraries etc...(15\%), community-based organizations (11\%), direct contact with study personnel (9\%), and news/radio/internet (2\%; Dishon, 2013). Inclusion criteria were as follows, a) 18 years of age or older; b) report of one or more experience(s) of lifetime physical or sexual victimization by a parent or caretaker during childhood (18 years old or younger), and/or physical or sexual victimization by an intimate partner at any age; c) report of having sex with men or men and women ${ }^{26}$; and d) currently sentenced to probation/parole.

A total of 636 women were screened; $90 \%$ were screened via phone, while study personnel screened the remaining $10 \%$ in person ${ }^{27}$. Of the total respondents screened, $19 \%$ of women were ineligible to participate. Reasons for ineligibility included the respondent's probation/parole status ${ }^{28}(51 \%)$, no lifetime victimization history (26\%), and only having female partners (22\%). The average age of women who were screened and eligible for participation was 36 . Women reported a number of victimization experiences ${ }^{29}$. Sixty percent of women reported physical childhood victimization; more than one-third reported childhood sexual victimization; $90 \%$ reported adult physical

\footnotetext{
${ }^{26}$ Similarities and/or differences in intimate partner violence dynamics between same gender and different gender partners are currently unknown, although greatly important and understudied. Moreover, same gender female partner participants were excluded due to concern about this subsample size, which would be too small for meaningful analysis.

27 A copy of the screening form is included in Appendix 1.

${ }^{28} 34 \%$ were not on probation/parole; $17 \%$ were either not on probation/parole in Jefferson County, Kentucky or on Conditional Discharge only.

${ }^{29}$ Victimization data were recorded for childhood victimization (parent/caretaker violence) and victimization by people other than parents or caretakers (nonparent/caretaker violence) such as a boyfriend or partner throughout their life.
} 
victimization; and $67 \%$ reported forced rape at some point in their life. See Appendices 2-3 for further screening data information.

\section{Data Collection}

For the primary study, participants were consented prior to participation and interviewed by trained female staff (See Appendix 4 for informed consent form) using audio computer assisted self-interview (ACASI) program on laptop computers (Williams, et al., 2000). Interviews lasted for approximately three hours and were conducted in places convenient to the respondents. Locations of the interviews conducted include community-based organizations (6\%), participant's homes (4\%), local restaurants $(9 \%)$, a private office at the university (1\%), public libraries (19\%), and an office located in a public assistance building (54\%). Respondents were debriefed upon completion of the interview and compensated $\$ 35$ in cash and provided local transit bus tickets to cover transportation costs. Data were stored on an encrypted, password-protected computer and participant's identifying information was not collected from the survey. The Women's Health Research study was granted a Certificate of Confidentiality, and the University of Louisville's Institutional Review Board approved this study.

\section{Measures.}

Demographics. Six demographic factors were examined including age, race, education attained, intimate partner status, work status, and homelessness. Demographics were included to provide general descriptive information for this sample, and were not included in the model. Age was measured in years, and race/ethnic background was operationalized by seven categories (African-American or Black (non-Hispanic), 
Hispanic or Latina, White (non-Hispanic), Asian or Pacific Islander, Native American, Multi-racial, and Other). Educational attainment was operationalized by five categoriesless than high school education/diploma; high school diploma/GED; trade or technical training; some college/college degree; and some graduate college/graduate degree). Intimate partner status was operationalized with three categories- single/never married; married/living with someone/common law; and separated/widowed/divorced. Work status was operationalized by five categories- unemployed; working part/full time; disabled; in school; or other). Lastly homelessness was a dichotomous (yes $=1 / \mathrm{no}=0$ ) variable reflecting whether a woman consider herself to be homeless.

Victimization. The Lifetime Victimization Measure, tailored from the National Crime Victimization Survey, Tolman's Psychological Maltreatment of Women Inventory, and the Revised Conflict Tactics Scale (Straus, Hamby, Boney, \& Sugarman, 1996; Tjaden \& Thoennes, 2000; Tolman, 1989, 1999) as utilized to measure behavior specific cumulative victimization, with psychological, physical, and sexual abuse subscales (Breiding, et al., 2008). The questions in this survey assessed age of first occurrence, number of perpetrators, and frequency of victimization. Additionally, the survey was divided by childhood (violence that occurred by a parent or caretaker under the age of 18) and adult victimization experiences (victimization at any age by an intimate partner or non-intimate partner [stranger, uncle, coworker, etc...]). Each subscale ranges from 0-7 for adult IPV frequency, while childhood victimization subscale ranges from 0-6. Higher scores indicate more frequent occurrences of victimization. The same questions were utilized to measure child and adult violence. Participants answered questions such as, "Did your parents or caretaker ever physically hurt you on purpose 
(including grabbing, slapping, burning, scalding, punching, choking, throwing you around, or harshly spanking you)?" An example of an adulthood victimization question answered by participants was, "Has an intimate partner every physically hurt you on purpose?" Variables that measure the frequency of psychological, physical, and sexual victimization were the proposed indicators to measure both latent victimization constructs (adult IPV [Construct 1] and childhood victimization [Construct 2]).

Psychological distress. The proposed primary measure of psychological distress was the Global Severity Index (GSI) of the Brief Symptoms Inventory (BSI; Derogatis, 1993; Foa, Cashman, Jaycox, \& Perry, 1997; Radloff, 1977). Two proposed secondary measures of psychological distress included the Center for Epidemiologic StudiesDepression Scale (CES-D), and the Posttraumatic Stress Diagnostic Scale (PDS). The $B S I$ is one the most sound instruments to measure psychological symptom status, particularly with more clinical samples; this measure has sound inter-item and test-retest reliability (Cronbach's alpha ranging from .71 to .85 on the various dimensions; and testretest coefficient of .90 for GSI), as well as convergent and discriminant validity (all coefficients $\geq .30$; Derogatis, 1993). An example item of this measure was, "feeling lonely even when you are with people" and "feeling easily annoyed or irritated." The 20item $C E S-D$ is a self-report measure that was used to assess thoughts, feelings, and behaviors of depression over the past 6 months; this measure has sufficient reliability (Radloff, 1977). An example question of this measure was, "I thought my life had been a 
failure." The 49-item $P D S$ was used to operationalize the four indicators ${ }^{30}$ that assess symptoms of Post-Traumatic Stress Disorder (Foa et al., 1997).

Mediators. Four mediators comprised the latent mediator construct, which included self-esteem, coping, social support, and substance use.

Self-esteem. One observed variable was used to measure self-esteem based on the Rosenberg Self-Esteem Scale (Rosenberg, 1989). Ten items were summed for a cumulative score of self-esteem; each item was then scored on an ordinal scale with answers ranging from strongly disagree, disagree, agree, and strongly agree. Higher cumulative scores indicate higher levels of self-esteem, and respondents answered questions such as "On the whole, I am satisfied with myself" to reflect how they view themselves. This measure was a proposed indicator for the latent mediator construct.

Coping. Carver, Scheier, and Weintraub's (1989) Brief COPE Inventory was utilized to operationalized this measure. Eight original items were removed from the scale and four subscales were created to measure coping ${ }^{31}$. The subscales represented

\footnotetext{
30 The first indicator assesses whether or not any events of IPV were considered traumatic according to DSM diagnostic criterion; the second measures the severity of re-experiencing, avoidance and numbing, and arousal symptoms; the third indicator measures the number of impacted domains effected by symptoms; and the fourth indicators measures a cut-off score for whether or not the woman met the formal diagnostic criteria for PTSD in the past 6 months.

31 Items were removed through exploratory factor analysis (items 27, 22, 20, 19, 1, 21, 9, and 12; removed independently in this order) to force four components, based upon Eigen values and scree plot analysis. Four component subscales were then created through Principal Component Analysis. Items 23, 10, 15, 5, 7,25,17,24,2, and 14 comprised Subscale 1 (Generally Positive Coping), alpha reliability .881; items 6, 13,3,8,26, and 16 comprised Subscale 2 (Generally Negative Coping), alpha reliability .791; items 4 and 11
} 
generally positive coping, with measures such as "I have been getting help and advice from other people"; generally negative coping, with measures such as "I have been giving up trying to deal with it"; coping by utilizing substances, with measures such as "I have been using alcohol or other drugs to make myself feel better"; and coping through minimization, with measures such as "I have been making fun of the situation". Participants rated responses on a four-point Likert scale where "1" represented "I haven't been doing this at all", "2" represented "I've been doing this a little bit", "3" represented "I've been doing this a medium amount", and "4" represented "I've been doing this a lot." Only the generally negative coping subscale was proposed as additional indicator of the latent mediator construct.

Social support. The 19-item questionnaire adapted from the MOS Social Support Survey was used to measure social support (Sherbourne \& Stewart, 1991). The measures assessed the types of supports available if needed including supports like "someone to help you if you were confined to a bed" and "someone to get together with for relaxation" on a scale of 0 (none of the time) to 4 (all of the time). This scale was chosen due to its high level of reliability $(=>.91)$. This measure resulted in a mean score of social support, proposed as an indicator of the latent mediator construct.

Substance use. The Risk Behavior Assessment (RBA) was used to measure alcohol and drug use/dependence. This measure has been tested for sound reliability and validity; with test-retest coefficients ranging from .69 to .79 and internal consistency Cronbach's alpha of .87 to .90 (Dowlinger-Guyer et al., 1994; Needle et al., 1995). This measure

comprised Subscale 3 (Coping by Utilizing Substances), alpha reliability .943; and items 18 and 28 comprised Subscale 4 (Coping through Minimization), alpha reliability .781. 
comprehensively assessed for the number of drugs of use, including drug type and severity, as well as lifetime prevalence (age of first use, years of regular use ${ }^{32}$ ) to assist in understanding drug use patterns in victimized populations. For purposes of this study, the mean age of first use for alcohol to intoxication, marijuana, and cigarettes operationalized substance use. This was a proposed indicator for the latent mediator construct.

\section{Analysis Strategy}

The primary aim of the present study was to explore the relationship between cumulative victimization (childhood and adult IPV), the hypothesized mediators (selfesteem, social support, coping, and substance use), and psychological distress among a sample of 406 victimized women on probation/parole (See Figure 1). The proposed analysis method for this study utilized structural equation modeling (SEM) ${ }^{33}$. SEM follows an iterative process whereby a measurement model is first estimated for sufficiency. SEM provides a robust method of analysis that accounts for measurement error, missing data, and the investigation of both measurement and structural models. The goal of SEM is to test a model built upon theory, "not find a model that fits the data best" (Adelson, 2012). SEM utilizes latent variables (unobservable constructs) through related indicators of the same construct; this allows unaccounted for variance to be attributed to measurement error rather than the construct itself (Adelson, 2012). SEM provides a thorough understanding of relationship patterns, particularly in mediation models, which test the direct, indirect, and total effects of the variables. Further, prior SEM research

32 Regular use was defined as utilizing the substance an average of three times a week. 33 This method of analysis was chosen for its ability to examine the proportion of variance by both direct and indirect effects. If this statistical measure and the data fail to fit, regression will be utilized in order to examine the total proportion of variance. 
states that this methodology is best suited for studies that utilize mediation models as it can explain a mathematical relationship (through covariances) among the independent, dependent, and potentially mediating variables (Baron and Kenny, 1986; Kline, 2011). The following order of steps was utilized to examine the data:

1) Model identification: Identification of model, to check that there is mathematically unique solution that can be estimated for the model (Kline, 2011, p.93). The model is required to be just-identified or over identified, with a minimum degrees of freedom being zero (Kline, 2011). The following formula is used to compute identification/power analysis: $\mathrm{V}(\mathrm{V}+1) / 2$, where $\mathrm{V}$ represents the number of indicators and the computation must equal zero (justidentified) or greater than zero (over-identified). The hypothesized power analysis for this proposed SEM model is provided in the table below (Table 4). This model is over-identified.

Table 4. Power Analysis.

\begin{tabular}{llll}
\hline & $\begin{array}{l}\text { Number of } \\
\text { Knowns }\end{array}$ & $\begin{array}{l}\text { Number of } \\
\text { Unknowns }\end{array}$ & $\begin{array}{l}\text { Degrees of } \\
\text { Freedom }\end{array}$ \\
\hline Formula & $\mathrm{V}(\mathrm{V}+1) / 2$ & Error Variance- 11 & $\begin{array}{l}\text { Number of } \\
\text { Knowns- }\end{array}$ \\
& & Factor Variance-3 & Number of \\
& & Paths-16 & Unknowns \\
& & Correlations- 1 & \\
& & $11+3+16+1=31$ & $66-31=35$ \\
\hline
\end{tabular}


2) Operationalize data: Identify latent variable constructs by operationalizing the data with indicators (observed variables in SEM), which define these constructs (See Table 5).

Table 5. Operationalization of the Data.

\begin{tabular}{lll}
\hline Latent Construct & Variable & Operationalization \\
\hline Childhood Victimization & Psychological & Lifetime Victimization \\
& Physical & Measure Frequency Subscale \\
& Sexual & \\
Adult IPV & Psychological & Lifetime Victimization \\
& Physical & Measure Frequency Subscale \\
Sexual & \\
& & \\
& Self-Esteem & Rosenburg's Self-Esteem \\
Mediators & Social Support & Scale \\
& Coping & BOS Social Support Survey \\
& & Negative Coping Subscale \\
& Substance Use & AgeFirstUse \\
& General Psychological & GSI \\
Psychological Distress & Distress & CES-D \\
& Depression & PDS \\
\hline & Post-Traumatic Stress & \\
& &
\end{tabular}

3) Descriptive statistics: The mean, standard deviation, skewness, kurtosis, and variance, missing data, and outliers of the indicators utilized will be examined $\left(\right.$ See Table $6^{34}$ ). Specifically, issues with skewness and kurtosis (any value greater than or equal to three), as well as categorical proportions are necessary to explore to verify the data are appropriate for the model (if proportions are too skewed, the conceptualization of the construct will be dropped or

${ }^{34}$ Kurtosis is expected to be higher for victimization variables, as the data are from a victimization population. Multiple operationalizations of variables are presented, however some may be dropped from the final model. 
operationalized differently according to what theory and prior empirical research states is an appropriate concept of the variable. 
Table 6. Descriptive Statistics.

\begin{tabular}{|c|c|c|c|c|c|c|c|}
\hline Variable & Mean & Median & Mode & $\begin{array}{l}\text { Standard } \\
\text { Deviation }\end{array}$ & Skewness & Kurtosis & Range \\
\hline \multicolumn{8}{|l|}{ Adult IPV } \\
\hline Psychological & 3.83 & 4.00 & .00 & 1.67 & -.54 & -.41 & $0-7$ \\
\hline Physical & 2.53 & 2.33 & 1.00 & 1.57 & .38 & -.35 & $0-7$ \\
\hline Sexual & 1.33 & 1.00 & .00 & 1.76 & 1.37 & 1.39 & $0-7$ \\
\hline \multicolumn{8}{|l|}{ Child Vic. } \\
\hline Psychological & 1.39 & .86 & .00 & 1.47 & .96 & .01 & $0-6$ \\
\hline Physical & 1.18 & .75 & .00 & 1.43 & 1.31 & .97 & $0-6$ \\
\hline Sexual & .80 & .00 & .00 & 1.35 & 1.79 & 2.49 & $0-6$ \\
\hline Self-Esteem & 12.61 & 13.00 & 15.00 & 5.47 & .02 & -.04 & $0-28$ \\
\hline Social Support & 2.60 & 2.74 & 4.00 & .99 & -.46 & -.64 & $0-4$ \\
\hline $\begin{array}{l}\text { Age First Used } \\
\text { Any Drug }\end{array}$ & 19.9 & 19.00 & 15.00 & 5.19 & .90 & 2.1 & $0-44$ \\
\hline $\begin{array}{l}\text { Negative } \\
\text { Coping }\end{array}$ & 2.20 & 2.00 & 2.00 & .79 & .38 & -.72 & $0-4$ \\
\hline GSI & 1.19 & 1.01 & .00 & .86 & .63 & -.42 & $0-3.75$ \\
\hline PTSD & .41 & .00 & .00 & .49 & .39 & -1.86 & $0-1$ \\
\hline CESD & 44.44 & 44.00 & 44.00 & 13.94 & .06 & -.57 & $3-77$ \\
\hline
\end{tabular}

4) Bivariate correlations: This step in the process investigates the innercorrelations among all indicators checking for reliability. This will be done within each measurement separate scale, then also as a collapsed latent construct. It is expected to see higher correlations for indicators of the same construct, rather than for other constructs.

5) Confirmatory factor analysis (CFA)/ measurement model: This step of the analysis examines indicator loadings, correlations between the constructs, and fit indices for adequate mathematical sufficiency of data. Fit indices to be 
examine include Chi-square, the root mean square error of approximation (RMSEA), the Tucker-Lewis index (TLI), the comparative fit index (CFI), and the standardized root-mean-square (SRMR). A desired Chi square is nonsignificant; RMSEA desired cut-off is .08 or lower (prefer .05 or lower), with high confidence intervals lower than .80 and a non-significant p-close value; for both TLI and CFI acceptable cut-off scores are .90 or above; SRMR desired cut-off is .80 or higher. If issues with measurement arise, the operationalization of the latent construct victimization will be reviewed for model building, looking at categorical proportions, direct effects of both child and adult victimization on psychological distress, and the cumulative correlated effect to appropriately tease out victimization effect on psychological distress.

6) Structural model: This step of the process will explore the structural paths between the constructs, looking for significance and fit indices. Significance is desired of the paths ( $\mathrm{p}<=.05$ ), and fit indices will be evaluated for this step as stated above. 


\section{CHAPTER 4: RESULTS}

\section{Introduction}

The primary aim of this study was to investigate the relationship between cumulative victimization (childhood and adult IPV), the hypothesized mediators (selfesteem, social support, coping, and substance use), and psychological distress among 406 victimized women on probation/parole. As such, structural equation modeling was proposed to examine this relationship due to its adaptable and comprehensive approach to modeling both direct and indirect relationships among variables while accounting for measurement error (Kline, 2011). This chapter will present descriptive findings of the measures utilized in the study. Following this, the results of the structural equation model are presented.

\section{Descriptive Findings}

Demographics. The Women's Health Research Study consisted of 406 women ranging in age from 19 to 69 years old, with the mean age of 37 at the time of their interview. More than half of the sample was White (51\%), while 42\% were African American/Black. Less than one-fifth (17\%) of the participants were married, living with a partner, or living as married (common law); forty-four percent were single; and $38 \%$ were separated, widowed, or divorced. Over one-third (36\%) of the women reported having a high school diploma/GED equivalent and 30\% reported having some college 
education or a college degree. Twenty percent of the women reported being disabled, while $40 \%$ were unemployed and $29 \%$ were working part or full time. Further, $34 \%$ of the participants reported being homeless at the time of data collection. Additional descriptive data are reported in Table 7 (raw numbers, means, percentages, standard deviations, and range). 
Table 7. Demographic Characteristics.

\begin{tabular}{|c|c|c|c|}
\hline Demographics & $\begin{array}{l}\text { NumbersMeans/ } \\
\text { Percentages }\end{array}$ & $\begin{array}{c}\text { Standard } \\
\text { Deviations }\end{array}$ & Range \\
\hline Age & 37.20 & 10.24 & $19-69$ \\
\hline \multicolumn{4}{|l|}{ Partner Status } \\
\hline Single/Never Married & $44.0 \%$ & & \\
\hline Married/Living with & $16.5 \%$ & & \\
\hline Someone/Common Law & & & \\
\hline $\begin{array}{l}\text { Separated/Widowed/ } \\
\text { Divorced }\end{array}$ & $38.2 \%$ & & \\
\hline \multicolumn{4}{|l|}{ Education } \\
\hline $\begin{array}{l}\text { Less than High School } \\
\text { Diploma }\end{array}$ & $27.1 \%$ & & \\
\hline $\begin{array}{l}\text { High School Diploma/ } \\
\text { GED }\end{array}$ & $36.0 \%$ & & \\
\hline $\begin{array}{l}\text { Trade/Technical } \\
\text { School }\end{array}$ & $3.4 \%$ & & \\
\hline $\begin{array}{l}\text { Some College/College } \\
\text { Degree }\end{array}$ & $30.0 \%$ & & \\
\hline $\begin{array}{l}\text { Some Graduate School/ } \\
\text { Graduate School }\end{array}$ & $3.2 \%$ & & \\
\hline \multicolumn{4}{|l|}{ Race } \\
\hline African American/Black & $41.6 \%$ & & \\
\hline White & $50.5 \%$ & & \\
\hline Hispanic & $0.7 \%$ & & \\
\hline Asian & $0.2 \%$ & & \\
\hline Native American & $1.5 \%$ & & \\
\hline Multi-Racial & $3.2 \%$ & & \\
\hline Other & $2.0 \%$ & & \\
\hline \multicolumn{4}{|l|}{ Work Status } \\
\hline Unemployed & $39.7 \%$ & & \\
\hline Working Part/Full Time & $28.8 \%$ & & \\
\hline Disabled & $20.0 \%$ & & \\
\hline In School & $3.7 \%$ & & \\
\hline Other & $6.4 \%$ & & \\
\hline Homeless & $34.0 \%$ & & \\
\hline
\end{tabular}




\section{Victimization.}

Child victimization. Victimization statistics were reported including yes/no (ever) experiences of victimization, number of perpetrators, and the frequency of the violence for psychological, physical, and sexual child victimization. Seventy-five percent of women reported experiencing at least one form of psychological victimization with an average of more than eight different perpetrators (parents and/or caretakers) for this type of abuse. The mean frequency (3.60) of these experiences occurred between one to two times a week and one to two times a month. Of the types of psychological violence reported, $62 \%$ of respondents rated "insult, shame, and humiliation in front of others by a parent or caretaker" as the most common form of psychological violence.

Sixty-four percent $(63.8 \%)$ of the sample reported experiencing at least one form of physical violence, with a mean frequency (3.18) around one to two times a month. The most commonly experienced form of physical violence in childhood $(62.1 \%)$ was "a parent or caretaker who physically hurt you on purpose (including, grabbing, slapping, burning, scalding, punching, choking, throwing you around, or harshly spanking you." Women reported an average of four different perpetrators of child physical violence.

Approximately $38 \%$ of women reported experiencing one or more types of sexual victimization, with an average frequency $(0.79)$ a little less than a few times per year and an average of three individuals who were sexually violent towards them. From the types of sexual violence reported, over one-third (33\%) of participants rated "parents or caretakers who forced or threatened you to do sexual things other than sexual intercourse (for example forced petting or forced oral sex)" as the most commonly experienced form of sexual victimization. 
Of the three types of childhood victimization (psychological, physical, and sexual), $44 \%$ of women reported only having experienced psychological child victimization, $32 \%$ reported only experiencing physical violence as a child, and less than five percent reported only experiencing child sexual victimization.

Adult victimization. As with childhood victimization, statistics were similarly reported for IPV. In terms of psychological IPV, more than 95\% reported experiencing this type of violence at least once in their lifetime. Psychological IPV was reported to occur almost one to two times a week (3.83), and was perpetrated on average by 12 individual partners. Four-fifths (85.2\%) of the women reported the most common experience of psychological IPV was: "has an intimate partner ever treated you like you were stupid or inferior and or called you names in private."

Ninety percent of women reported physical IPV at least once in their lifetime, with an average of six partners who perpetrated this type of violence. Physical IPV was reported to occur on average more than a few times a year but less than one to two times a month (2.53). As with child physical violence, the most common reported form of physical violence (84\%) was "intimate partners who have physically hurt you on purpose (including grabbing, slapping, burning, scalding, punching, choking, or throwing you around)."

Lastly, sexual IPV was experienced at least once by over half of the sample (53.2\%). On average, two partners perpetrated sexual victimization, and women reported experiencing this between a few times in their life, to one to two times a year (1.32). Of the types of sexual violence reported, $42 \%$ of women experienced "partners who forced 
or threatened sexual intercourse and it actually happened" as the most common sexually violent experience.

Of the three types of IPV (psychological, physical, and sexual), 43\% reported only experiencing psychological IPV, $38 \%$ only experienced physical IPV, and less than one percent $(0.7 \%)$ reported only being subjected to sexual IPV.

Cumulative victimization. Psychological victimization was examined among the subsample that experienced this type of childhood violence and adult IPV. Of those, three percent (3.2\%) only experienced psychological violence in childhood with no psychological adult IPV, while $23 \%$ experienced psychological IPV but did not experience this type of child victimization. However almost three-fourths (71.9\%) of women reported experiencing childhood and adult IPV psychological violence. In terms of physical victimization, almost six percent (5.7\%) of women reported childhood physical violence only with no physical IPV, while $32 \%$ experienced only physical IPV with no childhood experiences of physical violence. More than half (58.1\%) of the sample experienced child and adult IPV physical victimization. Lastly, $13 \%$ of those who reported sexual victimization only experienced it in childhood with no adult sexual IPV; over one-fourth $(27.1 \%)$ reported only adult sexual IPV with no child sexual victimization experiences. Twenty-six percent reported cumulative accounts of sexual victimization. Descriptive victimization statistics for child victimization and adult IPV are located in Table 8. 
Table 8. Victimization Demographics, reported in percentages, raw numbers, and means with standard deviations and range.

\begin{tabular}{|c|c|c|c|}
\hline Victimization: & $\begin{array}{l}\text { Numbers/Means/ } \\
\text { Percentages: }\end{array}$ & $\begin{array}{c}\text { Standard } \\
\text { Deviation }\end{array}$ & Range \\
\hline \multicolumn{4}{|c|}{ Childhood Victimization $^{35}$} \\
\hline Psychological & $75.4 \%$ & & \\
\hline Physical & $63.8 \%$ & & \\
\hline Sexual & $38.7 \%$ & & \\
\hline \multicolumn{4}{|l|}{ Number of } \\
\hline \multicolumn{4}{|c|}{$\begin{array}{l}\text { Parents/Caretakers who } \\
\text { were Violent }\end{array}$} \\
\hline Psychological & 8.24 & 8.85 & $0-66$ \\
\hline Physical & 3.78 & 3.67 & $1-28$ \\
\hline Sexual & 3 & 3 & $1-21$ \\
\hline \multicolumn{4}{|l|}{ Lifetime Adulthood } \\
\hline \multicolumn{4}{|l|}{ Victimization $^{35}$} \\
\hline Psychological & $95.3 \%$ & & \\
\hline Physical & $90.4 \%$ & & \\
\hline Sexual & $53.2 \%$ & & \\
\hline \multicolumn{4}{|c|}{ Number of Partners who } \\
\hline \multicolumn{4}{|c|}{ Perpetrated Victimization } \\
\hline Psychological & 12.2 & 13.20 & $0-151$ \\
\hline Physical & 6.11 & 2.61 & $0-56$ \\
\hline Sexual & 2.05 & 3.30 & $0-23$ \\
\hline
\end{tabular}

35 Dichotomous Yes Variable for Experience. 


\section{Psychological distress.}

$\boldsymbol{C E S}-\boldsymbol{D}$. This scale measures depression symptomology, with scores of 16 or greater representing diagnostic criteria for depression. The mean score reported among the sample was over 24, indicating the sample as a whole met diagnostic criteria for depression.

BSI. Nine indicators of psychological symptom dimensions (somatization, obsessive-compulsive, interpersonal sensitivity, depression, anxiety, hostility, phobic anxiety, paranoid ideation, and psychoticism) as well as a global severity index (GSI) were examined within the sample. The highest score was the obsessive-compulsive dimension (1.44) and the lowest score was the phobic anxiety dimension (.91).

PTSD. Based upon the PDS, 40\% of the sample met criteria for the DSM-IV-TR diagnosis of Post-Traumatic Stress Disorder. Additionally, when specifically asked regarding the different types of traumatic events, $40 \%$ of women reported the most traumatic event was experiencing sexual assault by a family member or someone they knew (for example, rape or attempted rape). Descriptive psychological distress statistics are presented in Table 9. 
Table 9. Psychological Distress Demographics reported in percentages, raw numbers, and means with standard deviations and range.

\begin{tabular}{lccc}
\hline \multicolumn{1}{c}{ Variable } & $\begin{array}{c}\text { Numbers/Percentages } \\
\text { /Mean }\end{array}$ & Standard Deviation & Range \\
\hline CES-D & & & \\
$\quad$ (Dichotomous Cut- & $71.7 \%$ & & \\
Off Yes/No Score & & & \\
for Depression & & 12.61 & $0-57$ \\
Criteria) & 24.57 & & \\
Mean Score & & .89 & $0-4$ \\
BSI & 1.04 & 1.04 & $0-4$ \\
Somatization & 1.44 & 1.10 & $0-4$ \\
Obsessive Compulsive & 1.32 & 1.05 & $0-4$ \\
Interpersonal Sensitivity & 1.26 & .99 & $0-4$ \\
Depression & 1.19 & .87 & $0-4$ \\
Anxiety & .95 & 1.00 & $0-4$ \\
Hostility & .91 & .96 & $0-4$ \\
Phobic Anxiety & 1.32 & .96 & $0-3.75$ \\
Paranoid Ideation & 1.18 & .86 & \\
Psychoticism & 1.18 & & \\
GSI & & & \\
PDS & $39.9 \%$ & & \\
(Dichotomous Yes & & & \\
Variable Indicating & & & \\
Criteria Met for DSM- & & & \\
IV-TR PTSD) & & & \\
& & & \\
\hline
\end{tabular}

\section{Mediators.}

Self-esteem. Seventy-one percent of the respondents raw score was 15 or below (indicating "low” self-esteem), with an average raw score of 12.6 (Rosenberg, 1965).

Substance use. Ninety-three percent of the women reported using at least one of the following drugs in their lifetime: alcohol to intoxication, marijuana, cocaine, crack, heroin, opiates, non-prescription methamphetamines, inhalants, hallucinogens (sedatives, tranquilizers, barbiturates), crank (meth), amphetamines, and club drugs. Additionally, $59 \%$ reported using at least one of the previous drugs within the last two years. Women 
reported an average age of first use at approximately 20 years old and regular use of drugs around eight years.

Respondents reported age of first use for alcohol to intoxication around 15 years old, with regular use for almost 11 years. Women reported the same age of first use for marijuana (14.61 years old), with regular use of this substance also around 11 years. Lastly, women were slightly younger on average at the age they reported first smoking cigarettes (13.61 years old), while reporting an average use of almost 19 years (18.88 years). Descriptive substance use statistics are presented in Table 10.

Coping. Four coping subscales were examined: generally positive coping, generally negative coping, coping by utilizing substances, and coping through minimization. Women reported using positive coping between "doing this a little bit to doing this a medium amount" (mean=2.76). Generally negative coping was utilized "a little bit" (mean=2.2), with substance use (mean=1.54) and minimization coping (mean=1.97) reported between "not doing it at all, and doing it a little bit." Descriptive coping statistics are presented in Table 11.

Social support. Women reported all types of support between "occasionally and some of the time," with the most prevalent form of social support being "someone to love and make you feel wanted." The least prevalent form of social support reported was "someone to help you do daily chores if you get sick." Descriptive social support statistics are presented in Table 12. 
Table 10. Substance Use Demographics reported in percentages, raw numbers, and means with standard deviations and range.

\begin{tabular}{|c|c|c|c|}
\hline Variable & $\begin{array}{c}\text { Numbers/Means/ } \\
\text { Percentages }\end{array}$ & Standard Deviation & Range \\
\hline $\begin{array}{l}\text { Lifetime Drug Use } \\
\text { (Dichotomous Yes Variable } \\
\text { for Experience) }\end{array}$ & $93.1 \%$ & & \\
\hline $\begin{array}{l}\text { Past Two Year Drug Use } \\
\text { (Dichotomous Yes Variable } \\
\text { for Experience) }\end{array}$ & $59.1 \%$ & & \\
\hline Age of First Use & 19.9 & 5.19 & $9-44$ \\
\hline Regular Use in Years & 8.16 & 6.70 & $0-42.17$ \\
\hline \multicolumn{4}{|l|}{ Age of First Use } \\
\hline Alcohol to Intoxication & 15.34 & 5.36 & $9-44$ \\
\hline Marijuana & 14.61 & 4.47 & $9-45$ \\
\hline Cigarettes & 13.61 & 5.37 & $9-41$ \\
\hline \multicolumn{4}{|l|}{ Regular Use in Years } \\
\hline Alcohol to Intoxication & 10.93 & 10.98 & $0-47$ \\
\hline Marijuana & 11.48 & 10.52 & $0-47$ \\
\hline Cigarettes & 18.88 & 11.93 & $0-60$ \\
\hline
\end{tabular}


Table 11. Coping Demographics reported in means with standard deviations and range.

\begin{tabular}{cccc}
\hline Variable & Mean & Standard Deviation & Range \\
\hline $\begin{array}{c}\text { Generally Positive } \\
\text { Coping }\end{array}$ & 2.76 & 0.75 & $1-4$ \\
$\begin{array}{c}\text { Generally Negative } \\
\text { Coping }\end{array}$ & 2.20 & 0.79 & $1-4$ \\
$\quad \begin{array}{c}\text { Coping with } \\
\text { Substance Use }\end{array}$ & 1.55 & 0.97 & $1-4$ \\
$\begin{array}{c}\text { Coping through } \\
\text { Minimization }\end{array}$ & 1.97 & 0.97 & $1-4$ \\
\hline
\end{tabular}

Table 12. Social Support Demographics reported in means with standard deviations and range.

\begin{tabular}{cccc}
\hline Variable & Mean & Standard Deviation & Range \\
\hline $\begin{array}{c}\text { Someone to help with } \\
\text { daily chores if you get } \\
\text { sick }\end{array}$ & 2.42 & 1.32 & $0-4$ \\
$\begin{array}{c}\text { Someone to turn to for } \\
\text { suggestions about } \\
\text { how to deal with a } \\
\text { personal problem }\end{array}$ & 2.51 & 1.27 & $0-4$ \\
$\quad \begin{array}{l}\text { Someone to do } \\
\text { something enjoyable } \\
\text { with }\end{array}$ & 2.65 & 1.22 & $0-4$ \\
$\begin{array}{c}\text { Someone to love and } \\
\text { make you feel wanted }\end{array}$ & 2.69 & & \\
\hline
\end{tabular}

\section{Structural Equation Modeling.}

Step 1: model identification. As stated in Chapter 3, the original conceptual model was over-identified, with 35 degrees of freedom. This number is equivalent to the number of values/parameters that are free to vary within the model (Kline, 2011). As 
such, this model may be theoretically possible to calculate a number of unique estimates for each of the free parameters if just or over-identified (Adelson, 2012; Kline, 2011). This over-identified model met the first step of identification with a positive degrees of freedom value. Second, the model met sample size requirements for identification. Sample size minimums are determined through a ratio of cases $(\mathrm{N})$ to the number of parameters to be estimated, based on a ten to one formula. In this study, the formula equates to ten multiplied by 35 (number of free parameters to estimate), thus a sample size of 350 participants would be the suggested minimum. This study includes 406 participants meeting criteria for sample size (Kline, 2011).

Step 2: Operationalize the data. Six variables were utilized to measure the independent variables (child victimization and adult IPV) in the model. Three indicator variables operationalized the latent child victimization construct including the frequency measure of psychological, physical, and sexual violence. Three indicator variables were utilized to measure the latent construct adult IPV, those included the frequency measure of psychological, physical, and sexual IPV.

In terms of the mediators, four indicators of the latent mediator construct included: the mean score variable for self-esteem; the mean score variable for the negative coping subscale; the age of first use mean variable for alcohol to intoxication, marijuana, and cigarettes as the measure of substance use ${ }^{36}$; and social support was measured by a mean score of four variables from scale (based upon previous

${ }^{36}$ Additional variables utilized to measure substance use included: the mean score for age of first use for all substance in the RBA; the mean score for regular use in years for all substances in the RBA; the mean score for regular use in years for alcohol to intoxication, marijuana, and cigarettes; and the mean score of regular use in years for opiate use. However, regardless of operationalization, none of the substance use variables were retained in any of the models. 
confirmatory factor analysis with these data; Higgins, Marcum, Golder, Hall, \& Logan, 2015).

In terms of the dependent variable, psychological distress was operationalized as an observed construct ${ }^{37}$ in each of the investigated SEM models. The primary SEM model utilized the GSI measure of the BSI scale to operationalize psychological distress. The second SEM model utilized a mean score variable of the CES-D scale; the final SEM model utilized the PDS scale cut-off variable.

Step 3: Descriptive statistics. The variables utilized in the study were normally distributed and withheld to skewness $(<3)$ and kirtosis $(<10)$ cut-offs (See Table 6 ). Because the variables were normally distributed, the model was tested using Maximum Likelihood (ML) estimation in the IBM ${ }^{\circledR}$ SPSS $®$ AMOS statistical software package. ML estimation was chosen for its iterative process that determines the ability of different parameters to find values with the maximum likelihood, given the data (Adelson, 2012; Barron \& Kenny, 1986; Hayes, 2009; Tabachnick \& Fidell, 2007). This method was also chosen for its ability to handle missing data, as it allows for uncertainty within the data by estimating means and intercepts, resulting in unbiased parameters with standard errors (Peters \& Enders, 2002). All variables in the model had less than eight percent missing data (See Table 13).

Step 4: Bivariate correlations. Data were screened for bivariate correlations (See Table 14 for correlation matrix). Results of the correlation matrix revealed that some data

37 The psychological distress construct was operationalized as three separate observed constructs rather than one latent construct due to issues of multicollinearity among the three utilized measures of psychological distress. 
were not sufficiently correlated (correlations loading less than .300 and/or nonsignificant). Based on the robust nature of SEM, and the theory building nature of this research, variables were left in the original conceptual model. Reliability testing indicated that all scales represented in the model had sound test-retest and inter-item content validity (See Table 15).

Table 13. Missing Data.

Variable Number of Missing Cases Missing Percentage

Adult IPV

Psychological

8

$2 \%$

Physical

8

$2 \%$

Sexual

10

$2 \%$

Child Victimization

Psychological

0

Physical

1

$0 \%$

Sexual

2

$0 \%$

Self-Esteem

0

Social Support

2

$0 \%$

Negative Coping

4

$1 \%$

Substance Use

28

$7 \%$

GSI

13

$3 \%$

CES-D

2

$0 \%$

PTSD

3

$1 \%$ 
Table 14. Correlation Matrix ${ }^{38}$.

\begin{tabular}{|c|c|c|c|c|c|c|c|c|c|c|c|c|c|}
\hline Variable & CESDS & $\begin{array}{l}\text { Sub } \\
\text { Use }\end{array}$ & $\begin{array}{l}\text { Psych } \\
\text { IPV }\end{array}$ & $\begin{array}{l}\text { Physical } \\
\text { IPV }\end{array}$ & $\begin{array}{l}\text { Sexual } \\
\text { IPV }\end{array}$ & $\begin{array}{l}\text { Child } \\
\text { Psych }\end{array}$ & $\begin{array}{c}\text { Child } \\
\text { Physical }\end{array}$ & $\begin{array}{l}\text { Child } \\
\text { Sexual }\end{array}$ & $\begin{array}{l}\text { Neg. } \\
\text { Cope }\end{array}$ & $\begin{array}{c}\text { Self- } \\
\text { Esteem }\end{array}$ & GSI & PTSD & $\begin{array}{c}\text { Social } \\
\text { Support }\end{array}$ \\
\hline CESDS & 1 & & & & & & & & & & & & \\
\hline Sub Use & -.060 & 1 & & & & & & & & & & & \\
\hline Psych IPV & .248 & -.039 & 1 & & & & & & & & & & \\
\hline $\begin{array}{l}\text { Physical } \\
\text { IPV }\end{array}$ & .213 & -.051 & .596 & 1 & & & & & & & & & \\
\hline $\begin{array}{l}\text { Sexual } \\
\text { IPV }\end{array}$ & .229 & -.077 & .464 & .484 & 1 & & & & & & & & \\
\hline $\begin{array}{l}\text { Child } \\
\text { Psych }\end{array}$ & .279 & -.126 & .313 & .314 & .329 & 1 & & & & & & & \\
\hline $\begin{array}{l}\text { Child } \\
\text { Physical }\end{array}$ & .266 & -.167 & .247 & .289 & .294 & .791 & 1 & & & & & & \\
\hline $\begin{array}{l}\text { Child } \\
\text { Sexual }\end{array}$ & .180 & -.152 & .219 & .214 & .304 & .536 & .492 & 1 & & & & & \\
\hline Neg. Cope & .554 & -.122 & .198 & .202 & .209 & .140 & .131 & .042 & 1 & & & & \\
\hline $\begin{array}{c}\text { Self- } \\
\text { Esteem }\end{array}$ & .577 & -.041 & .204 & .183 & .128 & .204 & .232 & .080 & .480 & 1 & & & \\
\hline GSI & .843 & -.061 & .268 & .252 & .253 & .301 & .278 & .124 & .550 & .510 & 1 & & \\
\hline PTSD & .420 & .000 & .177 & .248 & .203 & .205 & .168 & .172 & .173 & .244 & .379 & 1 & \\
\hline $\begin{array}{l}\text { Social } \\
\text { Support }\end{array}$ & -.284 & .020 & -.055 & -.037 & -.062 & -.228 & -.176 & -.107 & -.197 & -.292 & -.288 & -.083 & 1 \\
\hline
\end{tabular}

${ }^{38}$ All correlations that were significant $(\mathrm{p} \leq .05)$ are presented in bold. 
Table 15 . Reliability testing of the measures.

\begin{tabular}{cc}
\hline Variable & Reliability (Cronbach's alpha) \\
\hline Psychological IPV & .970 \\
Physical IPV & .853 \\
Sexual IPV & .906 \\
Child Psychological Victimization & .874 \\
Child Physical Victimization & .817 \\
Child Sexual Victimization & .787 \\
Negative Coping & .801 \\
Self-Esteem & .889 \\
Substance Use & .719 \\
Social Support & .893 \\
GSI & .977 \\
\hline
\end{tabular}

Measurement models. Results of the original CFA (See Figure $2^{39}$ ) revealed sufficient model fit: $\chi^{2}=27.83, p=.114$; TLI of .989; CFI of .994; RMSEA $=.031, p=.879$; $\mathrm{SRMR}=.05$. All variable factor loadings were .400 or higher except for social support (.359) and substance use (.178). Due to the low factor loadings, these two indicators were dropped from the original latent mediator construct. As such, the model only retained two mediator variables, which were thus operationalized as two observed, correlated variables. This decision was made due to the recommended requirement of a minimum of ${ }^{39}$ No statistics are presented in the figure due to insufficient factor loadings and the respecification of the model. 
three indicators per latent construct (Kline, 2011). The indicators with the highest loadings for the latent victimization constructs were set to 1.00 as marker variables of the construct. 
Figure 2. Original CFA.

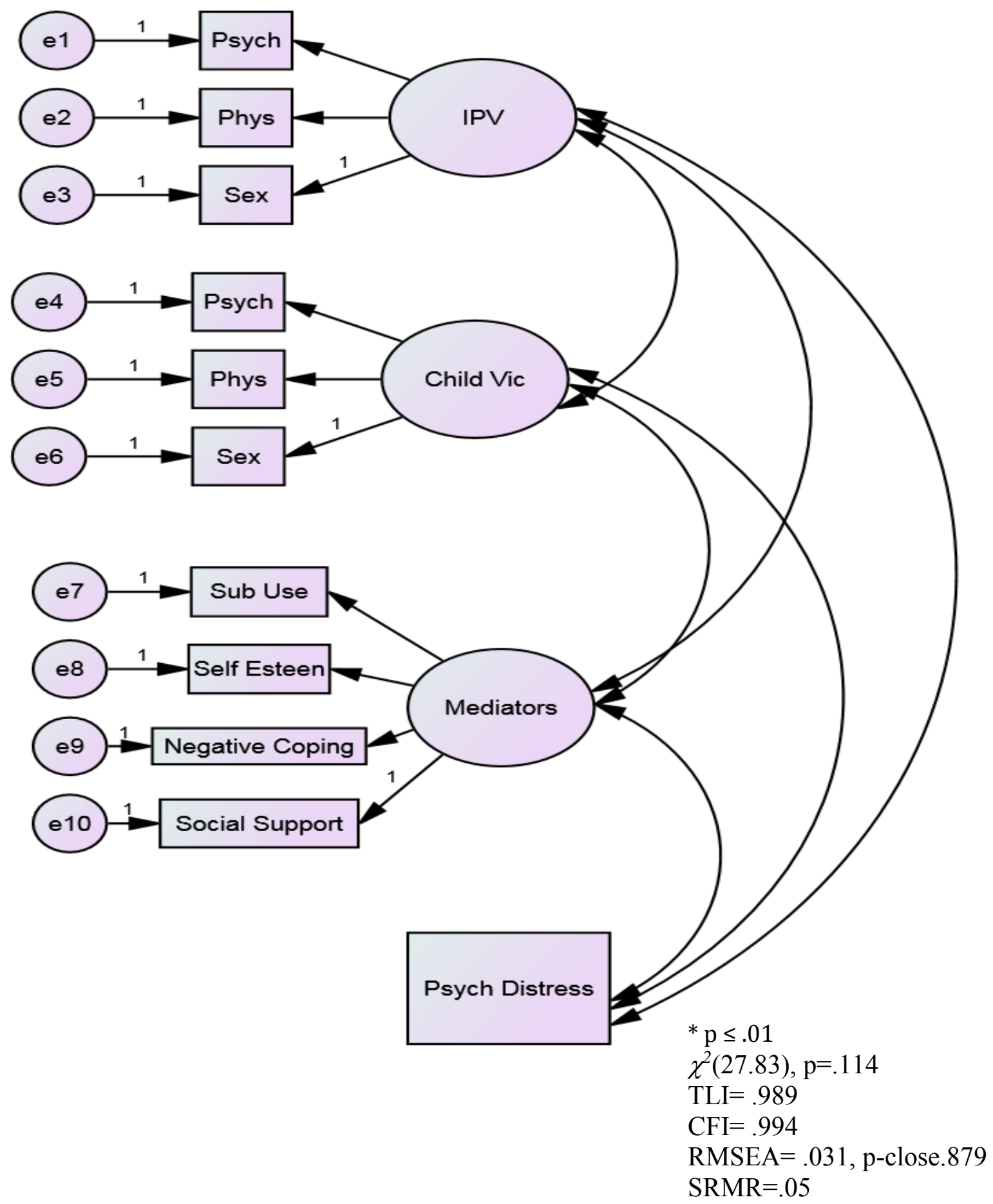


A second CFA (See Figure $3^{40}$ ) was conducted with the respecification of the mediator variables. Results indicated sufficient model fit: $\chi^{2}=28.01, p=.140$; TLI of .991; CFI of $.995 ;$ RMSEA $=.02, \mathrm{p}=.909 ;$ SRMR $=.03$. All factor loadings were above .400 (See Table 16). Correlations among the constructs were sufficient, with the exception of child victimization and negative coping $(r(406)=.148, \mathrm{p}<.01)$ as well as the correlation between self-esteem with both IPV $(r(406)=.20, \mathrm{p}<.01)$ and child victimization $(r(406)=.20$, $\mathrm{p}<.01$ ). All correlations among the constructs were significant (See Table 17).

Table 16. Factor Loadings

\begin{tabular}{cc}
\hline Factor Loading & Estimate \\
\hline $\begin{array}{c}\text { Child Vic } \rightarrow \text { Child } \\
\text { Psych }\end{array}$ & .930 \\
$\begin{array}{l}\text { Child Vic } \rightarrow \text { Child } \\
\text { Physical }\end{array}$ & .850 \\
$\begin{array}{l}\text { Child Vic } \rightarrow \text { Child } \\
\text { Sexual }\end{array}$ & .577 \\
IPV $\rightarrow$ Psych IPV & .752 \\
IPV $\rightarrow$ Physical IPV & .774 \\
IPV $\rightarrow$ Sexual IPV & .636 \\
\hline
\end{tabular}

${ }^{40}$ Results presented are unstandardized. 
Table 17. Correlations of Trimmed CFA.

\begin{tabular}{cc}
\hline Correlation & Estimate \\
\hline Child Vic $\leftrightarrow$ IPV & .462 \\
IPV $\leftrightarrow$ Psych Distress & .352 \\
Child Vic $\leftrightarrow$ Psych & .319 \\
Distress & \\
IPV $\leftrightarrow$ Self-Esteem & .243 \\
IPV $\leftrightarrow$ Neg. Coping & .276 \\
Self-Esteem $\leftrightarrow$ Neg. \\
Coping \\
Child Vic $\leftrightarrow$ Self- \\
Esteem \\
Child Vic $\leftrightarrow$ Neg. \\
Coping
\end{tabular}


Figure 3. Trimmed CFA.

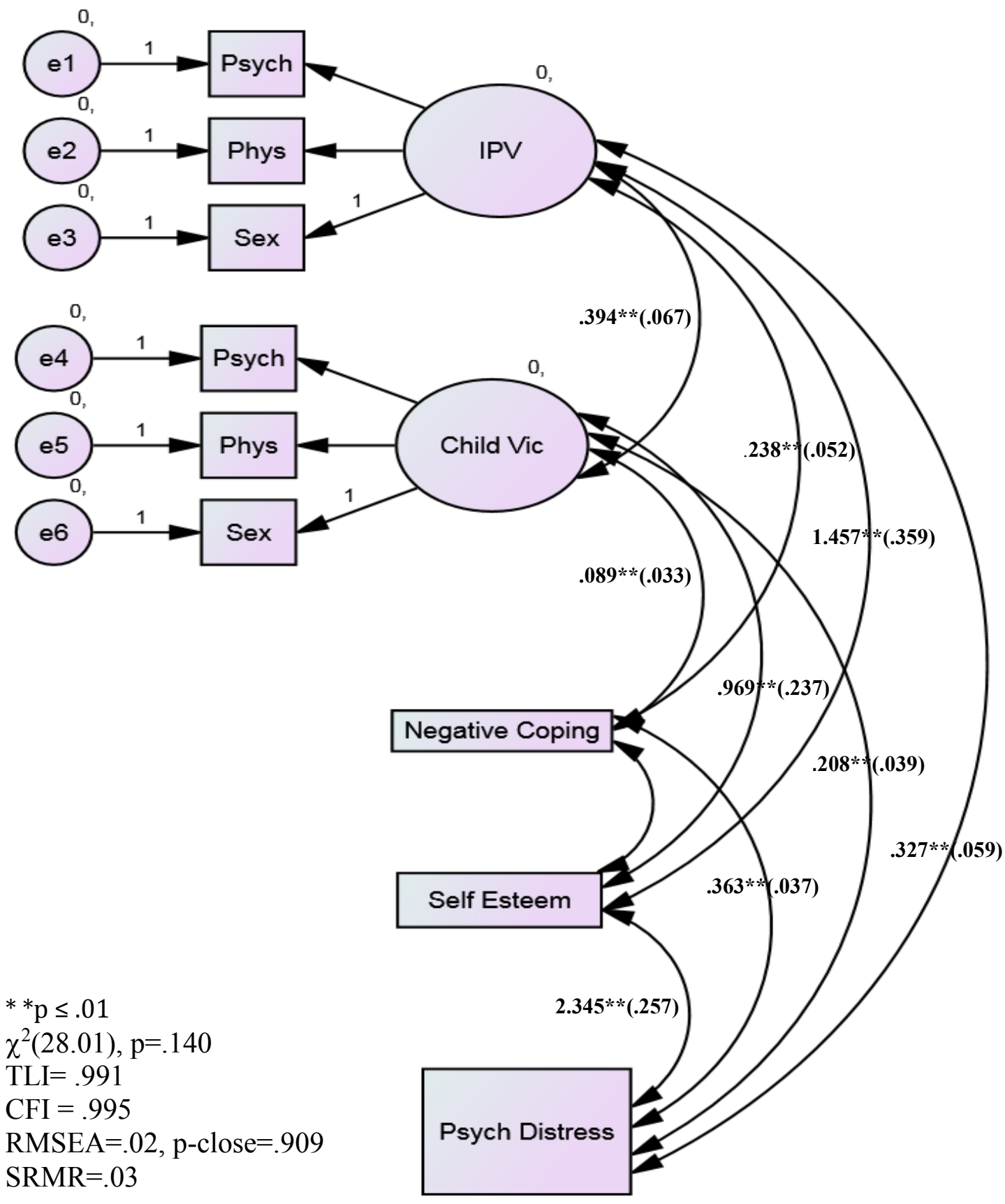


Step 6: Structural model. The first structural model tested the relationship of child victimization and IPV with psychological distress, when mediated by self-esteem and negative coping. The model fit was adequate: $\chi^{2}=27.83, p=.114$; TLI of .989 ; CFI of .994; RMSEA $=.031, \mathrm{p}=.879 ; \mathrm{SRMR}=.03$. All paths and correlations were significant except for childhood victimization to coping $(\mathrm{p}=.67)$. This path was trimmed from the model due to the non-significant relationship and a second structural model (See Figure 4) was evaluated.

Figure 4. Final Trimmed Structural Model.

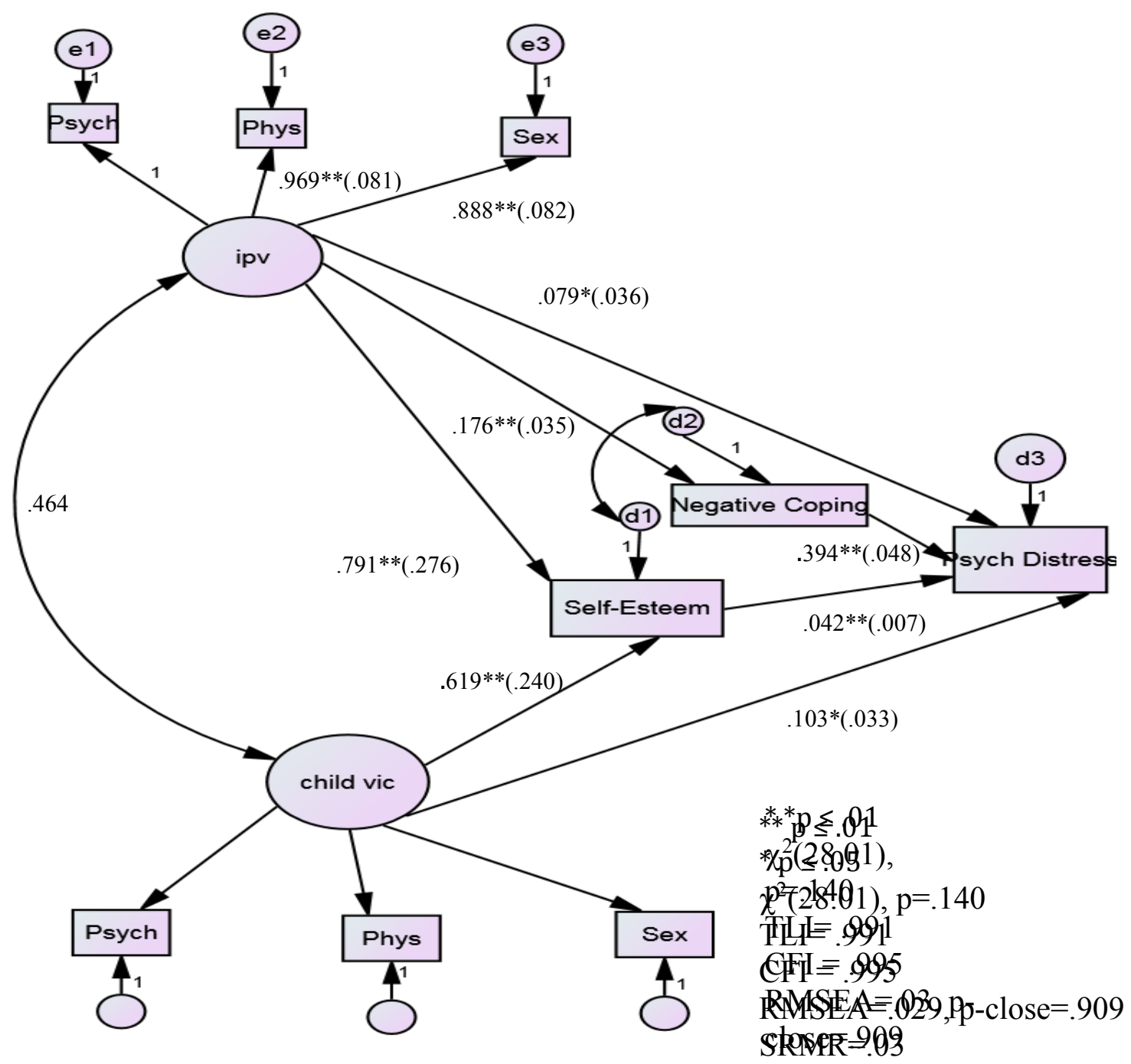


This final trimmed model adequately fit the data: $\chi^{2}=28.01, \mathrm{p}=.140$; TLI of .991 ; CFI of .995; RMSEA $=.029, p=.909 ;$ SRMR $=.03$. Results of this model indicated all paths were significant as well as the correlation $(r=.50)$ between child victimization and adult IPV (See Table $18^{41}$ ). The significant results of this model indicate there is a direct effect of cumulative victimization (child victimization and IPV) on psychological distress. In terms of adult IPV, for every one unit increase in adult IPV, there is a .08 increase in psychological distress, when controlling for child victimization, self-esteem, and negative coping. When considering child victimization, for every one unit increase in child victimization, there is a .10 increase in psychological distress, when controlling for adult IPV and self-esteem (as the path was removed to negative coping from child victimization).

Additionally, there is a strong indirect effect of cumulative victimization on psychological distress, when mediated by self-esteem and negative coping (See Table 19). Results indicated a partial mediation model, with the mediated paths from both child victimization (20\%) and adult IPV (57\%) accounting for seventy-seven percent of the variance in psychological distress when mediated by self-esteem and negative coping ${ }^{42}$. Based upon the chi-square difference test ${ }^{43}$, the original and final models were

${ }^{41}$ Estimates given are unstandardized.

${ }^{42}$ These percentages were found based on the calculation of indirect effects divided by the total effects. Thus, the formula for child victimization was $.026 / .129=.201$, which converted to $20 \%$ of the variance explained. The formula for IPV was $.103 / .182=.565$, which converted to $57 \%$.

${ }^{43} \mathrm{Chi}$-square difference tests are examined to test for the preferred model. If results of the test indicate a non-significant chi-square, the more parsimonious or trimmed model is the preferred model. 
investigated to identify the preferred model (See Table 20). The more parsimonious, final trimmed model was preferred. 
Table 18. Maximum Likelihood Estimates.

\begin{tabular}{|c|c|c|c|}
\hline \multirow[t]{2}{*}{ Parameter } & \multicolumn{3}{|c|}{ Maximum Likelihood Estimates } \\
\hline & Estimate & Standard Error & $p$-value \\
\hline $\begin{array}{l}\text { Adult IPV } \rightarrow \\
\text { Psychological } \\
\text { Distress }\end{array}$ & .079 & .036 & .028 \\
\hline $\begin{array}{c}\text { Child Victimization } \\
\rightarrow \text { Psychological } \\
\text { Distress }\end{array}$ & .103 & .033 & .002 \\
\hline $\begin{array}{l}\text { Adult IPV } \rightarrow \\
\text { Negative Coping }\end{array}$ & .176 & .035 & $<.000$ \\
\hline $\begin{array}{c}\text { Adult IPV } \rightarrow \text { Self- } \\
\text { Esteem }\end{array}$ & .791 & .276 & .004 \\
\hline $\begin{array}{l}\text { Child Victimization } \\
\rightarrow \text { Self-Esteem }\end{array}$ & .619 & .240 & .010 \\
\hline $\begin{array}{c}\text { Negative Coping } \rightarrow \\
\text { Psychological } \\
\text { Distress }\end{array}$ & .394 & .048 & $<.000$ \\
\hline $\begin{array}{l}\text { Self-Esteem } \rightarrow \\
\text { Psychological } \\
\text { Distress }\end{array}$ & .042 & .007 & $<.000$ \\
\hline
\end{tabular}


Table 19. Direct, Indirect, and Total Effects.

\begin{tabular}{cccc}
\hline Variable & Direct Effects & Indirect Effects & Total Effects \\
\hline $\begin{array}{c}\text { Adult IPV } \rightarrow \text { Psych } \\
\text { Distress }\end{array}$ & .079 & .103 & .182 \\
Child Vic $\rightarrow$ Psych & .103 & .026 & .129 \\
Distress & .042 & & .042 \\
$\begin{array}{c}\text { Self-Esteem } \rightarrow \\
\text { Psych Distress }\end{array}$ & .394 & & .394 \\
$\begin{array}{c}\text { Neg. Coping } \rightarrow \\
\text { Psych Distress }\end{array}$ & & & \\
\hline
\end{tabular}

Table 20. Chi-square difference test.

\begin{tabular}{|c|c|c|c|c|c|c|c|c|c|}
\hline Model & $\overline{X^{2}}$ & $\overline{\mathrm{Df}}$ & $\mathrm{P}$ & TLI & $\mathrm{CFI}$ & $\begin{array}{l}\text { RMSEA } \\
\text { (Con. } \\
\text { Interval) } \\
\text { pCLOSE }\end{array}$ & $\begin{array}{l}X^{2} \text { Difference } \\
\text { Test with } \\
\text { Original } \\
\text { Model, Df }\end{array}$ & Significant? & $\begin{array}{l}\text { Preferred } \\
\text { Model }\end{array}$ \\
\hline Original & 27.829 & 20 & .114 & .989 & .994 & $\begin{array}{l}.031 \\
(.000- \\
.057) \\
.879\end{array}$ & & & \\
\hline Trimmed & 28.011 & 21 & .140 & .989 & .994 & $\begin{array}{l}.029 \\
(.000- \\
.054) \\
.909\end{array}$ & $.182,1$ & No & Trimmed \\
\hline
\end{tabular}

As psychological distress is a broad concept, the model was also estimated with depression and PTSD, respectively. Results of the structural depression model indicated adequate fit: $\chi^{2}=28.30, p=.102$; TLI of .989; CFI of .994; RMSEA=.032, $p=.868$; $\mathrm{SRMR}=.03$ (See Figures 5 and 6). All paths were significant within this model, with the exception of the direct effect (path) from IPV to psychological distress $(p=.210)$, and the indirect effect (path) from child victimization to negative coping $(\mathrm{p}=.669)$. Additionally, when the dependent variable was operationalized as PTSD, structural model fit again was 
minimally sufficient: $\chi^{2}=31.04, p=.06$; TLI of .982 ; CFI of .990 ; RMSEA $=.037, p=.793$, SRMR $=.03$ (See Figures 7 and 8 ). All paths were statistically significant with the exception of the direct effect (path) from child victimization to PTSD ( $\mathrm{p}=.163$ ), child victimization to negative coping ( $\mathrm{p}=.666)$, as well as negative coping to PTSD ( $\mathrm{p}=.632$ ). 
Figure 5. CFA with Psychological Distress operationalized by depression.

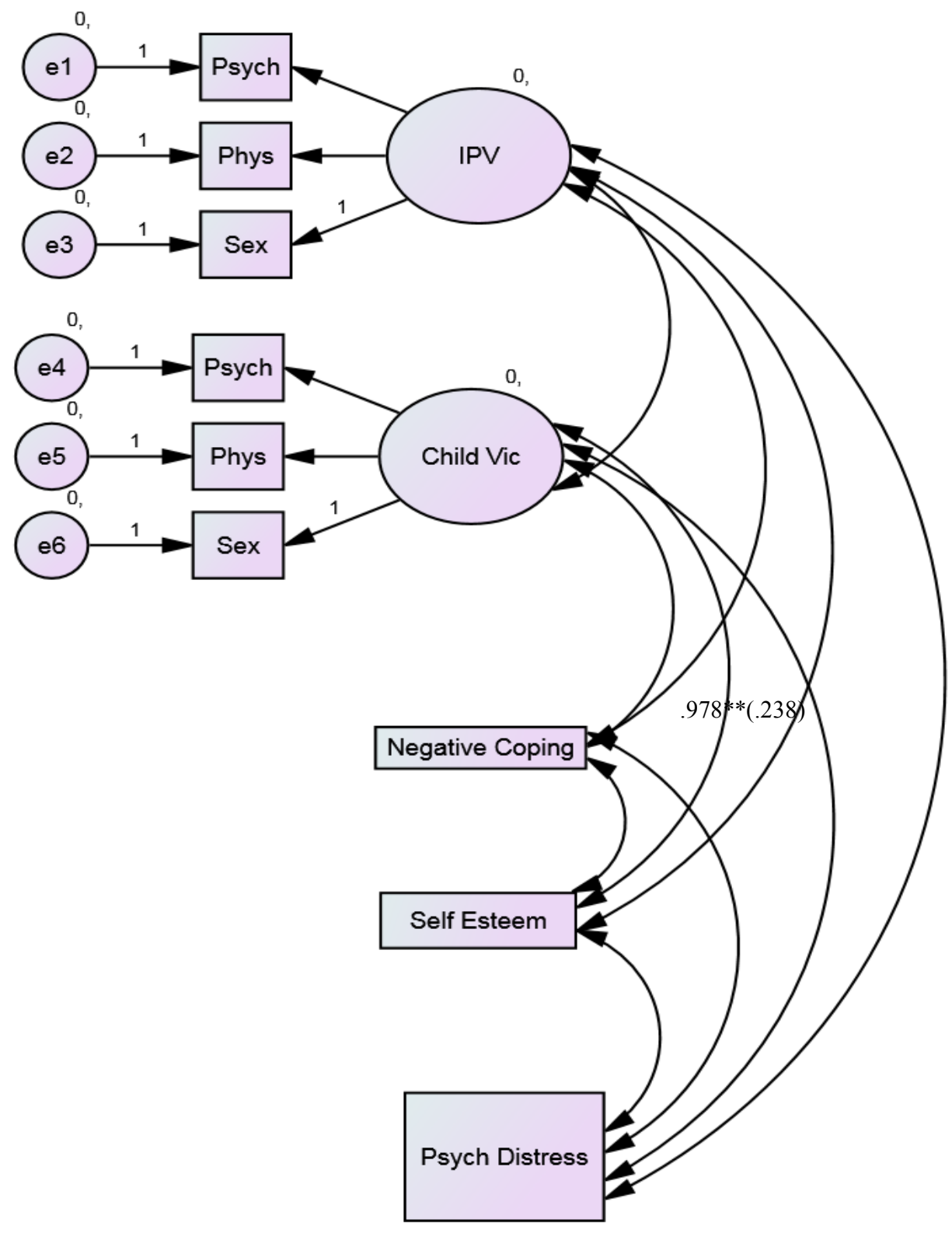


Figure 6. Structural Model with Psychological Distress Operationalized by Depression.

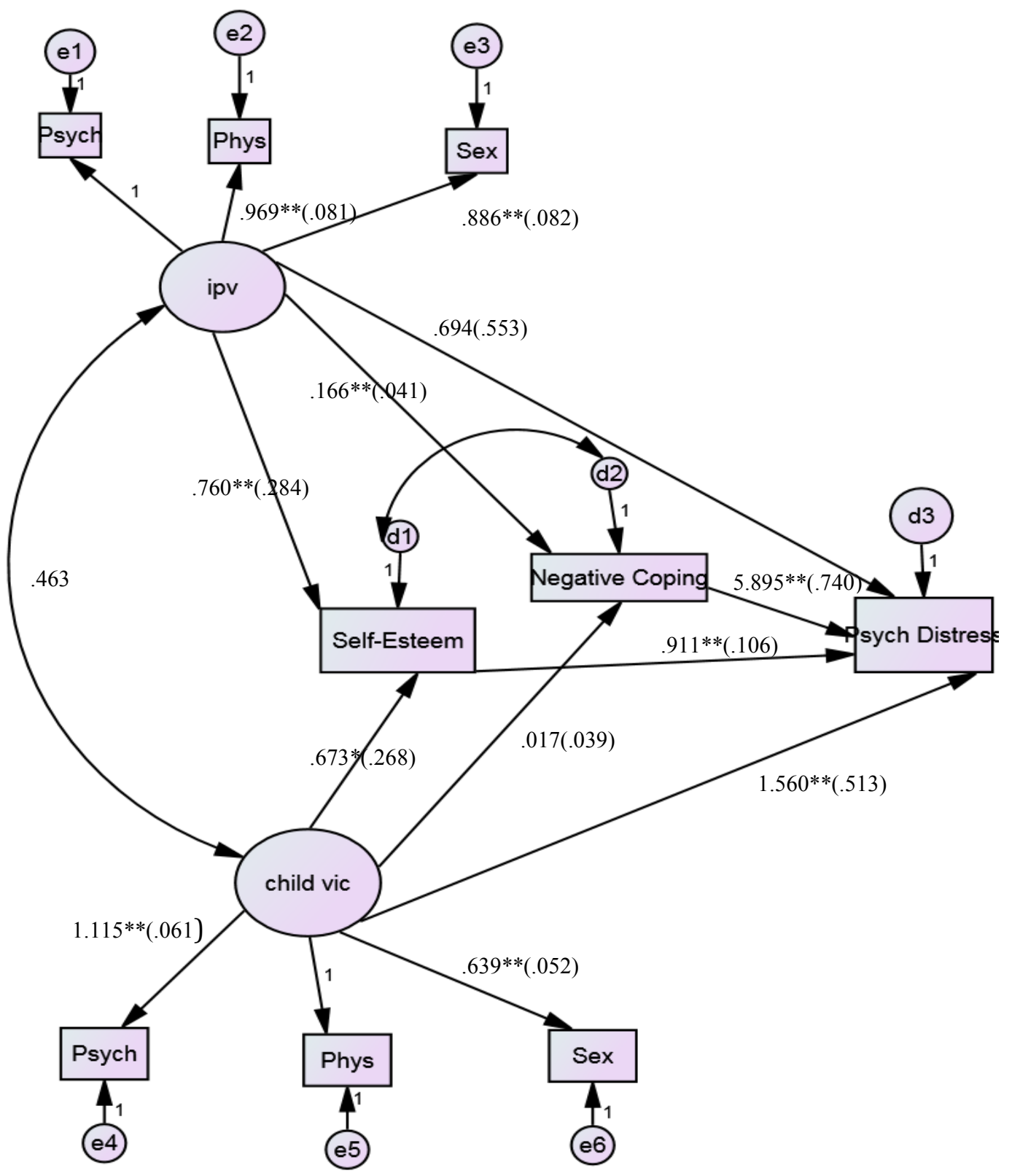


Figure 7. CFA with Psychological Distress operationalized by PTSD.

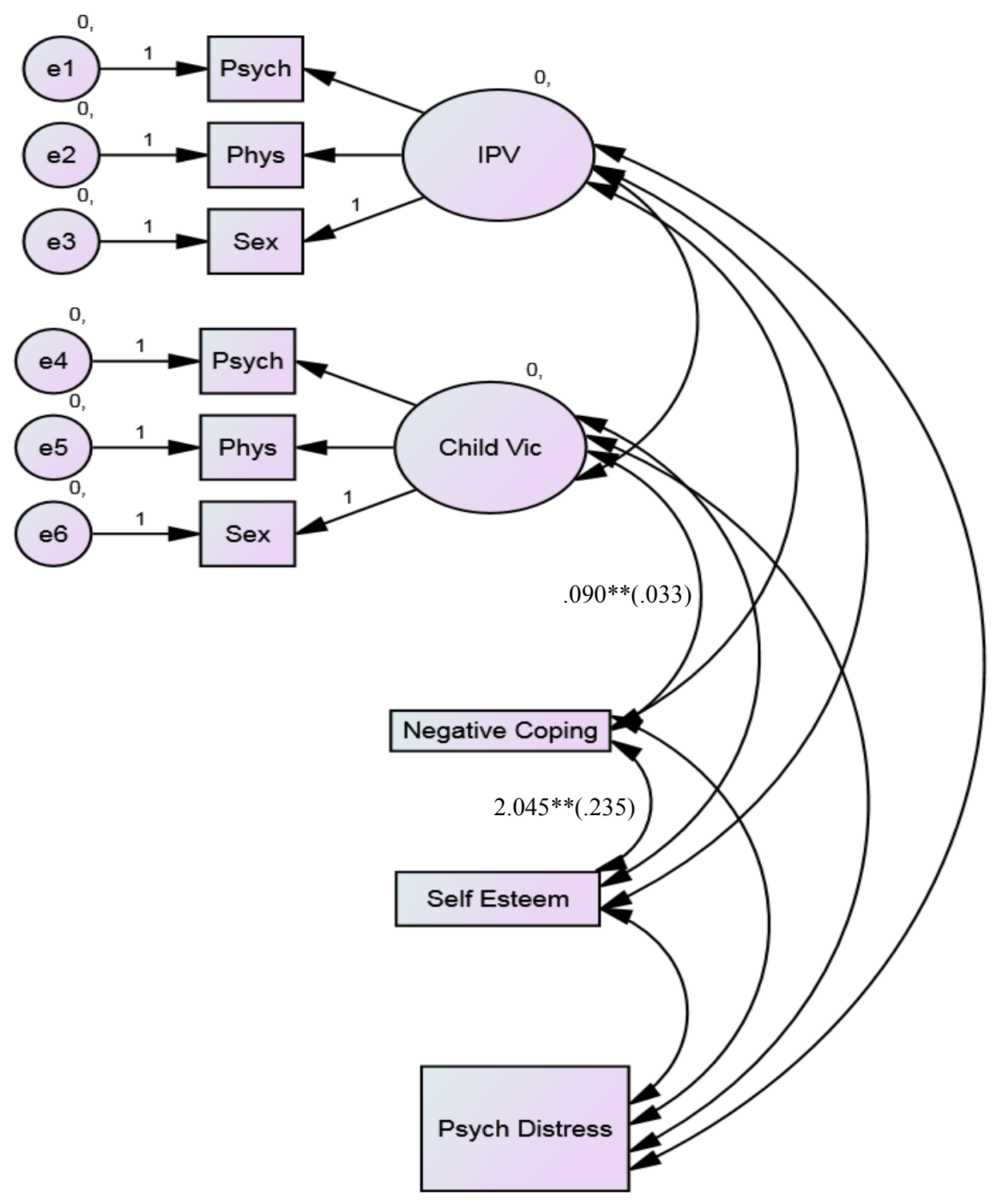


Figure 8. Structural Model with Psychological Distress operationalized by PTSD.

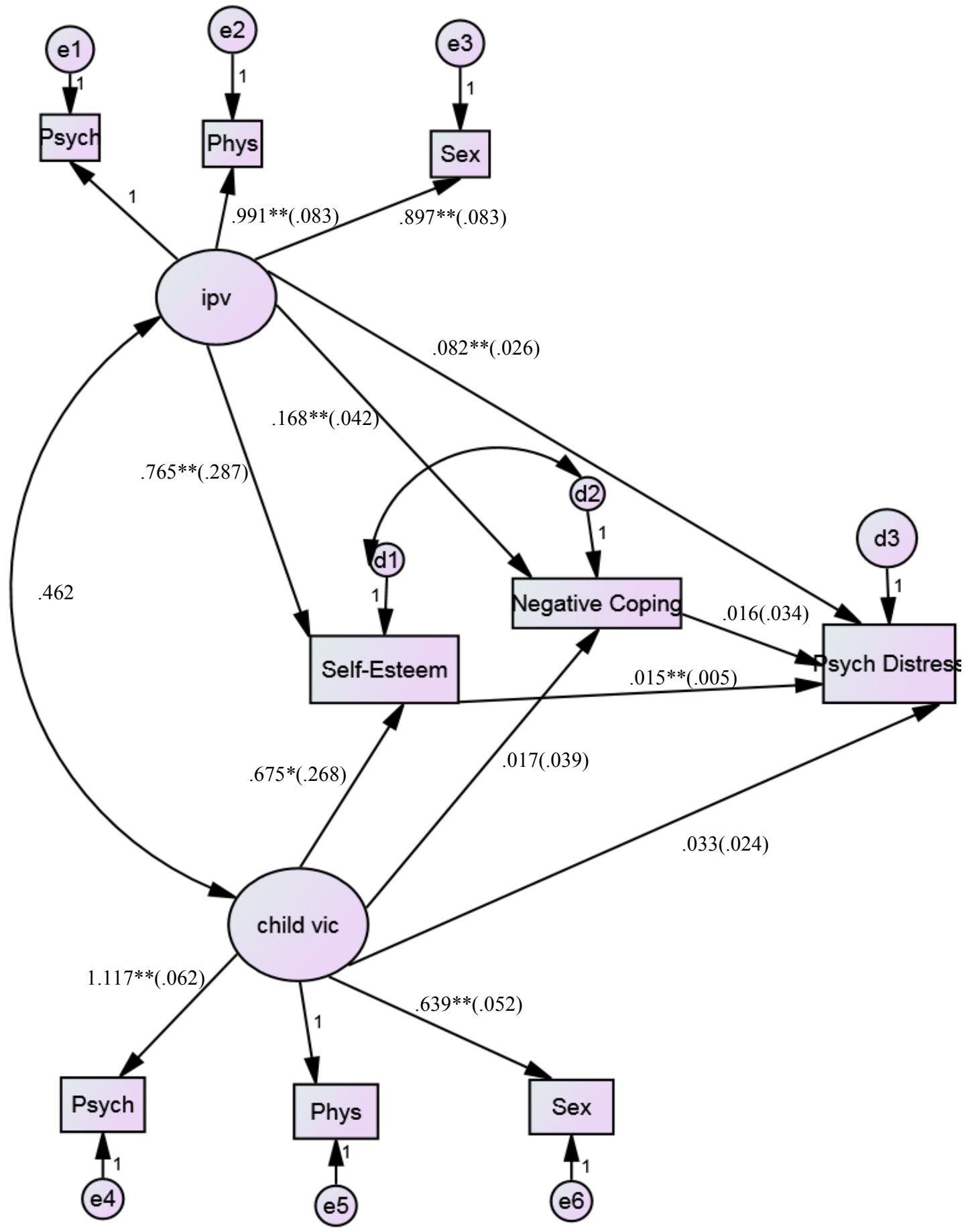




\section{CHAPTER 5: DISCUSSION}

\section{Introduction}

This study was designed to address identified gaps in substantive victimization and psychological distress literature, as well as research focused on justice-involved women sanctioned in the community. Prior childhood victimization and adult IPV research highlights psychological distress as a predominant outcome of these events (Classen, et al., 2001; Logan, Walker, Jordan, Leukefeld, 2006; Fargo, 2009; Follette et al., 1996; Renner \& Slack, 2006; Tjaden \& Thoennes, 2000). Additionally, a small body of literature has investigated the relationship between violence and psychological distress when measuring victimization cumulatively (Carlson, McNutt, \& Choi, 2003; Engstrom, El-Bassel, \& Gilbert, 2012; Golder \& Logan, 2011; Salisbury \& Voorhis, 2009). Further, previous literature has separately examined potentially related mechanisms that contribute to this relationship, including self-esteem, social support, coping, and substance use (Bonanno, 2004; Briere \& Jordan, 2009; Charney, 2004; Classen, et al., 2001). As such, the contributions of this study address current gaps within the literature including an absence of studies that: examine simultaneous experiences of both childhood and adult violence (cumulative victimization), related factors contributing to the relationship between victimization and psychological distress, and related factors that occur simultaneously as opposed to those that occur independently. 
This chapter will discuss the results of the primary research question, including descriptive results as well as findings from the structural equation model, explore implications for practice, present the limitations of the study, and highlight areas for future research.

\section{Interpretation of Results}

\section{Descriptive results.}

Victimization. The primary aim of this research was to explore the relationship between cumulative victimization (childhood violence and adult IPV), the hypothesized mediators (self-esteem, social support, coping, and substance use), and psychological distress among a sample of 406 victimized women sanctioned in the community, using secondary data from the Women's Health Research Study. Findings indicated that more than one-fourth of the sample experienced cumulative victimization (both child violence and adult IPV) of all three types (psychological, physical, and sexual), confirming the hypothesis that a significant portion of women experience victimization cumulatively rather than in isolation. Over half of the sample reported experiencing two types of cumulative victimization (physical and psychological) while more than seventy-five percent reported experiencing one type of cumulative victimization (psychological). These findings are similar to previous studies that descriptively examine violence across the lifespan confirming that child victimization experiences often lead to adult IPV and lifespan victimization (Briere \& Jordan, 2004, 2009; Classen et al., 2001; Dong, et al., 2003; Messman-Moore \& Long, 2000; Sitaker, 2008; Tjaden \& Thoennes, 2000; Whitfield, et al., 2003). Further, descriptive victimization findings from this study 
confirmed prior research that has examined polyvictimization (the overlapping and simultaneous occurrence of the three types of violence), as over half of this sample reported experiencing more than one type of IPV (Barnett, Miller-Perrin, \& Perrin, 2011; Krebs et al., 2011).

Related factors. While the risk of child victimization for subsequent adult IPV is not fully understood, it is theorized that experiences of violence in childhood negatively impact biological, psychological, and social functioning, which includes the development of positive self-esteem, healthy coping skills, and the ability to seek social support (Briere \& Jordan, 2009; Classen et al., 2001; Ehrensaft, 2008; Engstrom, El-Bassel, \& Gilbert, 2012). As the majority of women in this study experienced child victimization, it was hypothesized that women would have lower rates of self-esteem, utilize more negative coping skills, and have lower levels of social support. This hypothesis was supported as the majority of women in the sample reported having low rates of selfesteem and social support. The hypothesis was not supported in terms of coping, as the sample reported slightly higher use of positive coping mechanisms than negative coping. Conversely, women reported high rates of substance use for alcohol to intoxication, marijuana, and smoking. A potential explanation for this discrepancy between the measures of coping and substance use in the sample is that prior literature may not have taken into account individual participant's definitions of substance use as a coping skill. Further, women in this study reported they were young adolescents when they first started using substances. As such these mechanisms may have developed over time as a protective factor (conceptualized as a positive coping mechanism) and utilized as an 
avoidance technique (Carbone-Lopez, Kruttschnitt, \& Macmillan, 2006; Filipas, \& Ullman, 2006; Peltan \& Cellucci, 2011; Peters, Khondkaryan, \& Sullivan, 2012).

Psychological distress. In addition to the measure of PTSD, this study also measured forms of psychological distress such as depression (CESD-S) and global psychological functioning $(B S I)$. More than seventy percent $(71.7 \%)$ of the sample met criteria for depression, and among all nine of the $B S I$ dimensions, women reported symptomology significantly higher than normative adult female non-patient standards. Additionally, the GSI average among the sample indicated high rates of psychopathology when compared to a normative community sample ${ }^{44}$ (Derogatis, 1993).

Justice-involved women. Prior victimization research regarding justice-involved women reported lifetime victimization as high as 60\%-99\% among this sub-population (Bloom, Owen, Covington, 2003; Browne, Miller, \& Maguin, 1999; Kubiak, Nnawulezi, Karim, Sullivan, \& Beeble, 2012; Richie, 2000; Reichert, Adams, \& Bostwick, 2010; Salisbury \& Voorhis, 2009). Because women in this sample were selected based upon victimization, results of this study cannot be compared to earlier research; however, distressing rates of victimization in both childhood and adult IPV were indicated. Additionally, past research involving women in the justice system reported significantly higher rates of depression and PTSD, with decreased overall psychological functioning when compared to normative populations (McDaniels-Wilson \& Belknap, 2008; Messina Grella, 2006; Peltan \& Cellucci, 2011; Reichert, Adams, \& Bostwick, 2010; Tripodi \&

44 Raw score means for normative adult non-patient females are as follows: Somatization (.46), obsessive-compulsive (.54), interpersonal sensitivity (.55), depression (.56), anxiety (.54), hostility (.45), phobic anxiety (.44), paranoid ideation (.49), psychoticism (.34), and GSI (.37). 
Pettus-Davis, 2013). The results of this investigation solidifies the empirical findings of prior work, as forty percent of the sample qualified for a PTSD diagnosis (based on the $D S M-I V T R$ criteria), in addition to the high rates of depression and decreased psychological functioning as previously mentioned above.

Structural equation model results. Results of the SEM analysis indicated accurate model fit for the primary model, which utilized the GSI to measure psychological distress. The model indicated significant direct and indirect effects that include the following: (1) a significant correlation between child victimization and adult IPV indicating the existence of cumulative victimization, (2) the impact on psychological distress from child victimization and adult IPV, and (3) the impact on psychological distress outcomes as a result of victimization when mediated by self-esteem and coping (as substance use and social support were not retained in the model). A detailed discussion of these main findings are below.

Specifically in terms of the direct effects, both child victimization and adult IPV significantly impacted the variation within psychological distress, with significant correlation between the two victimization constructs. This confirms the hypothesis that cumulative victimization is a more comprehensive construct of violence in relationship to psychological distress, as it accounts for incidents across one's lifespan as opposed to examining isolated experiences of violence. The results also confirm the theorized direct relationship between victimization and negative psychological consequences, indicating that women who are victimized are at greater risk to also experience psychological distress. Further, women who experience both child victimization and adult IPV are at even greater risk for subsequent decreased psychological functioning (Carlson, McNutt, 
\& Choi, 2003; Engstrom, El-Bassel, \& Gilbert, 2012; Golder \& Logan, 2011; Salisbury \& Voorhis, 2009).

In terms of the indirect effects, both child victimization and adult IPV were investigated in relationship to psychological distress. Child victimization mediated by self-esteem accounted for $20 \%$ of the variance in psychological distress (controlling for adult IPV). Additionally, adult IPV mediated by self-esteem and negative coping accounted for $57 \%$ of the variance in psychological distress (controlling for child victimization). Thus, over seventy-five percent (77\%) of the total variation was explained through the behavior-specific mediated relationship between violence and psychological distress. Guided by a theoretical model, these results provide new empirical evidence regarding specific mechanisms (self-esteem and coping) that contribute to the relationship between victimization and psychological distress. This is groundbreaking for justice-involved women specifically, as both violence and psychological distress have both been found to directly influence women's initial and repetitive involvement in the criminal justice system (McDaniels-Wilson \& Belknap, 2008; Salisbury \& Voorhis, 2009; Tripodi \& Pettus-Davis, 2013). Additionally, this finding suggests that these particular behavior mechanisms can be targeted aims of intervention to reduce the overall effect of victimization leading to psychological distress, with the potential to decrease women's involvement in the justice system. Further, these types of targeted intervention strategies could greatly reduce negative sequelae associated with experiencing violence while increasing protective factors for subsequent victimization and decreased psychological functioning. 
Two additional models were analyzed using different measures of psychological distress. When operationalized as depression, the model provided adequate fit. Results indicated both direct and indirect effects from victimization to depression, with the exception of a direct effect from adult IPV to depression. When operationalized as PTSD, the model provided minimal fit criteria. Results indicated a direct effect from adult IPV to PTSD, but there was no significant direct effect from child victimization or negative coping to PTSD. These findings suggest that the relationship between victimization experiences and psychological distress may be better understood by type of violence and psychological distress. For example, previous research indicates that among the three types of victimization, PTSD and depression are a common outcome of sexual victimization, while additional studies indicate only depression as a common outcome of physical victimization (Coker, et al., 2002b; Coker, Watkins, Smith, \& Brandt, 2003; Hedtke, 2008; Young-Wolff, et al., 2013). This conceptualization of women's victimization experiences addresses the gap identified by prior research to study victimization beyond dichotomous yes/no experiences of violence by comprehensively measuring the type, severity, frequency, and number of partners who perpetrated victimization (Briere \& Jordan, 2004; 2009; Carbone-Lopez, Kruttschnitt, \& MacMillian, 2006; Classen et al., 2002; Fargo, 2009; Follette, Polusay, Bechtle, \& Nangie, 1996; Kelly, 2011; Kennedy et al., 2012; Krebs, et al., 2011; Nurius \& Macy, 2008, 2010; Tjaden \& Thoennes, 2000). While continued research regarding relationship(s) between types of victimization and types of psychological distress is needed, the information gleaned in this study is crucial to the formation of targeted interventions for justice- 
involved women as well as women in the general population who experience multiple types of violence and have co-occurring psychological distress symptoms.

\section{Implications for Practice}

Although substance use and social support were not retained in the final model, selfesteem and negative coping mediated the relationship between cumulative victimization and psychological distress, with the exception of child victimization to negative coping. While prior empirical evidence demonstrates relationship(s) between victimization, psychological distress and other related factors such as self-esteem and coping, current literature fails to understand and explain the function of the relationship(s) among these factors. In particular, given the high rates of psychological distress and victimization histories reported, evidence from this empirical study suggests that this sample have cooccurring presentations of victimization and psychological distress. Secondly, women in this study reported multiple partners as perpetrators for all three types of adult IPV. This finding suggests that though women may exit abusive relationships, they often continue to experience polyvictimization by multiple partners over the course of their lifetime. This cycle creates the potential for continued decrease in overall psychological functioning and increases the risk for future victimization (Logan et al, 2006). Lastly, as self-esteem and negative coping impacted the relationship between cumulative victimization and psychological distress, it is critical to understand in treatment model design and implementation that these mechanisms directly impact the effects of victimization, particularly in terms of psychological distress. Therefore, findings from this study would be beneficial and influential for programs and interventions that are created to address and treat these related issues. 
Targeted treatment models. Briere and Jordan (2004) found that a number of intervention programs that treat women with psychological distress fail to screen and assess for past or present victimization. Currently, psychotherapies utilized for psychological distress include Cognitive Therapies, Exposure Therapy, and Eye Movement Desensitization Reprocessing (EMDR) in addition to simultaneous use of antidepressant psychotropic medications (Logan et al., 2006). Although these interventions have been created to promote safety and assist women, the majority of interventions are offered in isolation without screening for other co-occurring issues. Therefore, victimized women with co-morbid occurrences of psychological distress are typically treated for only one of the presenting problems (Briere \& Jordan, 2009; Burgess-Proctor, 2011; Katerndahl, et al., 2012; Logan et al., 2006).

In 1998, the Substance Abuse and Mental Health Administration (SAMHSA) conducted a seminal study entitled "Women, Co-occurring Disorders, and Violence," which highlighted trauma as the organizing theme among women who were previously identified as mentally instable, substance users, and/or criminals. Based on findings from SAMHSA's study, a push towards research informed, evidence-based practice programs grew (Federal Committee on Women and Trauma, 2011). In fact, the Center for Substance Abuse Treatment (2007) urges treatment programs to use a "systems integration" concept model as best practice for co-occurring problems, particularly for women with trauma histories and co-morbid psychological distress. This movement is based upon recent research that demonstrates better outcomes with the integrated model for those with co-occurring problems. In an attempt to implement a program modeled from system integration, trauma-informed treatment programs have developed; however, 
these are not specific to victimization and "effective interventions (for IPV) remain elusive" (The Center for Substance Abuse Treatment, 2007; Ehrensaft, 2008; Elliot, Bjelajac, Fallot, Markoff, \& Reed, 2005; The Federal Partners Committee on Women and Trauma, 2013; Fitzgerald, McCart, \& Kilpatrick, 2009; Katerndahl,et al., 2012; Mitchell, et al., 2006).

Limited treatment models for victimized women aimed to address psychological distress exist; these models typically utilize cognitive-behavioral interventions with a combination of psycho-education related to diagnosis, anxiety management, exposure therapy, and cognitive therapy (Briere \& Jordan, 2004, 2009; Fitzgerald, McCart, \& Kilpatrick, 2009). However, lacking from the current interventions are psycho-education components aimed to address recognizing and responding to the red flags associated with potentially high-risk partners (Briere \& Jordan, 2004, 2009; Krebs et al., 2011). For women who have been victimized in childhood and do not have a healthy "blueprint" in terms of relationships, it is imperative that treatment models include modules addressing family-of-origin dynamics that impact the intergenerational transmission of violence. Literature demonstrates that children who experience victimization, particularly by their caretakers, will also experience violence in interpersonal adult relationships (Banford, Brown, Ketring, \& Mansfield, 2015; Franklin \& Kercher, 2012). From a family-of-origin perspective, it is theorized that victimized children eventually learn to accept violence within relationships as appropriate and thus maladaptive emotional regulation strategies develop overtime due to feeling un-protected by caregivers (Franklin \& Kercher, 2012). Additionally, this phenomenon has been linked in prior research that examines attachment style within adults who experienced violence as children by their caretaker; 
the results indicate anxious/insecure attachment styles that also further contribute to potentially hostile interactions with partners as adults (Franklin \& Kercher, 2012).

Given this perspective, modules that address these dynamics are vital components of treatment models aimed to reduce the negative effects of victimization. A current intervention that focuses on healthy relationship skills building is Within My Reach (WMR), a derivative of Prevention and Relationship Enhancement Program (PREP). The WMR module was designed specifically for individuals who have experienced IPV (Antle, Karam, Christensen, Barbee, \& Sar, 2011). The foundational components of WMR include teaching participants components of healthy relationships (in particular physical, emotional, and commitment safety), skills to choose safe partners, and strategies to leave unsafe relationships (Antle et al., 2011). This module was designed in particular for low-income individuals who were high-risk for IPV relationships; however, treatment models for justice-involved women would also greatly benefit from incorporating similar relationships skills for managing unsafe relationships and developing healthy partner picking skills.

Further, existing treatment models tend to focus heavily on coping strategies but do not treat other behavior specific mechanisms (such as self-esteem) associated with victimization and psychological distress (The Center for Substance Abuse Treatment, 2007; Ehrensaft, 2008; Elliot, et al., 2005; The Federal Partners Committee on Women and Trauma, 2013; Fitzgerald, McCart, \& Kilpatrick, 2009; Katerndahl, et al., 2012; Mitchell, et al., 2006). This appears to be a necessary component of comprehensive treatment, as evidence from this study as well as prior research suggests that these targeted behaviors may not only decrease risk, but also increase resiliency and protective 
factors for subsequent abuse and/or psychological distress (Briere \& Jordan, 2004, 2009; Clements \& Sawhaney, 2000; Cohen \& Wills, 1985; Mitchell et al., 2006; Soler, Kirchner, Paretilla, \& Forns, 2013). Further, the majority of models that currently exist are provided in women's shelters and are short-term; therefore, a large majority of women who experience victimization and/or associated psychological distress are not treated (Johnson and Zlotnick, 2009; Logan, et al., 2006). In fact, according to research from the NCIPC (2010), only half of women who experience victimization receive needed treatment or intervention.

Targeted treatment models for justice-involved women. Treatment intervention is especially vital for justice-involved women. This group of women experience significantly high rates of victimization, and these experiences directly impact ongoing offenses when left untreated (Browne, Miller, \& Macguin, 1999; Messina \& Grella, 2006; Salisbury \& Voorhis, 2009; Tripodi \& Petruss-Davis, 2013). According to Kubiak and colleagues (2014), as of 2011, there were no interventions that primarily treated victimization among justice-involved women. Additionally, although women in the criminal justice system are disproportionately diagnosed with psychological distress (depression, anxiety, PTSD), less than twenty-five percent receive mental health treatment (The Sentencing Project: Research and Advocacy for Reform, 2007). Moreover, while substance use was not found to mediate victimization and psychological distress in this study's model, prior empirical evidence suggests that this group of women particularly experience substance use, psychological distress, and victimization concurrently (Salisbury \& Voorhis, 2009). Further exacerbating these co-occurring problems, literature demonstrates that women's experiences of victimization, substance 
use, and psychological distress are unique; as such, intervention models must encompass a gender-specific, person-centered approach that is tailored to the specific needs of each woman as it addresses co-occurring problems (Bloom, Owen, \& Covington, 2003; McDaniels-Wilson \& Belknap, 2008; Messina \& Grella, 2006; Nurius \& Macy, 2008; Salisbury \& Voorhis, 2009).

Given the high rates of victimization and psychological distress among this group of women, it is crucial that treatment models for this population include the following: psycho-education regarding victimization and high-risk partners; intervention for symptoms of psychological distress (CBT or other evidence-based models such as Eye Movement Desensitization Reprocessing (EMDR)); and skill building exercises/education targeted to decrease risk and increase resiliency through related behavior-specific mechanisms (self-esteem, coping).

Of the existing treatment models, Seeking Safety and Beyond Violence: A Prevention Model for Criminal Justice-Involved Women are two group interventions specifically designed and/or evaluated for utilization with women in the criminal justice system. Seeking Safety's intervention model is based upon cognitive behavioral therapy and focuses on the co-occurrence of substance use and PTSD among vulnerable populations by addressing stabilization, coping skills, and the reduction of self-destructive behaviors (Wolff, Frueh, Shi, \& Schumann, 2012). This model has been evaluated as a best-practice model by the International Society for Traumatic Stress Studies Practice Guidelines (Wolff, et al., 2012). In particular, three outcome studies have evaluated the effectiveness of this intervention with women in prison. Findings from all three studies suggest that this model decreased PTSD (Lynch, Heath, Matthews, \& Cepeda, 2012; Wolff, et al., 
2012; Zlotnick, Najavits, Rohsenow, \& Johnson, 2003). While these findings are demonstrative in the development of interventions specific for justice-involved women, this particular model is built upon general trauma information rather than victimization specifically. Further, it has not been utilized and/or evaluated with justice-involved women sanctioned in the community.

In addition to Seeking Safety, Covington's (2013) Beyond Violence intervention program is a victimization specific treatment model that has been utilized with justiceinvolved women. This intervention model was created in response to the lack of treatment models aimed to target the unique victimization experiences of women in the criminal justice system by targeting violence, issues of mental health, substance use, and anger regulation (Kubiak et al., 2014). While this intervention has shown effectiveness with this population at reducing overall PTSD symptoms, as with Seeking Safety, this intervention has not been examined among women on probation/parole. Additionally, this intervention was primarily created for women offenders who themselves have perpetrated violence rather than being victimized themselves (Kubiak, et al., 2014). Despite these limitations, a promising component of this intervention is its ability to be implemented in both general population settings of prison as well as therapeutic communities within the prison system (Kubiak, et al., 2014). The general milieu prison setting is more comparative to community settings in which treatment models like Beyond Violence are typically disseminated, which have direct impact on women's access to treatment who are sanctioned in the community.

Due to the limited number of current treatment models in place for justice-involved women, a combined model that incorporates aspects of both Seeking Safety as well as 
Beyond Violence would greatly benefit this population of women. This type of treatment model would be victimization specific and target co-occurring presentations of psychological distress and/or substance use. Additionally, the inclusion of behaviorspecific mechanisms that contribute to the relationship(s) would significantly decrease risk for future victimization and psychological distress while increasing resiliency. This would directly impact women's risk of recidivism and continued involvement in the criminal justice system.

Given the results of this study and the author's clinical background, a comprehensive treatment model for justice-involved women would utilize components of Seeking Safety and Beyond Violence as a foundation for the model, since these models proven to be effective for incarcerated women. A treatment module specific for justice-involved women would involve a more comprehensive approach to assisting women in the development and management of skills to decrease the negative effects of victimization through the use of individual and group modalities. Individual modalities would provide a safe and controlled environment for women to process their unique experiences; group modalities would serve to help this population of women build a sense of community as well as social support to reduce the isolating effects of victimization experiences women often report (Messina, Calhoun, \& Braithwaite, 2014; Warshaw, Sullivan, \& Rivera, 2013).

Further, unique content areas incorporated into the treatment model would include four different modules to address self-esteem, coping, and trauma processing from an integrative perspective. Module 1 would address issues of self-esteem; this would include assessing and reframing negative beliefs about self, providing self-advocacy and 
assertiveness training, and teaching women empowerment techniques. Module 2 would focus on developing coping skills to manage the symptoms of psychological distress. This module would include an integrative Trauma-Focused CBT and Narrative Therapy framework for women to process their unique victimization experiences/stories.

Additionally, this module would focus on mindfulness techniques to encourage women in their ability to live in the present, and allowing the negative past experiences to no longer dictate their current experiences/stories. Mindfulness techniques are new in the treatment of IPV; however current available research affirms these techniques to be beneficial when used with participants (Dutton et al., 2013; Tesh, Learman, \& Pulliam, 2013). Module 3 would provide psycho-education about IPV and its impact, including transgenerational components to identify potential patterns in family interactions that are risky (or healthy). This module would also include psycho-education regarding attachment styles and their impact on interpersonal relationships/partner picking. Lastly, Module 4 would provide general education regarding access to treatment, safety planning, and community resources. These modules would be given simultaneously throughout treatment. Further, the design of these modules would be in collaboration with women who have experienced IPV, as their input is imperative to understanding the unique needs of this group of women (Warshaw, Sullivan, \& Rivera, 2013).

\section{Limitations}

While results of this investigation address a number of gaps in existing literature, limitations of the study must be recognized. These include the cross-sectional design of 
the study including retrospective reports of child violence, sampling limitations, and the potential for reporting bias. These limitations are explored below.

Design. Data collected for this research utilized a cross-sectional design; therefore, causal inferences cannot be made. To better account for causation, future research should examine the relationship between victimization, the associated mediators, and psychological distress through a longitudinal research investigation to better capture this relationship.

Additionally, accounts of childhood victimization were retrospective, thus relying on the participant's memory of an event that occurred years prior to the time of the study. Although this is a common form of data collection in child victimization studies, issues related to this form of questionnaire design include the potential for incorrect detail recollection of the events (age, rate, severity, symptomology), underreporting of events, and the potential effect of the participant's mood/affect regulation state at the time of reporting accurate details (Barnett, Miller-Perrin, \& Perrin, 2011; Tjaden \& Thoennes, 2000; Widom \& Shephard, 1996; Widom \& Morris, 1997; Widom, 1997). Therefore, readers must consider this when interpreting the results of this current study.

Sampling. Participants in this research were specifically recruited based on their report of at least one victimization experience. As such, regardless of the multiple recruitment methods utilized, this sample was not selected at random but rather was chosen based upon victimization histories. Therefore, this study is not generalizable to non-victimized women in the justice system. Future research would benefit to examine these same phenomena within a sample of women who have both an absence and 
presence of victimization histories for women involved in the CJ system. Additionally, respondents were included in the study based upon their probation/parole status at the time of eligibility screening. Therefore, this study is specific to this sub-population of justice-involved women being controlled in the community.

Reporting bias. Data were collected through self-report measures; as such there was the potential for participants to underreport sensitive information due to report bias. However, this study utilized the audio computer assisted interviewing (ACASI) program, as this has been a previously identified method of data collection to reduce self-report bias when measuring sensitive information such as victimization experiences (Wolff \& Shi, 2012).

\section{Areas for Future Research}

Until research exists which demonstrates an understanding of how these phenomena are related, treatment will continue to be under-developed and disjointed in serving victimized women (Classen et al., 2001). This is true for the general population as well as justice-involved women specifically. To improve understanding of this phenomenon and directly inform treatment models aimed to reduce the effects of victimization, future research that examines additional behavior specific mechanisms that could potentially influence the relationships between victimization and psychological distress would be greatly beneficial. Further, both qualitative and quantitative literature that examines the function of substance use measured as a coping mechanism would be crucial to researchers' understanding of women's utilization of substances. Additionally, research that examines the types of victimization (psychological, physical, and sexual) 
with specific types of psychological distress while controlling for the other types would inform treatment design and intervention of best practice given the unique experiences of victimization and psychological distress individual women encounter.

Lastly, the direct and indirect effects of the relationship between victimization and psychological distress are essential for development and empirical testing of treatment interventions that address the aforementioned components necessary to reduce the negative effects of victimization and psychological distress specifically for justiceinvolved women. In terms of direct effects, individual women would benefit from access to treatment that comprehensively utilizes a person-centered approach to address their unique treatment presentation to reduce the negative sequelae associated with cumulative victimization. Indirectly, this form of treatment would ultimately reduce recidivism rates among justice-involved women. 


\section{REFERENCES}

Adelson, J. L. (2012). Examining relationship and effects in gifted education research: An introduction to structural equation modeling. Gifted Child Quarterly, 56(1), p.47-55.

Aneshensel, C. S. (1992). Social stress: Theory and research. Annual Review Sociology, 18, p.1538.

Ansara, D. L., \& Hindin, M. J. (2010). Formal and informal help-seeking associated with women's and men's experiences of intimate partner violence in Canada. Social Science \& Medicine, 70, p.1011-1018.

Antle, B. F., Karam, E., Christensen, D. N., Barbee, A. P., \& Sar, B. K. (2011). An evaluation of healthy relationship education to reduce intimate partner violence. Journal of Family Social Work, 14(5), p. 387-406.

Banford, A. J., Brown, M. D., Ketring, S. A., \& Mansfiled, T. R. (2015). The relationship between family-of-origin experience and current family violence: A test of mediation by attachment style and mental health symptom distress. The American Journal of Family Therapy, 43, p.84-96.

Barnett, O. W., Miller-Perrin, C. L., \& Perrin, R. D., (2011). Family Violence Across the Lifespan: An Introduction. Thousand Oaks: Sage.

Baron, R. M., \& Kenny, D. A. (1986). The moderator-mediator variable distinction in social psychological research: Conceptual, strategic, and statistical considerations. Journal of Personality and Social Psychology, 51, p.1173-1182.

Basile, K. C., Arias, I., Desai, S., \& Thompson, M. P. (2004). The differential association of intimate partner physical, sexual, psychological, and stalking violence and posttraumatic 
stress symptoms in a nationally representative sample of women. Journal of Traumatic Stress, 17(5), p. 413-421.

Becker, K. D., Stuewig, J., \& McCloskey, L. A. (2009). Traumatic stress symptoms of women exposed to different forms of childhood victimization and intimate partner violence. Journal of Interpersonal Violence, 25(9), p.1699-1715.

Bloom, B., Owen, B., \& Covington, S. (2003). Gender-responsive strategies: Research, practice, and guiding principles for women offenders. Washington, D.C.: National Institute of Corrections.

Bogat, G. A., Levendosky, A. A., \& von Eye, A. (2005). The future of research on intimate partner violence: Person-oriented and variable-oriented perspectives. American Journal of Community Psychology, 36(1/2), p.49-70.

Bonanno, G. A. (2004). Have we underestimated the human capacity to thrive after extremely aversive events? American Psychological Association, 59(1), p. 20-28.

Bonomi, A. E., Thompson, R. S., Anderson, M., Reid, R. J., Carrell, D., Dimer J. A., \& Rivara, F. P. (2006). Intimate partner violence and women's physical, mental, and social functioning. American Journal of Preventive Medicine, 30(6), p. 458-466.

Borelli, J.L., Goshin, L., Joestl, S., Clark, J., \& Byrne, M. W. (2010). Attachment organization in a sample of incarcerated mothers: Distribution classifications and associations with substance abuse history, depressive symptoms, perceptions of parenting competency and social support. Attachment \& Human Development, 12(4), p.355-374.

Breiding, M.J., Black, M.C., \& Ryan, G.W. (2008). Prevalence and risk factors of intimate partner violence in eighteen U.S. States/Territories. American Journal of Preventive Medicine, 34(2), p.112-118. 
Brewin, C. R., Andrews, B., \& Valentine, J.D. (2000). Meta-analysis of risk factors for posttraumatic stress disorder in trauma-exposed adults. Journal of Consulting and Clinical Psychology, 68(5), p. 748-766.

Briere, J., \& Jordan, C. E. (2009). Childhood maltreatment, intervening variables, and adult psychological difficulties in women. Trauma, Abuse, \& Violence, 10(4), p. 375-388.

Briere, J., \& Jordan, C.E. (2004). Violence against women: Outcome complexity and implications for assessment and treatment. Journal of Interpersonal Violence, 19(11), p. 1252-1276.

Browne, A., Miller, B., \& Maguin, E. (1999). Prevalence and severity of lifetime physical and sexual victimization among incarcerated women. International Journal of Law and Psychiatry, 22(3-4), p. 301-322.

Burgess-Proctor, A. (2011). Pathways of victimization and resistance: Toward a feminist theory of battered women's help-seeking. Justice Quarterly, 29(3), p.309-346.

Carbone-Lopez, K., Kruttschnitt, C., \& MacMillan, R. (2006). Patterns of intimate partner violence and their associations with physical health, psychological distress, and substance use. Public Health Reports, 121, p.382-392.

Carlson, E. B., \& Dalenberg, C. (2000). A conceptual framework for the impact of traumatic experiences. Trauma, Violence, \& Abuse, 1(1), p.4-28.

Carver, C.S., Scheier, M.F., \& Weintraub, J. K. (1989). Assessing coping strategies: A theoretically based approach. Journal of Personality and Social Psychology, 56(2), p.267-283.

Center for Behavioral Health Statistics and Quality (2010). [Data spotlight: Half of women on probation or parole experience mental illness]. National Survey on Drug Use and Health. Retrieved from: http:/www.samhsa.gov/data/spotlight/Spot063WomenParole2012.pdf. Centers for Disease Control and Prevention. (2008). Adverse health conditions and health risk behaviors associated with intimate partner violence-United States, 2005. MMWR, 57(5), p.113-117. 
Chapman, D. P., Whitfield, C. L., Felitti, V. J., Dube, S. R., Edwards, V. J., \& Anda, R. F. (2004). Adverse childhood experiences and the risk of depressive disorders in adulthood. Journal of Affective Disorders, 82, p.217-225.

Charney, D. S. (2004). Psychobiological mechanisms of resilience and vulnerability: Implications for successful adaptation to extreme stress. The American Journal of Psychiatry, 161(2), p. 195-216.

Child Welfare Information Gateway. (2014). Child maltreatment 2012: Summary of key findings. Washington, DC: U.S. Department of Health and Human Services, Children's Bureau.

Classen, C., Field, N.P., Koopman, C., Nevill-Manning, K., \& Spiegel, D. (2001). Interpersonal problems and their relationship to sexual revictimization among women sexually abused in childhood. Journal of Interpersonal Violence, 16, p.495-509.

Classen, C., Nevo, R., Koopman, C., Nevill-Manning, K., Gore-Felton, C., Rose, D.S., \& Spiegel, D. (2002). Recent stressful life events, sexual revictimization, and their relationship with traumatic stress symptoms among women sexually abused in childhood. Journal of Interpersonal Violence, 17(12), p.1274-1290.

Clements, C. M., \& Sawhney, D. K. (2000). Coping with domestic violence: Control attributions, dysphoria, and hopelessness. Journal of Traumatic Stress, 13(2), 219-240.

Cohen, S. \& Wills, T. A. (1985). Stress, social support, and the buffering hypothesis. Psychological Bulletin,98(2), p.310-357.

Coker, A. L., Davis, K. E., Arias, I., Desai, S., Sanderson, M., Brandt, H. M., \& Smith, P. H. (2002a). Physical and mental health effects of intimate partner violence for men and women. American Journal of Preventive Medicine, 23(4), p.260-268. 
Coker, A. L., Smith, P. H., McKeown, R. E., \& King, M. J. (2000b). Frequency and correlates of intimate partner violence by type: Physical, sexual, and psychological battering. American Journal of Public Health, 90(4), p. 553-559.

Coker, A. L., Watkins, K. W., Smith, P. H., \& Brandt. (2003). Social support reduces the impact of partner violence on health: Application of structural equation models. Preventive Medicine, 37, p.259-267.

Cook P., Morris M. F., \& Kelly, N. (2006). Statewide strategic plan for the prevention for sexual assault, domestic violence, and child abuse- 2006. Frankfort, KY: Kentucky Cabinet for Health and Family Services.

Daro, D., Edleson, J. L., \& Pinderhughes, H. (2004). Finding common ground in the study of child maltreatment, youth violence, and adult domestic violence. Journal of Interpersonal Violence, 19(3), p.282-298.

Derogatis, L. R. (1993). BSI Brief Symptom Inventory: Administration, Scoring, and Procedure Manual (4th ed.). Minneapolis, MN: National Computer Systems.

Dong, M., Anda, R. F., Dube, S. R., Giles, W. H., \& Felitti, V. J. (2003). The relationship of exposure to childhood sexual abuse to other forms of abuse, neglect, and household dysfunction during childhood. Child Abuse \& Neglect, 27, p. 625-639.

Dowlinger-Guyer, S., Needle, R., Weatherby, N., et al. (1994). Reliability of drug users'selfreported HIV risk behaviors and validity of self-reported recent drug use. Assessment, 1, p. 383-392.

Dube, S. R., Felitti, V. J., Dong, M., Giles, W. H., \& Anda, R. F. (2003). The impact of adverse childhood experiences on health problems: Evidence from four birth cohorts dating back to 1900. Preventive Medicine, 37, p.268-277.

Dutton, M. A., Bermudez, D., Matas, A., Majid, H., \& Myers, N. L. (2013). Mindfulness-based stress reduction for low-income, predominantly African American women with PTSD 
and a history of intimate partner violence. Cognitive and Behavioral Practice 20(1), p.2332.

Dutton, M. A., (2009). Pathways linking intimate partner violence and posttraumatic disorder. Trauma, Violence, \& Abuse, 10, p.211-224.

Elliott, D. E., Bjelajac, P., Fallot, R. D., Markoff, L. S., \& Reed, B. G. (2005). Trauma-informed or trauma-denied: Principles and implementation of trauma-informed services for women. Journal of Community Psychology, 33(4), p.461-477.

Elliot, D. M., Mok, D. S., \& Briere, J. (2004). Adult sexual assault: Prevalence, symptomatology, and sex differences in the general population. Journal of Traumatic Stress, 17(3), p. 203211.

Engstrom, M., El-Bassel, N., \& Gilbert, L. (2012). Childhood sexual abuse characteristics, intimate partner violence exposure, and psychological distress among women in methadone treatment. Journal of Substance Abuse Treatment, 43, p.366-376.

Fargo, J. D. (2009). Pathways to adult sexual revictimization.: Direct and indirect behavioral risk factors across the lifespan. Journal of Interpersonal Violence, 24(11), p. 1771-1791.

Federal Committee on Women and Trauma (2013). Trauma-informed approaches: Federal activities and initiatives. Retrieved from: http://www.nasmhpd.org/Publications/Women_and_Trauma.aspx.

Federal Committee on Women and Trauma (2011). Report of the federal partners committee on women and trauma. Retrieved from: http://www.vawnet.org/Assoc_Files_VAWnet/WomenAndTrauma.pdf.

Filipas, H. H., \& Ullman, S. E. (2006). Child sexual abuse, coping responses, self-blame, posttraumatic stress disorder, and adult sexual revictimization. Journal of Interperonsal Violence, 21(5), p. 652-672.

Finkelhor, D., \& Dziuba-Leatherman, J. (1994). Victimization of children. American Psychologist, 49(3), p.173-183. 
Fizgerald, M. M., McCart, M. R., \& Kilpatrick, D. G. (2009). Psychological-behavioral treatment with victims of interpersonal violence. In P. M.. Kleespies (Ed). Behavioral emergencies: An evidence-based resource for evaluating and managing risk of suicide, violence, and victimization. (pp.377-401). Washington, DC: American Psychological Association.

Foa, E. B., Cashman, L., Jaycox, L., \& Perry, K. (1997). The validation of a self-report measure of PTSD: The posttraumatic diagnostic scale. Psychological Assessment, 9, p. 445-451.

Follette, V. M., Polusay, M. A., Bechtle, A. E., \& Nangie, A. E., (1996). Cumulative trauma: The impact of child sexual abuse, adult sexual assault, and spouse abuse. Journal of Traumatic Stress, 9(1), p.25-35.

Franklin, C. A., \& Kercher G. A. (2012). The intergenerational transmission of intimate partner violence: Differentiating correlates in a random community sample. Journal of Family Violence, 27, p.187-199.

Golder, S., Connell, C.M., \& Sullivan, T.P. (2012). Psychological distress and substance use among community-recruited women currently victimized by intimate partners: A latent class analysis and examination of between-class differences. Violence Against Women, 18(8), p.934-957.

Golder, S. and Logan, TK. (2011) Cumulative victimization, psychological distress, and highrisk behavior among substance-involved women. Violence and Victims, 26 (4), p.477495.

Golding, J. M. (1999). Intimate Partner Violence as a risk factor for mental disorders: A metaanalysis. Journal of Family Violence, 14(2), p.99-132.

Hayes, A. F. (2009). Beyond baron and Kenny: Statistical mediation analysis in the new millennium. Communication Monographs, 76(4), p.408-420.

Hedtke, K. A., Ruggiero, K. J., Fitzgerald, M. M., Zinzow, H. M., Saunders, B. E., Resnick, H. S., \& Kilpatrick, D. G. (2008). A longitudinal investigation of interpersonal violence in 
relation to mental health and substance use. Journal of Consulting and Clinical Psychology, 76(4), p.633-647.

Higgins, G., Marcum, C. D., Golder, S., Hall, M., \& Logan, T.K. (2015). Confirmatory factor analysis of the medical outcomes study-social support survey: Examining the factor structure among victimized women on probation and parole. American Journal of Criminal Justice. doi:10.1007/s12103-015-9290-x.

Hill, T. D., Kaplan, L. M., French, M. T., \& Johnson, R. J. (2010). Victimization in early life and mental health in adulthood: An examination of the mediating and moderating influences of psychosocial resources. Journal of Health and Social Behavior, 51(48), p. 48-63.

Houry, D., Kaslow, N. J., \& Thompson, M. P. (2005). Depressive symptoms in women experiencing intimate partner violence. Journal of Interpersonal Violence, 20(11), p.1467-1477.

Houskamp, B. M., \& Foy, D. W. (1991). The assessment of posttraumatic stress disorder in battered women. Journal of Interpersonal Violence, 6, p.367-375.

Johnson, D.M., \& Zlotnick, C. (2009). HOPE for battered women with PTSD in domestic violence shelters. Professional psychology, research, and practice, 40(3), p.234-241.

Kelly, U. A., (2011). Theories of intimate partner violence: From blaming the victim to acting against injustice. Advances in Nursing Science, 34(3), p.E29-E51.

Kendall-Tackett, K. (2002). The health effects of childhood abuse: Four pathways by which abuse can influence health. Child Abuse \& Neglect, 26, p.715-729.

Kennedy, A. C., Adams, A., Bybee, D., Campbell, R., Kubiak, S. P., \& Sullivan, C. (2012). A model of sexually and physically victimized women's process of attaining effective formal help over time: The role of social location, context, and intervention. American Journal of Community Practice, 50, p.217-228.

Kline, R.B. (2011). Principles and Practice of Structural Equation Modeling (3 ${ }^{\text {rd }}$ ed.). New York: Guilford Press. 
Krebs, C., Breiding, M.J., Browne, A., \& Warner, T. (2011). The association between different types of intimate partner violence experienced by women. Journal of Family Violence, 26, p.487-501.

Krug, E. G., Dahlber, L.L., Mercy, J.A., Zwi, A.B., \& Lozano, R. (Eds.). (2002). Violence by intimate partners In World Report on Violence and Health. Geneva: World Health Organization.

Kubiak, S. P., Kim, W. J., Fedock, G., \& Bybee, D. (2014). Testing a violence-prevention intervention for incarcerated women using a randomized control trial. Research on Social Work Practice. DOI: 10.1177/10497315143534300.

Kubiak, S. P., Nnawulezi, N., Karim, N., Sullivan, C. M., \& Beeble, M. L. (2012). Examining disclosure of physical and sexual victimization by method in samples of women involved in the criminal justice system. Journal of Offender Rehabilitation, 51(3), p. 161-175.

Lacey, K. K., McPherson, M. D., Samuel, P. S., Sears, K.P., \& Head, D. (2013). The impact of different types of intimate partner violence on the mental and physical health of women in different ethnic groups. Journal of Interpersonal Violence, 28(2), p. 359-385.

Lang, A. J., Stein, M. B., Kennedy, C. M., \& Foy, D. W. (2004). Adult psychopathology and intimate partner violence among survivors of childhood maltreatment. Journal of Interpersonal Violence, 19(10), p.1102-1118.

Lazarus, R. S. (2006). Emotions and interpersonal relationships: Toward a person-centered conceptualization of emotions and coping. Journal of Personality, 74(1), p.10-46.

Logan, T.K., Walker, R., Jordan, C., Leukefeld, C. (2006). Women and Victimization: Contributing Factors, Interventions, and Implications. Washington, D.C.: American Psychological Association.

Lynch, S. M., Heath, N. M., Matthews, K. C., \& Cepeda, G. J. (2012). Seeking safety: An intervention for trauma-exposed incarcerated women? Journal of Trauma \& Dissociation, 13, p. 88-101. 
McDaniels- Wilson, C., \& Belknap, J. (2008). The extensive sexual violation and sexual abuse histories of incarcerated women. Violence Against Women, 14(10), p. 1090-1127.

Messina, N., Calhoun, S., \& Braithwaite, J. (2014). Trauma-informed treatment decreases posttraumatic stress disorder among women offenders. Journal of Trauma \& Dissociation, 15(1), p.6-23.

Messina, N., \& Grella, C. (2006). Childhood trauma and women's health outcomes in a California prison population. American Journal of Public Health, 96(10), p. 1842-1848.

Messman-Moore, T. \& Long, P. (2000). Child sexual abuse and revictimization in the form of adult sexual abuse, adult physical abuse and adult psychological maltreatment. Journal of Interpersonal Violence, 15(5), p.489-502.

Mitchell, M. D., Hargrove, G. L., Collins, M. P., Reddick, T. L., \& Kaslow, N. J. (2006). Coping variables that mediate the relation between intimate partner violence and mental health outcomes among low-income, African-American women. Journal of Clinical Psychology, 62(12), p.1503-1520.

National Center for Injury Prevention and Control (NCIPC). (2010). An overview of 'Intimate partner violence in the United States'- 2010 Findings. Retrieved from: http://www.cdc.gov/violenceprevention/pdf/ipv-nisvs-factsheet-v5-a.pdf.

National Center for Injury Prevention and Control (NCIPC). (2003). Costs of Intimate Partner Violence Against Women in the United States. Atlanta: Centers for Disease Control and Prevention.

Needle, R., Fisher, D., Weatherby, N. et al. (1995). Reliability of self-reported HIV risk behaviors of drug users. Psychology of Addictive Behaviors, 9, p. 242-250.

Nurius, P. S., \& Macy, R. J. (2010). Person-oriented methods in partner violence research: distinct biopsychosocial profiles among battered women. Journal of Interpersonal Violence, 25(6), p.1064-1093. 
Nurius, P. S., \& Macy, R. J. (2008). Heterogeneity among violence-exposed women: Applying person-oriented research methods. Journal of Interpersonal Violence, 23(3), p.389-415.

Peltan, J. R., \& Cellucci, T. (2011). Childhood sexual abuse and substance use treatment utilization among substance-dependent incarcerated women. Journal of Substance Abuse Treatment, 41, p. 215-224.

Peters, C. L.O., \& Enders, C. (2002). A primer for the estimation of structural equation models in the presence of missing data: Maximum likelihood algorithms. Journal of Targeting Measurement and Analysis for Marketing, 11(1), p.81-95.

Peters, E. N., Khondkaryan, E., \& Sullivan, T. (2012). Associations between expectancies of alcohol and drug use, severity of partner violence, and posttraumatic stress among women. Journal of Interpersonal Violence, 27(11), p. 2108-2127.

Pico-Alfonso, M. A., Garcia-Linares, M. I., Celda-Navarro, N., Blaso-Ras, C., Echeburua, E., \& Martinez, M. (2006). The impact of physical, psychological, and sexual intimate male partner violence on women's mental health: Depressive symptoms, posttraumatic stress disorder, state anxiety, and suicide. Journal of Women's Health, 15(5), p. 599-611.

Powers, A., Ressler, K. J., Bradley, R. (2009). The protective role of friendship on the effects of childhood abuse and depression. National Institute of Health: Depression Anxiety, 26(1), p.46-53.

Radloff, L. S. (1977). The CES-D Scale: A self-report depression scale for research in the generalpopulation. Applied Psychological Measurement, 1, 385-401.

Reichert, J., Adams, S., \& Bostwick, L. (2010). Victimization and help-seeking behaviors among female prisoners in Illinois. Illinois Criminal Justice Information Authority. Retrieved from: http://www.icjia.state.il.us.

Renner, L. M., \& Slack, K. S. (2006). Intimate partner violence and child maltreatment: Understanding intra- and intergenerational connections. Child Abuse \& Neglect, 30, p. 599-617. 
Richie, B. E. (2000). Exploring the link between violence against women and women's involvement in illegal activity. In Research on Women and Girls in the Justice System: Plenary Papers of the 1999 Conference on Criminal Justice Research and EvaluationEnhancing Policy and Practice Through Research, Volume 3. Washington, DC: National Institute of Justice.

Roodman, A. A., \& Clum, G. A. (2001). Revictimization rates and method variance: A metaanalysis. Clinical Psychology Review, 21(2), p.183-204.

Rosenberg, M. (1989). Society and the Adolescent Self-Image (Rev. ed). Middletown, CT: Wesleyan University Press.

Rosenberg, M. (1965). Society and the adolescent self-image. Princeton, NJ: Princeton University Press.

Rubin, A., \& Babbie, E. (2011). Research Methods for Social Work. Belmont: Brooks.

Salisbury, E.J., \& Van Voorhis, P. (2009). Gendered pathways: A quantitative investigation of women probationers' paths to incarceration. Criminal Justice and Behavior, 36(6), p.541566.

The Sentencing Project: Research and Advocacy for Reform. (2007). Women in the Criminal Justice System: Briefing Sheets. Washington DC: The Sentencing Project.

Sherbourne, C. D., \& Stewart, A. L. (1991). The MOS social support survey. Social Science Medicine, 32(6), p. 705-714.

Sitaker, M. (2007). The ecology of intimate partner violence: Theorized impacts on women's use of violence. Journal of Aggression, Maltreatment, \& Trauma, 15(3-4), p.179-219.

Soler, L., Kirchner, T., Paretilla, C., \& Forns, M. (2013). Impact of poly-victimization on mental health: The mediator and/or moderator role of self-esteem. Journal of Interpersonal Violence, 28(13), p. 2695-2712. 
Straus, M., Hambly, S.L., Bondey-McCoy, S., \& Sugarman, D.B. (1996). The revised conflict tactics scales (cts2): Development and preliminary psychometric data. Journal of Family Issues, 17(3), p.283-316.

Tesh, M., Learman, J., \& Pulliam, R. (2013). Mindful self-compassion strategies for survivors of intimate partner abuse. Mindfulness, DOI: 10.1007/s12671-013-0244-4

Testa, M., Livingston, J. A., \& Leonard, K. E. (2004). Women's substance use and experiences of intimate partner violence: A longitudinal investigation among a community sample. Research Institute on Addictions, 28, p. 04-2- 04-5.

Thomas, R., DiLillo, D., Walsh, K., \& Polusny, M. A. (2011). Pathways from child sexual abuse to adult depression: The role of parental socialization of emotions and alexithymia. Psychology of Violence, 1(2), p. 121-135.

Tjaden, P. \& Thoennes, N. (2000). Full report of the prevalence, incidence, and consequences of violence against women. U.S. Department of Justice: Office of Justice Programs, National Institure of Justice.

Tolman, R.M. (1989). The development of a measure of the psychological maltreatment of women by their male partners. Violence and Victims, 4(3), p.159-178.

Tripodi, S. J., \& Pettrus-Davis, C. (2013). Histories of childhood victimization and subsequent mental health problems, substance use, and sexual victimization for a sample of incarcerated women in the US. International Journal of Law and Psychiatry, 36, p.30-40.

U.S. Department of Health and Human Services, Administration for Children and Families, Administration on Children, Youth and Families, Children's Bureau. (2013). Child maltreatment 2012.

Warshaw, C., Sullivan, C. M., \& Rivera, E. A. (2013). A systematic review of trauma-focused interventions for domestic violence survivors. National Center on Domestic Violence, Trauma, \& Mental Health. 
Westbrook, L., \& Finn, J. (2012). Community information as boundary object: Police responsibility for abuse survivors. Journal of Documentation, 68(6), p. 806-825.

Whitfield, C. L., Anda, R. F., Dube, S.R., \& Felitti, V. J. (2003). Violent childhood experiences and the risk of intimate partner violence in adults: Assessment in a large health maintenance organization. Journal of Interpersonal Violence, 18(2), p.166-185.

Widom, C.S, \& Shepard, R. L. (1996). Accuracy of adult recollections of childhood victimization: Part 1. Childhood physical abuse. Psychological Assessment, 8(4), p.412421.

Widom, C. S., \& Morris, S. (1997). Accuracy of adult recollections of childhood victimization: Part 2. Childhood sexual abuse. Psychological Assessment 9(1), p.34-46.

Widom, C. S. (1997). Accuracy of adult recollections of early childhood abuse. Recollections of Trauma: Scientific Evidence and Clinical Practice, 291. p. 49-78.

Williams, M. L., Freeman, R. C., Bowen, A. M., Zhao, Z., Rusek, R., \& Signes, C. (2000). A comparison of the reliability of self-reported drug use and sexual behaviors using computer-assisted versus face-to-face interviewing. AIDS Education and Prevention, 12, p. 199-213.

Wolff, N., Frueh, B. C., Shi, J., \& Schumann, B. E. (2012). Effectiveness of cognitive-behavioral trauma treatment for incarcerated women with mental illnesses and substance abuse disorders. Journal of Anxiety Disorder, 26, p.703-710.

Zlotnick, C., Najavits, L. M., Rohsenhow, D. J., \& Johnson, D. M. (2003). A cognitivebehavioral treatment for incarcerated women with substance abuse disorder and posttraumatic stress disorder: Findings from a pilot study. Journal of Substance Abuse Treatment, 25, p.99-105. 
Appendix 1- Screening Form

Check One: Eligible ___ Not Eligible

\section{Screening Protocol for the Women's Health Research Study}

Interviewer: Thank you for being interested in participating in our study. I am going to tell you a little about the study and then I am going to ask you some questions that will tell us whether you are eligible to participate in this study. We call this process our screening procedure; this allows us to determine who is eligible to participate in the study. The whole thing shouldn't take us more than 10 minutes. Does that sound ok? [Probe for and address any questions.]

If you are eligible, the study you would be participating in is called the Women's Health Research Study. Generally speaking it is a study about victimization, substance use, and psychological distress (e.g. things like depression and anxiety) among women who are involved with the criminal justice system. If you are interested and eligible to participate in this study, you will be asked to participate in three separate interviews over a two year time period. During the interviews, a trained female staff person will be present to assist you in answering survey questions on a laptop computer. Each of the interviews will last about 3 hours. You will be asked a variety of questions related to victimization, substance use, psychological distress and other issues facing women in the criminal justice system. You will also be asked to provide information about your place of residence and the names and telephone numbers of up to five people most likely to know your whereabouts. This information is being collected so that we can more easily contact you for your follow-up interviews. Also, any of the data or information being collected during the course of the study is for research purposes only; no one participating in the study will be individually identified. Any questions about this? [Probe for and address any questions.]

If you are eligible and interested in participating in the Women's Health Research Study you will be compensated for your time. You can make up to $\$ 135$. You will be compensated $\$ 35$ for your 
first interview; $\$ 45$ for your second interview; and $\$ 55$ for your third interview. Do you have any questions about anything I have told you so far before we move on? [Probe for and address any questions.]

Ok, as I said, I am going to ask you several questions to determine whether you are eligible to participate in the study. Some of these questions will be related to victimization; for example whether you have ever experienced certain types of violence. I will not tell anyone else what you have told me as I am required to keep all information confidential. You are free to not answer any questions you do not wish to answer. In addition, you are free to not participate in the study and can withdraw (e.g. stop talking to me) at any time. Participation or lack of participation in this study will not affect any legal/criminal justice involvement you may have or your treatment at any agency. Just like in the larger study, the questions I am asking you are for research purposes only. Your screening data will be destroyed, with no questions asked, at your request. Do you have any questions? [Probe for and address any questions.] 
Interviewer's Name:

1. Date:

Method of Contact: Phone

In Person

2. Can you tell me your first, middle and last initials? [WE ARE NOT COLLECTING FULL NAMES FOR THE SCREENING. DO NOT WRITE DOWN A FIRST AND/OR LAST NAME. ]

[FIRST, MIDDLE, AND LAST INITIALS]

3. How old are you? [DO NOT COLLECT BIRTHDATES.]

[IF YOUNGER THAN 18 YEARS OLD, SHE IS NOT ELIGIBLE. TERMINATE SCREENING AND INFORM HER THAT SHE IS NOT ELIGIBLE. ]

4. How did you hear about the study? [CHECK ALL THAT APPLY.]

Flyer

Direct Contact w/Study

Direct Mail

PO or other law enforcement $\square$ Location of reporting office:

Community-based organization (e.g. VOA, Wayside) $\boldsymbol{\square}$ Identify:

Newspaper, radio, internet $\square$ Source:

Other $\boldsymbol{\square}$ Describe:

5. Are you currently sentenced to probation or parole under the Kentucky Department of Correction?

口YES $\quad$ WNO [If YES, proceed to the next question.] 
- Which? Probation or Parole

[Mark an $\mathrm{X}$ next to the correct sentence option.]

- Location of her reporting office:

[IF NOT CURRENTLY ON PROBATION OR PAROLE, SHE IS NOT ELIGIBLE. TERMINATE SCREENING AND INFORM HER THAT SHE IS NOT ELIGIBLE. ] 
6. Were you born a female? [If YES, proceed to the next question. If NO, she is not eligible. TERMINATE SCREENING AND INFORM HER THAT SHE IS NOT ELIGIBLE.]

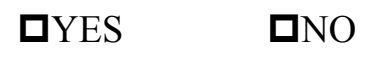

7. Now I am going to ask you a question about sexual or intimate relationships you currently have and those you might have had in the past. When you have sex, do you typically have sex with [CHECK ALL THAT APPLY]:

men only [If YES, proceed to question \#8.]

women only [If YES, proceed to question \#7a.]

both men and women [If YES, proceed to question \#7a.]

7a. During the past year, have you had sex with a partner of the opposite sex (i.e. a man)?

DYES $\quad$ DNO

[FOR A WOMAN WHO WAS INCARCERATED IN THE PRIOR YEAR OR WHO HAS BEEN OUT OF PRISON/JAIL FOR LESS THAN 30 DAYS:]

During the year prior to your incarceration, did you have sex with a partner of the opposite sex?

DYES $\quad$ पNO

[If YES to either 7 or 7 a, proceed to the next question. If she reports NOT having sex with a man/only having sex with women, she is not eligible. TERMINATE SCREENING AND INFORM HER THAT SHE IS NOT ELIGIBLE.]

8. Now I am going to ask you some questions that pertain to violence that you may have experienced in your life time.

\begin{tabular}{|l|l|}
\hline & $\begin{array}{l}\text { Circle the correct } \\
\text { Response }\end{array}$ \\
\hline
\end{tabular}




\begin{tabular}{|c|c|c|}
\hline \multicolumn{3}{|c|}{$\begin{array}{l}\text { Interviewer: Did any of the following ever happened to you as a child (age } 18 \text { or under) } \\
\text { by your parents or other caretakers? }\end{array}$} \\
\hline $\begin{array}{l}\text { Physically hurt you on purpose (including grabbing, slapping, } \\
\text { burning, scalding, punching, choking, throwing you around, } \\
\text { or harshly spanking you)? }\end{array}$ & YES & NO \\
\hline Beat you up? & YES & $\mathrm{NO}$ \\
\hline $\begin{array}{l}\text { Used a knife or gun or some other thing (like a club or a bat) } \\
\text { to get something from you? }\end{array}$ & YES & $\mathrm{NO}$ \\
\hline $\begin{array}{l}\text { Attacked you with a weapon in their hands and you were } \\
\text { afraid they wanted to injure, rape or kill you? }\end{array}$ & YES & $\mathrm{NO}$ \\
\hline $\begin{array}{l}\text { Forced or threatened you to do sexual things other than sexual } \\
\text { intercourse (e.g. forced petting, forced oral sex)? }\end{array}$ & YES & $\mathrm{NO}$ \\
\hline $\begin{array}{l}\text { Forced or threatened you to have sexual intercourse but it did } \\
\text { not actually occur? }\end{array}$ & YES & $\mathrm{NO}$ \\
\hline $\begin{array}{l}\text { Forced or threatened you to have sexual intercourse and it } \\
\text { actually happened? }\end{array}$ & YES & NO \\
\hline \multicolumn{3}{|c|}{$\begin{array}{l}\text { Interviewer: Now I'm going to ask you if any people other than your parents or } \\
\text { caretakers have done things to you (over age } 18 ; 19 \text { and above). In this section, I am } \\
\text { specifically asking you about your intimate partners (like a boyfriend or husband) and } \\
\text { about people other than your intimate partner, parents, and/or caretakers (like an uncle, } \\
\text { friend, co-worker, acquaintance, or stranger). }\end{array}$} \\
\hline $\begin{array}{l}\text { Physically hurt you on purpose (including grabbing, slapping, } \\
\text { burning, scalding, punching, choking, or throwing you } \\
\text { around)? }\end{array}$ & YES & NO \\
\hline Beat you up? & & \\
\hline
\end{tabular}




\begin{tabular}{|l|ll|}
\hline & YES & NO \\
\hline $\begin{array}{l}\text { Forced or threatened you to do sexual things other than sexual } \\
\text { intercourse (e.g. forced petting, forced oral sex)? }\end{array}$ & YES & NO \\
\hline $\begin{array}{l}\text { Forced or threatened you to have sexual intercourse and it } \\
\text { actually happened? }\end{array}$ & YES & NO \\
\hline
\end{tabular}

In order to be eligible for participation, a woman must meet ALL the following criteria [Indicate the appropriate response next to each criteria]:

\begin{tabular}{|l|ll|}
\hline$>$ be 18 or older and born female; & 口YES & 口NO \\
\hline$>\begin{array}{l}\text { in response to Question \#7, they must } \\
\text { report typically having sex with men } \\
\text { only OR if they report sex with women } \\
\text { only or both men and women, they } \\
\text { must report having sex with a person } \\
\text { of the opposite sex (i.e. a man) in the } \\
\text { past 12 months; }\end{array}$ & 口YES & 口NO \\
\hline $\begin{array}{l}\text { they are under probation or parole with } \\
\text { the KY Department of Corrections; }\end{array}$ & 口YES & 口NO \\
\hline $\begin{array}{l}\text { they have an affirmative response to at } \\
\text { least ONE type of victimization in } \\
\text { Question \#8 }\end{array}$ & DYES & 口NO \\
\hline
\end{tabular}

\section{For Eligible Participants:}

Interviewer: Thank you for taking the time to talk to us today. You are eligible to participate in the study. Given what I have told you about the study so far, are you still interested in participating? Do you have any more questions? Ok, then let's schedule you for your first interview. [FOLLOW SCHEDULING PROCEDURES]

\section{For Women who are NOT Eligible:}


Interviewer: Thank you for taking the time to talk to us today. Due to the nature of the study we are looking for women who meet specific criteria for inclusion. These criteria are related to age, gender, patterns of sexual behavior, lifetime experiences of victimization and being on probation and parole. Unfortunately, you do not meet one or more of the criteria needed for inclusion in the study. Do you have any questions about any of this? Thanks again for taking the time to talk to us today.

If questioned, potential explanation for same sex relationship: The study is looking at violence in intimate relationships between men and women only. 
Appendix 2- Victimization and Age Data Report of Women Screened Eligible

\section{PARENT/CARETAKER VIOLENCE}

VIC 1- Physically hurt you on purpose (including grabbing, slapping, burning, scalding, punching, choking, throwing you around, or harshly spanking you)

\begin{tabular}{|l|l|l|}
\hline Yes & No & Total \\
\hline $\mathrm{N}=314$ & $\mathrm{~N}=203$ & $\mathrm{~N}=517$ \\
$60.74 \%$ & $39.26 \%$ & \\
\hline
\end{tabular}

VIC 2- Beat you up

(Of the 517 total screening forms, only 516 responses were recorded for VIC 2)

\begin{tabular}{|l|l|l|}
\hline Yes & No & Total \\
\hline $\mathrm{N}=209$ & $\mathrm{~N}=306$ & $\mathrm{~N}=515$ \\
\hline & $59.58 \%$ & \\
\hline
\end{tabular}

VIC 3- Used a knife or a gun or some other thing (like a club or a bat) to get something from you

\begin{tabular}{|l|l|l|}
\hline Yes & No & Total \\
\hline $\mathrm{N}=105$ & $\mathrm{~N}=412$ & $\mathrm{~N}=517$ \\
\hline
\end{tabular}




\begin{tabular}{|l|l|l|}
\hline $20.31 \%$ & $79.69 \%$ & \\
& & \\
\hline
\end{tabular}

VIC 4- Attacked you with a weapon in their hands and you were afraid they wanted to injure, rape, or kill you

\begin{tabular}{|l|l|l|}
\hline Yes & No & Total \\
\hline $\mathrm{N}=147$ & $\mathrm{~N}=370$ & $\mathrm{~N}=517$ \\
\hline $28.43 \%$ & $71.57 \%$ & \\
\hline
\end{tabular}

VIC 5- Forced or threatened you to do sexual things other than sexual intercourse (e.g. forced petting, forced oral sex)

(Of the 517 total screening forms, only 516 responses were recorded for VIC 5)

\begin{tabular}{|l|l|l|}
\hline Yes & No & Total \\
\hline $\mathrm{N}=189$ & $\mathrm{~N}=327$ & $\mathrm{~N}=516$ \\
\hline $36.63 \%$ & $63.37 \%$ & \\
\hline
\end{tabular}

VIC 6- Forced or threatened you to have sexual intercourse but it did not actually occur (Of the 517 total screening forms, only 514 responses were recorded for VIC 6)

\begin{tabular}{|l|l|l|}
\hline Yes & No & Total \\
\hline $\mathrm{N}=143$ & $\mathrm{~N}=371$ & $\mathrm{~N}=514$ \\
\hline $27.82 \%$ & $72.18 \%$ & \\
\hline
\end{tabular}


VIC 7- Forced or threatened you to have sexual intercourse and it actually happened (Of the 517 total screening forms, only 515 responses were recorded for VIC 7)

\begin{tabular}{|l|l|l|}
\hline Yes & No & Total \\
\hline $\mathrm{N}=168$ & $\mathrm{~N}=347$ & $\mathrm{~N}=515$ \\
\hline $32.62 \%$ & $67.38 \%$ & \\
\hline
\end{tabular}

\section{NON-CARETAKER/PARENT VIOLENCE}

VIC 8- Physically hurt you on purpose (including grabbing, slapping, burning, scalding, punching, choking, or throwing you around)

\begin{tabular}{|l|l|l|}
\hline Yes & No & Total \\
\hline $\mathrm{N}=466$ & $\mathrm{~N}=51$ & $\mathrm{~N}=517$ \\
\hline $90.14 \%$ & $09.87 \%$ & \\
\hline
\end{tabular}

VIC 9- Beat you up

\begin{tabular}{|l|l|l|}
\hline Yes & No & Total \\
\hline $\mathrm{N}=425$ & $\mathrm{~N}=92$ & $\mathrm{~N}=517$ \\
\hline $82.21 \%$ & $17.80 \%$ & \\
\hline
\end{tabular}

VIC 10- Forced or threatened you to do sexual things other than sexual intercourse (e.g. forced petting or forced oral sex)

\begin{tabular}{|l|l|l|}
\hline Yes & No & Total \\
\hline $\mathrm{N}=294$ & $\mathrm{~N}=223$ & $\mathrm{~N}=517$ \\
\hline
\end{tabular}




\begin{tabular}{|l|l|l|}
\hline $56.87 \%$ & $43.13 \%$ & \\
& & \\
\hline
\end{tabular}

VIC 11- Forced or threatened you to have sexual intercourse and it actually happened

\begin{tabular}{|l|l|l|}
\hline Yes & No & Total \\
\hline $\mathrm{N}=345$ & $\mathrm{~N}=172$ & $\mathrm{~N}=517$ \\
\hline $66.73 \%$ & $33.27 \%$ & \\
\hline
\end{tabular}

VIC 12- Stalked or obsessively pursued you when you did not want them to (Of 517 total, only 84 answers were recorded. The screening form was changed shortly after the screening process began, and this screening question was removed from form)

\begin{tabular}{|l|l|l|}
\hline Yes & No & Total \\
\hline $\mathrm{N}=65$ & $\mathrm{~N}=19$ & $\mathrm{~N}=84$ \\
\hline $77.38 \%$ & $22.61 \%$ & \\
\hline
\end{tabular}

AGE:

Of 517 screening forms completed, 516 were recorded.

\begin{tabular}{|l|l|l|l|l|l|}
\hline Total & Min & Max & Mean & Median & Mode \\
\hline $\mathrm{N}=516$ & 18 & 72 & 36 & 36 & 31 \\
& & & $(19,009 / 516=$ & & \\
& & & $36.8391)$ & & \\
\hline
\end{tabular}


Appendix 3- Final Recruitment Data Report

\section{Recruitment Data}

Women were recruited through a number of methods. Breakdown of recruitment methods are as follows ${ }^{45}$ :

\begin{tabular}{|l|l|l|}
\hline Form of Recruitment: & & $\%$ \\
\hline Flyer & 75 & $14.51 \%$ \\
\hline Direct Mail & 170 & $32.88 \%$ \\
\hline Direct Contact & 48 & $09.28 \%$ \\
\hline Community Based Organization & 58 & $10.60 \%$ \\
\hline News/Radio/Internet & 12 & $02.32 \%$ \\
\hline $\begin{array}{l}\text { Other (Mother, Friend, PO, Cousin, } \\
\text { Co-worker) }\end{array}$ & 154 & $32.79 \%$ \\
\hline
\end{tabular}

\section{$\underline{\text { Screening Data }}$}

Total:

45 Participants could identify more than one form of recruitment method, thus these numbers will not equal to the total number of participants screened.

Referral coupons accounted for 4 of the total "other" category. 
From the direct mailing recruitment method, breakdown of screening information is as follows:

\begin{tabular}{|l|l|l|}
\hline From Direct Mail Total: & N & $\%$ \\
\hline Screened Eligible & 170 & $83.74 \%$ \\
\hline Screened Ineligible & 33 & $16.26 \%$ \\
\hline
\end{tabular}

Screening method ${ }^{46}$ :

\begin{tabular}{|l|l|l|}
\hline Screening Method: & $\mathrm{N}$ & $\%$ \\
\hline Phone & 568 & $89.72 \%$ \\
\hline In-Person & 65 & $10.28 \%$ \\
\hline
\end{tabular}

Eligibility status based on type of screening:

\begin{tabular}{|l|l|l|}
\hline Screening Data: & N & $\%$ \\
\hline Total Screened & 636 & $100 \%$ \\
\hline Total Screened Eligible & 517 & $81.41 \%$ \\
\hline Total Screened Ineligible & 119 & $18.58 \%$ \\
\hline
\end{tabular}

\begin{tabular}{|l|l|l|}
\hline Phone Screen Data: & N & $\%$ \\
\hline Eligible & 455 & $80.25 \%$ \\
\hline
\end{tabular}

46 Three screening forms are unknown whether they were conducted in person or in phone thus there is a discrepancy with total here and complete total above. 


\begin{tabular}{|l|l|l|}
\hline Ineligible & 113 & $19.75 \%$ \\
\hline
\end{tabular}

\begin{tabular}{|l|l|l|}
\hline In-Person Data: & $\mathrm{N}$ & $\%$ \\
\hline Eligible & 59 & $90.77 \%$ \\
\hline Ineligible & 6 & $9.23 \%$ \\
\hline
\end{tabular}

\section{Ineligible Screening Data:}

\begin{tabular}{|l|l|l|}
\hline Reason for Ineligibility & N & $\%$ \\
\hline No History of Victimization & 31 & $26.05 \%$ \\
\hline $\begin{array}{l}\text { Not currently on } \\
\text { Probation/Parole }\end{array}$ & 41 & $34.45 \%$ \\
\hline Women Partners Only & 26 & $21.85 \%$ \\
\hline $\begin{array}{l}\text { Wrong type of } \\
\text { Probation/Parole (Not on p/p } \\
\text { Cefferson County or on } \\
\text { Conditional Discharge) }\end{array}$ & 20 & $16.81 \%$ \\
\hline $\begin{array}{l}\text { Distressed during } \\
\text { screening/Terminated }\end{array}$ & 1 & $0.01 \%$ \\
\hline
\end{tabular}

\section{Self-Select Out /Partial Screening Data:}

Regardless of Eligibility status, 4 women self-selected out of the study, and 3 partial screenings were unable to complete for unspecified reasons. These 7 were not counted in above totals.

47 Total of 119 instead of 118 because one screening form reported two ineligibility statuses. 
Appendix 4- Informed Consent

\title{
Subject Informed Consent Document Victimization and Women in the Criminal Justice System
}

\author{
Sponsor assigned number: 1 R01 DA027981-01A2 Grant assigned number: IRB assigned \\ number: Industry Contracts number: OGMB100085 Sponsor(s) name \& address: National \\ Institute on Drug Abuse, 9000 Rockville Pike, Bethesda, MD, 20892. \\ Investigator(s) names \& addresses: Drs. Seana Golder and George Higgins; University of \\ Louisville, Louisville, KY Site(s) where study is to be conducted: Private or public setting to be \\ chosen by participant, (e.g., private office at the University of Louisville, a private room within \\ their home, or a private office within a community agency), or if incarcerated at follow-up, place \\ of incarceration.
}

Phone number for subjects to call for questions: (502) 852-0432, (502) 852-3743

\section{Introduction and Background Information}

You are invited to participate in a research study. The study is being conducted by Seana Golder, M.S.W., Ph.D., Principal Investigator and Investigator, George Higgins, Ph.D. The study is sponsored by the National Institute on Drug Abuse and the University of Louisville, Kent School of Social Work. The study will take place in a public or private location of your choice in the Louisville, KY area or if incarcerated at follow-up, at the place of incarceration. Approximately 410 subjects will be invited to participate.

\section{Purpose}

The purpose of this study is to examine victimization, substance use, and psychological distress among women on probation and parole.

\section{Procedures}

In this study, you will be asked to participate in three separate interviews over a two year time period. During the interviews, a trained female staff person will be present to assist you in 
answering survey questions on a laptop computer. Each of the interviews will last about 3 hours. You will be asked questions about your age, race/ethnicity, education, marital status, socioeconomic status, and parenting status.

In addition you will be asked questions related to a range of issues listed below (examples of questions are also provided):

self-esteem: ( "I feel that I have a number of good qualities"); perceived control: ( "Are some people just born lucky?"); physical health: "In general, would you say your health is: excellent, very good, good, fair, or poor?"); lifetime experiences of victimization: This includes questions about the age of first occurrence, number of different people (parents/caretakers, boyfriends/intimate partners, and strangers, acquaintances, and other relatives that victimized you, and an estimate of the number of times the abuse (e.g., psychological, physical, and sexual abuse as well as stalking) occurred; social support: ("How often is someone available to help you if you were confined to bed?'); your use of formal services such as medical, legal, psychological, employment and other services: (e.g., food, housing, transportation); what your friends and family think about safer sex practices and the criminal justice system: ("How many of your girlfriends use a condom most of the time when they have sex?" "How many of your friends/family members talk about their involvement in the criminal justice system (e.g., like visiting a probation/parole officer; time spent in jail or prison; being arrested; etc..)?"; financial, housing and spiritual issues: ("How often have you had difficulty paying for current expenses for (e.g., food, clothing, transportation etc...) in the past year?"; "Do you consider yourself homeless?"; "My relation with God contributes to my sense of well- being."); participation in social activities: (including 12-step programs such as AA, NA, and CA, cultural and sports attendance, religious involvement, outdoor activities, studying, reading books, listening to recorded music, singing, photography, painting, or collecting); relationships with other people: ("I am comfortable depending on others"), community involvement: ("How often to you participate in a neighborhood cleanup?"), stressful experiences: ("Have you, your partner, your child(ren), relative or close friend been in a serious accident or injured?"); loss of resources: ("Have you recently lost a job?"); coping: (“How you generally feel and/or act when they experience a difficult or stressful event?); use of prescription and other drugs; psychological distress: (“About how often did you feel restless or fidgety?"); sexual behavior: (Number of different sexual partners; condom use; number of acts of vaginal and/or anal sex); lawbreaking: ("Purposely damaged or destroyed something that did not belong to you?"); criminal justice involvement: ("How long they have been on your current probation/parole assignment?").

Finally, so that we can find you more easily for the follow-up interviews, you will be asked to provide information about your place of residence and the names and telephone numbers of people most likely to know your whereabouts. In addition, we will also ask you to providethe names and telephone numbers for different agencies or organizations that you might be involved with; again, this information will only be used to help us to find you for follow-up interviews should we not be able to reach you at the address(s)/telephone number(s) you have provided.

We will also call you and/or send you a card (e.g. thank you, birthday, holiday, greetings) approximately four times between each interview. We are doing this to help us stay in contact 
with you between interviews.

We will use publically available information to search for you should we not be able to find you via the locator information. In some cases, we may come to your residence to personally deliver study correspondence if we are having difficulty contacting you through other methods.

You are free to decline to answer any questions that may make you uncomfortable.

\section{Potential Risks}

There are risks associated with participation in this study. There are psychological (emotional) risks. For example, you may become embarrassed by or be uncomfortable with some of the questions. As stated above, you are free to decline to answer any questions that may make you uncomfortable. There is a risk that participating in the study could lead to a breach in confidentiality. This means people could learn of your participation in the study. We are taking several steps to safeguard your confidentiality and the confidentiality of any information you provide. In addition, some of the information on illicit drug use or other illegal behaviors could be incriminating. However, prior experience of the research team with other similar studies has not resulted in any legal risk to participants. Furthermore, extensive safeguards have been implemented to protect the confidentiality of your information.

To help us protect your privacy, we have obtained a Certificate of Confidentiality from the National Institutes of Health. With this Certificate, the researchers cannot be forced to disclose information that may identify you, even by a court subpoena, in any federal, state, or local civil, criminal, administrative, legislative, or other proceedings. The researchers will use the Certificate to resist any demands for information that would identify you, except as explained below.

The Certificate cannot be used to resist a demand for information from personnel of the United States Government that is used for auditing or evaluation of Federally funded projects or for information that must be disclosed in order to meet the requirements of the federal Food and Drug Administration (FDA).

You should understand that a Certificate of Confidentiality does not prevent you or a member of your family from voluntarily releasing information about yourself or your involvement in this research. If an insurer, employer, or other person obtains your written consent to receive research information, then the researchers may not use the Certificate to withhold that information.

The Certificate of Confidentiality does not prevent the researchers from disclosing voluntarily, without your consent, information that would identify you as a participant in the research project if we learn about "imminent harm to self or others" including cases where there is sexual or physical abuse of a child. In these cases, we may take steps to protect the person or persons endangered even if it required telling authorities without your permission. However, we would only disclose information to the extent necessary to prevent harm to the person or persons believed to be endangered. 
There may also be unforeseen risks that cannot be anticipated.

\section{Benefits}

The possible benefits of this study include the receipt of referral information and potentially an increased awareness of your health seeking behaviors. In addition, research results may lead to information about and interventions for victimized women in the criminal justice system. The information collected may not benefit you directly. The information learned in this study may be helpful to other women in the criminal justice system.

\section{Compensation}

You will be compensated for your time and inconvenience for your participation in this study. You will be compensated $\$ 35$ for your first interview; $\$ 45$ for your second interview; and $\$ 55$ for your third interview. Compensation for participation will be prorated in the event that you withdraw before completion of the study.

Because you will be paid to be in this study the University of Louisville must collect your name, address, social security number, ask you to sign a W-9 form, and keep records of how much you are paid. You may or may not be sent a Form 1099 by the University. This will only happen if you are paid $\$ 600$ or more in one year by the University. We are required by the Internal Revenue Service to collect this information and you may need to report the payment as income on your taxes.

This information will be protected and kept secure in the same way that we protect your other private information. If you do not agree to give us this information, we can't pay you for being in this study. You can still be in the study even if you don't want to be paid.

\section{Confidentiality}

Total privacy cannot be guaranteed. Your privacy will be protected to the extent permitted by law. The researchers can disclose, without your consent, information that would identify you as a participant in the research project if we learn about "imminent harm to self or others" including cases where there is sexual or physical abuse of a child. In these cases, we may take steps to protect the person or persons endangered even if it required telling authorities without your permission. However, we would only disclose information to the extent

necessary to prevent harm to the person or persons believed to be endangered. If the results from this study are published, your name will not be made public. While unlikely, the following may look at the study records:

The sponsor, National Institutes of Health, National Institute on Drug Abuse, The University of 
Louisville Institutional Review Board, Human Subjects Protection Program Office, and others involved with research administration, People who make sure that billing is submitted correctly.

We are taking extensive steps to safeguard your confidentiality and the confidentiality of any information you provide. First, safeguarding confidentiality of personal information from interviews is maintained through use of special computer software (QDS) on the laptops used during interviews to record your responses. This computer software will encrypt (coded so that no one without a password can read) responses and password-protect questionnaires so that unauthorized users are unable to view, export, or modify collected data. Only study personnel will know the password and have access to the information from your interviews.

Second, your name will be removed from your interview information to further protect from any lapse in confidentiality. A list linking code number to name will be kept in an encrypted, password protected, and firewall protected computer and be accessible only by study personnel . The list linking names to numbers cues will be destroyed at the end of the study. Data analysis and reporting will not include any individually identifiable information.

Third, the information collected to help us locate you and schedule your follow-up interviews (participant's name, contact information, dates of participation, scheduled dates of follow-up) will be entered into a master file on the computer. This follow-up data file will not have subject identification numbers to prevent linking it with the main computer file with information from your interviews. The follow-up data file will be kept in encrypted, password protected, and firewall protected computers only. Only study personnel will have access to this file.

\section{Conflict of Interest}

This study does not involve a direct conflict of interest. The University will receive support to conduct the study from the National Institute of Drug Abuse, but the investigators will not be paid for your participation.

\section{Voluntary Participation}

Taking part in this study is voluntary. You may choose not to take part at all. If you decide to be in this study, you may stop taking part at any time. If you decide not to be in this study or if you stop taking part at any time, you will not lose any benefits for which you may qualify. You will be told about any changes that may affect your decision to continue in the study. The individuals conducting the study may need to withdraw you from the study. This may occur if you are not able to follow the directions they give you, if they find that your being in

the study is more risk than benefit to you, or if the agency funding the study decides to stop the study early for a variety of scientific reasons. 


\section{Research Subject's Rights, Questions, Concerns, and Complaints}

If you have any concerns or complaints about the study or the study staff, you have three options.

You may contact the principal investigator, Dr. Seana Golder, at 502-852-0432.

If you have any questions about your rights as a study subject, questions, concerns or complaints, you may call the Human Subjects Protection Program Office (HSPPO) (502) 852-5188. You may discuss any questions about your rights as a subject, in secret, with a member of the Institutional Review Board (IRB) or the HSPPO staff. The IRB is an independent committee composed of members of the University community, staff of the institutions, as well as lay members of the community not connected with these institutions. The IRB has reviewed this study.

If you want to speak to a person outside the University, you may call 1-877-852-1167. You will be given the chance to talk about any questions, concerns or complaints in secret. This is a 24 hour hot line answered by people who do not work at the University of Louisville.

This paper tells you what will happen during the study if you choose to take part. Your signature means that this study has been discussed with you, that your questions have been answered, and that you will take part in the study. This informed consent document is not a contract. You are not giving up any legal rights by signing this informed consent document. You will be given a signed copy of this paper to keep for your records.

Printed Name of Subject/Legal Representative Date Signed

Signature of Subject/Legal Representative Date Signed

Signature of Person Explaining the Consent Form Date Signed

(if other than the Investigator)

Signature of Investigator

Date Signed

LIST OF INVESTIGATORS

Seana Golder, MSW, PhD George Higgins, PhD
PHONE NUMBERS

502-852-0432, 502-852-3743

502-852-0331 
CURRICULUM VITAE

Amanda Dishon Brown

\begin{tabular}{|c|c|}
\hline \multicolumn{2}{|c|}{} \\
\hline University Contact: & Personal Contact: \\
\hline University of Louisville & 189 Locust Drive \\
Kent School of Social Work & Taylorsville, KY 40071 \\
Louisville, KY 40292 & (502) 489-2565 (cell) \\
(502) 489-2565 (cell) & kybrown8486@gmail.com \\
ajdish01@1louisville.edu & \\
\hline
\end{tabular}

\section{EDUCATION}

\begin{tabular}{|c|c|c|c|}
\hline 2014 & Doctoral Candidate & Social Work & $\begin{array}{c}\text { University of Louisville, } \\
\text { Louisville, KY }\end{array}$ \\
\hline 2011 & M.S.S.W. & $\begin{array}{l}\text { Social Work/ } \\
\text { Marriage and Family Therapy }\end{array}$ & $\begin{array}{c}\text { University of Louisville, } \\
\text { y Louisville, KY }\end{array}$ \\
\hline 2008 & B.A. & $\begin{array}{l}\text { Psychology/ } \\
\text { Women and Gender Studies }\end{array}$ & $\begin{array}{c}\text { University of Louisville, } \\
\text { Louisville, KY }\end{array}$ \\
\hline
\end{tabular}

\section{EMPLOYMENT HISTORY}

\section{Funded Research Positions}

2010-Present Data Analyst, Women's Health Research Study (R01DA27981)

Kent School of Social Work, University of Louisville

Louisville, KY

Analyzing data for publication collected through a NIH funded grant examining experiences of cumulative victimization, substance use, and psychological distress among women in the criminal justice system

2011-2013 Graduate Research Assistant, Women's Health Research Study (R01DA27981) Kent School of Social Work, University of Louisville Louisville, KY

Worked closely with the PI to develop recruitment, screening, and interviewing protocols/procedures; Lead screener of respondents during recruitment efforts; Lead recruitment team collaborating with community leaders, organizations, and individuals in urban settings; Conducted interviews and collected data in the 
community; Data analysis for publication and screening/recruitment summarization reports

2010-2011 Interviewer, Women's Health Research Study (R01DA27981)

Kent School of Social Work, University of Louisville

Louisville, KY

Collected data by conducting interviews in the community with participants, including the implementation of informed consent process and limits of confidentiality. Provided continued assessment of respondent's ability to participate in face-to-face surveys

2011 Research Assistant, Creating Healthy Adolescents through Meaningful Prevention Services (CHAMPS!)

Kent School of Social Work, University of Louisville

Louisville, KY

Coordinated planning of participant workshops including facilitator preparation, and implementation of the randomization process of respondent participation

2008-2009 Research Assistant

Department of Sociology, University of Louisville

Louisville, KY

Transcribed face-to-face qualitative interviews for PI

\section{Teaching Positions}

Fall 2014 Human Behavior in the Social Environment (HBSE) I

Bachelor's program

Kent School of Social Work

Spring 2015 Human Behavior in the Social Environment (HBSE) II

Bachelor's Program

Kent School of Social Work

Fall $2014 \quad$ Foundation Practice I

Distance Learning Sequence

Master's Program

Kent School of Social Work

Spring 2015 Foundation Practice II

Distance Learning Sequence

Master's Program

Kent School of Social Work

Fall $2012 \quad$ Psychopathology

Master's Program

Kent School of Social Work

\section{Training Positions}

2013- Present Kentucky Ethics, Supervision, and Law 
Continuing Education Units

Kentucky Association of Marriage and Family Therapy

Six hour state approved licensure requirement course offered quarterly per

calendar year throughout the state

\section{Clinical Positions}

2013-Present Certified Social Worker/ Marriage and Family Therapy Associate

Seven Counties Services

Louisville, KY

Conduct individual, family, and collateral therapeutic services for clients and their families with intellectual/developmental disabilities and co-occurring mood or behavior disorders; Perform assessments including intake, diagnosis, treatment plan; Utilize Cognitive Behavior Therapy, Solution Focused, Systems, Structural, and Emotionally Focused Therapy techniques of intervention in a community mental health agency

2012-Present Marriage and Family Therapy Associate Three Hearts Counseling Louisville, KY

Provide therapy to individual, family, and couples with anxiety, depression, addiction, and trauma/sexual abuse histories in a private practice setting

2012-2013 Marriage and Family Therapy Associate

Family Ministries

Archdiocese of Louisville, KY

Conducted therapy for individuals and couples through community mental health outreach agency

2010-2011 Social Work/ Marriage and Family Therapy Intern Seven Counties Services Louisville, KY Facilitated client-centered individual and family therapy for children (age 6-18) with reactive attachment, ADD/ADHD, Acute Stress, anxiety, depression, and behavioral health problems; Co-led Protective Parenting Group

2009-2010 Social Work/ Marriage and Family Therapy Intern Home of the Innocents Louisville, KY Led Cornerstone men's group therapy for young adults transitioning to independent living; Facilitated individual, family, and group therapy for culturally diverse adolescent girls who were pregnant/parenting with anxiety, depression, ODD, PTSD, and trauma

\section{PUBLICATIONS}

\section{Peer-Reviewed Journal Articles}


Golder, S., Hall, M., Logan, TK., Higgins, G., Dishon, A., Renn, T., \& Winham, K. (2014). Examining substance use among victimized women on probation and parole. Substance Use and Misuse, 49, 435-447.

Jewell, J. R.; Collins, K.V.; Gargotto, L.; \& Dishon, A. J. (2009). Building the unsettling force: Social workers and the struggle for human rights. Journal of Community Practice, 17(3), 309-322. doi 10.1080/10705420903130471

\section{In Review}

Winham, K., Golder, S., Brown, A., \& Renn, T., Higgins, G. E., Logan, T K. (2014). Psychological and social predictors of HIV risk behaviors among victimized women on probation and parole. Under review.

\section{Manuscripts In Process}

Dishon, A., Golder, S., Renn, T., Winham, K. \& Logan, TK. Understanding the occurrence of intimate partner violence, prior victimization, coping, substance use and attachment among a high-risk population of women.

Renn, T., Golder, S., Dishon, A., \& Winham, K. Health decision making among women on probation and parole: Self-reported health status and service utilization.

\section{Conference Presentations}

\section{State Conferences}

Clapper, D., \& Dishon-Brown, A. (February 2015). Kentucky supervision workshop at the 2015 KAMFT Division Annual Conference: Kentucky Association of Marriage and Family Therapy.

Clapper, D., \& Dishon-Brown, A. (February 2015). Kentucky law workshop at the 2015 KAMFT Division Annual Conference: Kentucky Association of Marriage and Family Therapy.

Dishon-Brown, A. (February 2015). The pre-clinical fellow experience: Implementing a professional roadmap for success workshop at the 2015 KAMFT Division Annual Conference: Kentucky Association of Marriage and Family Therapy. 
Clapper, D., \& Dishon-Brown, A. (February 2014). Kentucky supervision workshop at the 2014 KAMFT Division Annual Conference: Kentucky Association of Marriage and Family Therapy.

Clapper, D., \& Dishon-Brown, A. (February 2014). Kentucky law workshop at the 2014 KAMFT Division Annual Conference: Kentucky Association of Marriage and Family Therapy.

Karam, E., \& Dishon-Brown, A. (February 2014). The pre-clinical fellow experience: Navigating tough terrain towards licensure workshop at the 2014 KAMFT Division Annual Conference: Kentucky Association of Marriage and Family Therapy.

Karam, E., \& Dishon, A. (February 2013). Journey to pre-clinical fellow workshop at the 2013 KAMFT Division Annual Conference: Kentucky Association of Marriage and Family Therapy.

Sheldon, P., Miller, S., \& Dishon, A. (February 2012). Surviving graduation to licensure and beyond workshop at the 2012 KAMFT Division Annual Conference: Kentucky Association of Marriage and Family Therapy.

Dishon, A., Renn, T., \& Golder, S. (February 2012). A descriptive analysis of lifespan victimization among women on probation and parole:

Preliminary data and findings from the women's health research study. Poster Presentation at the Kentucky Association of Social Work Educators Spring Conference: University of Kentucky School of Social Work.

\section{National Conferences}

Renn, T., Golder, S., Winham, K.M., Dishon-Brown, A., Higgins, G.E., \& Logan, T. (October, 2014). Childhood victimization, health behaviors and health outcomes in adulthood: A mediated relationship. Paper presentation at the Annual Program Meeting: Council on Social Work Education, Tampa, FL.

Dishon, A., Renn, T., Winham, K., Golder, S., \& Logan, TK. (November 2013). Psychological distress, self-esteem, and child victimization: A SEM mediation model. Paper presentation at the Expanding the Core: Neglected Crimes, Groups, Causes and Policy Approaches Conference: American Society of Criminology, $69^{\text {th }}$ Annual Meeting. Atlanta, GA.

Renn, T., Golder, S., Dishon, A., Winham, K., Logan, T., \& Higgins, G. (November, 2013). Examining psychosocial factors affect on physical health and service utilization among victimized women on probation and parole. Paper accepted for poster presentation at the American Society of Criminology, Atlanta, GA. 
Winham, K., Renn, T., Dishon, A., Golder, S., Higgins, G., \& Logan, T. (November, 2013). Examining HIV risk behavior in women on probation and parole: Social and psychological predictors. Paper accepted for presentation at the American Society of Criminology, Atlanta, GA.

Karam, E., Sheldon, P., \& Dishon, A. (October 2013). Career paths for new professionals: Journey of the pre-clinical fellow. Presentation at the Raising Vibrant Children Conference: American Association of Marriage and Family Therapy Annual Conference: Portland, Oregon.

Renn, T., Golder, S., Winham, K., Dishon, A., Logan, T., \& Higgins, G. (October, 2013). A preliminary investigation of health decision-making among a sample of women on probation and parole through structural equation modeling. Poster presented at the American Public Health Association, Boston, MA.

Renn, T., Golder, S., Dishon, A., Winham, K., Logan, T., \& Higgins, G. (October, 2013). Examining psychosocial factors affect on physical health and service utilization among victimized women on probation and parole. Paper accepted for poster presentation at the American Public Health Association, Boston, MA.

Winham, K., Dishon, A., Renn, T., Golder, S., Higgins, G., \& Logan, T. (September, 2013). Victimized women on probation and parole: Understanding attachment and distress. Paper presented at the Institute on Violence, Trauma, and Abuse Conference, San Diego, CA.

Dishon, A., Renn, T., Winham, K., Golder, S., Higgins, G., \& Logan, TK. Psychological distress, self-esteem, and child victimization: A SEM mediation model. Paper presented at the $18^{\text {th }}$ International Conference and Summit on Violence, Abuse and Trauma, San Diego, CA, September 811, 2013 (Submitted)

Renn, T., Golder, S., Winham, K., Dishon, A., Logan, T., \& Higgins, G. (June, 2013). A preliminary investigation of health decision-making among a sample of women on probation and parole through structural equation modeling. Paper accepted for presentation at the International Conference on Social Work in Health and Mental Health, Los Angeles, CA.

Dishon, A., Winham, K., Renn, T., Golder, S. (November 2012). Involvement in substance use among women on probation and parole: An attachment and coping perspective. Paper presentation at the Thinking About Context: Challenges for Crime and Justice Conference: American Society of Criminology $68^{\text {th }}$ Annual Meeting.

Dishon, A., Renn, T., Winham, K., Golder, S. (July 2012). Attachment, coping, and substance use among women on probation and parole. Paper 
presentation at the International Family Violence and Child Victimization Research Conference: University of New Hampshire School of Law.

Dishon, A., Renn, T., \& Golder, S. (February 2012). A descriptive analysis of lifespan victimization among women on probation and parole:

Preliminary data and findings from the women's health research study. Poster Presentation at the Ending Domestic \& Sexual Violence: Innovations in Practice and Research Conference: University of New Hampshire School of Law.

Golder, S., Hall, M., Engstrom, M., Dishon, A., Renn, T., Higgins, G., \& Logan, TK. Substance use and associated psychological distress and lawbreaking among victimized women on probation and parole. American Society of Criminology Annual Meeting, Chicago, IL, November 14-17, 2012.

Hall, M., Golder, S., Dishon, A., Renn, T., Higgins, G., \& Logan, TK. Prescription opioid misuse among women on probation and parole. American Society of Criminology Annual Meeting, Chicago, IL, November 14-17, 2012.

\section{PROFESSIONAL LICENSURE}

Certified Social Worker (KY License No. 6241)

Marriage and Family Therapy Associate (KY License No. 2012-003)

\section{MEMBERSHIPS}

Council on Social Work Education (CSWE)

Kentucky Association of Marriage and Family Therapy (KAMFT)

American Association of Marriage and Family Therapy (AAMFT)

2014

AWARDS

Symposium

Nomination by KAMFT Board to attend AAMFT Leadership

2013

KAMFT Conference Scholarship to AAMFT Annual Convention

2012-Present

Pre-Clinical Fellow KAMFT Board Representative

2011-2013

Graduate Research Assistantship, 2011-2013 


\section{SERVICE ACTIVITIES}

\section{Profession}

Spring 2015

Fall 2013

Lecturer

July 2012-Present

October 2013- Present

May 2011- Present

November 2010-May 2011

September 2009-May 2010

\section{Community}

2008-2009

$2007-2008$
SW-692 Mental Health Integrative Seminar Guest Lecturer

SW-301 Human Behavior in the Social Environment Guest

Pre-Clinical Fellow Board Representative, KAMFT

Member, Marketing Committee KAMFT

Member, Division Conference Program Committee, KAMFT

Student Volunteer Coordinator, KAMFT

Student Volunteer, KAMFT

Board Member, Women in Transition, Louisville, Kentucky

Volunteer and Community Networking Committee, Women in Transition, Louisville, Kentucky

\section{REFERENCES}

$502-852-3743$

seana.golder@louisville.edu

$502-749-8825$

eli.karam@louisville.edu

$573-645-7089$ 